\title{
Childhood overweight: parents in control? : on the influence of parents in maintaining children's weight problems
}

\author{
Citation for published version (APA): \\ Jansen, E. (2011). Childhood overweight: parents in control? : on the influence of parents in maintaining \\ children's weight problems. [Doctoral Thesis, Maastricht University]. Datawyse / Universitaire Pers \\ Maastricht. https://doi.org/10.26481/dis.20110707ej
}

Document status and date:

Published: 01/01/2011

DOI:

10.26481/dis.20110707ej

Document Version:

Publisher's PDF, also known as Version of record

\section{Please check the document version of this publication:}

- A submitted manuscript is the version of the article upon submission and before peer-review. There can be important differences between the submitted version and the official published version of record. People interested in the research are advised to contact the author for the final version of the publication, or visit the DOI to the publisher's website.

- The final author version and the galley proof are versions of the publication after peer review.

- The final published version features the final layout of the paper including the volume, issue and page numbers.

Link to publication

\footnotetext{
General rights rights.

- You may freely distribute the URL identifying the publication in the public portal. please follow below link for the End User Agreement:

www.umlib.nl/taverne-license

Take down policy

If you believe that this document breaches copyright please contact us at:

repository@maastrichtuniversity.nl

providing details and we will investigate your claim.
}

Copyright and moral rights for the publications made accessible in the public portal are retained by the authors and/or other copyright owners and it is a condition of accessing publications that users recognise and abide by the legal requirements associated with these

- Users may download and print one copy of any publication from the public portal for the purpose of private study or research.

- You may not further distribute the material or use it for any profit-making activity or commercial gain

If the publication is distributed under the terms of Article $25 \mathrm{fa}$ of the Dutch Copyright Act, indicated by the "Taverne" license above, 


\section{Childhood overweight: parents in control?}

On the influence of parents in maintaining children's weight problems 


\section{Colophon}

Graphic Design and layout: Patriek Pelzers

Production: Datawyse, Universitaire Pers Maastricht

(c) Copyright Esther Jansen, Maastricht 2011

ISBN: 978-94-6159-062-6

The studies presented in this dissertation were funded by The Netherlands Organisation for Health and Development (ZonMw, grant 2100.0102). 


\title{
Childhood overweight: parents in control?
}

\author{
On the influence of parents \\ in maintaining children's weight problems
}

\section{Proefschrift}

Ter verkrijging van de graad van doctor aan de Universiteit Maastricht, op gezag van de Rector Magnificus, Prof. Mr. G.P.M.F. Mols, volgens het besluit van het College van Decanen, in het openbaar te verdedigen op donderdag 7 juli 2011 om 14:00 uur.

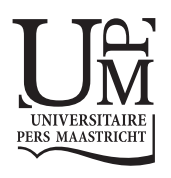




\section{Promotor}

Prof. Dr. A.T.M. Jansen

\section{Copromotor}

Dr. S. Mulkens

\section{Beoordelingscommissie}

Prof. Dr. A. Arntz (voorzitter)

Prof. Dr. H. Hospers

Dr. E. Moens (Universiteit Gent, België)

Prof. Dr. P. Muris (Erasmus Universiteit Rotterdam)

Dr. A. Vreugdenhil 
Chapter 2 How do children experience their parents' 22

feeding practices?

A study using the Dutch Child Feeding

Questionnaire-child version

Chapter 3 Do not eat the red food!

Prohibition of snacks leads to their relatively

higher consumption in children

Chapter 4 From the Garden of Eden to the land of plenty

Restriction of fruit and sweets intake leads to

increased fruit and sweets consumption in

children

Chapter 5 How to promote fruit consumption in children:

visual appeal versus restriction

Chapter 6

Assessing eating disordered behaviour in

overweight children and adolescents:

bridging the gap between a self-report

questionnaire and a gold standard interview

Chapter 7 Tackling childhood overweight: treating parents exclusively is effective

Chapter 8 General Discussion

Summary

Samenvatting

References

Dankwoord 
Chapter 1 
General introduction and thesis outline 


\section{The obesity epidemic}

Overweight and obesity are alarmingly prevalent in the Western society. In the United States of America the figures are shocking: $65 \%$ of all adults are now overweight (Body Mass Index (BMI) > $25 \mathrm{~kg} / \mathrm{m}^{2}$; Hedley et al., 2004), whereas one in every three is obese (BMI $>30 \mathrm{~kg} / \mathrm{m}^{2}$; Ogden et al., 2006). In the Netherlands we are heading for the same direction at fast speed; nearly as much as half of all Dutch adults struggle with overweight and $11 \%$ are obese (Schokker, Visscher, Nooyens, van Baak \& Seidell, 2007). Even more severe is the increase of overweight and obesity in children and adolescents over the past three decades. In the USA, 17\% of all children are overweight and an additional 31\% are at risk for becoming overweight (Ogden et al., 2006). The problem of childhood overweight is just as sizeable among Dutch children: between 12 and $21 \%$ of the children are overweight and 2 to $5 \%$ are obese (Schokker et al., 2007). Obesity prevalence doubled or even tripled between 1980 and 1997, and again it did between 1997 and 2004 (Schokker et al., 2007). Childhood overweight generally tracks into adulthood (Whitaker, Wright, Pepe, Seidel \& Dietz, 1997; Clarke \& Lauer, 1993; Serdula et al., 1993). According to Clarke and Serdula (1993), 50 to 75\% of the children in the upper quintile of BMI were still in the upper quintile as adults, implicating the majority of obese children remain obese during their whole lifetime.

\section{Defining obesity in children}

In adults, the Body Mass Index (BMl; weight / height ${ }^{2}$ ) is widely used, and cut off points of 25 and $30 \mathrm{~kg} / \mathrm{m}^{2}$ are acknowledged as definitions for overweight and obesity respectively (Kuczmarski, Carroll, Flegal \& Troiano, 1997; James, Leach, Kalamara \& Shayeghi, 2001). There is discussion on the use of BMI, as it does not distinguish between fat and fat-free mass (bone, muscles and body water; Dudeja, et al., 2001; Neovius, Linné \& Rossner, 2005). Therefore, in addition to BMI, other measures like the amount of body fat and waist circumference can be used (Neovius, Linné \& Rossner, 2005). 
In practice, overweight and obesity in adults are still diagnosed using BMI, as the World Health Organisation (WHO) does.

In children, overweight and obesity are less easy to define, as BMI in childhood changes considerably with age (Cole, Bellizzi, Flegal \& Dietz, 2000). Therefore, in the United States, an Expert Committee recommended the use of the $85^{\text {th }}$ and $95^{\text {th }} \mathrm{BMI}$ percentile for children and adolescents (Ogden, Flegal, Carroll \& Johnson, 2002). These percentiles are corrected for age and gender. Children with a BMI equal to or above the $95^{\text {th }}$ percentile are defined as obese, whereas children whose BMI falls between the $85^{\text {th }}$ and $95^{\text {th }}$ percentile are overweight and at risk for obesity (Barlow \& Dietz, 1998). In the studies described in this dissertation, we used these BMI percentiles to represent the child's weight status.

\section{Health consequences of obesity}

Generally, overweight and obesity have serious consequences, both physically and psychologically. The most common physical complications of obesity are diabetes mellitus, hypertension, cardiovascular diseases, sleep apnoea, bronchitis, infertility and low back pain (Foster, Wadden, Voght \& Brewer, 1997; Mokdad et al., 2003; Perri, Nezu \& Vliegener, 1992; Van Winckel \& Van Mil, 2001). In addition, orthopaedic complications of the knees and hips are associated with a high body weight (Van Winckel \& Van Mil, 2001).

Also in children, overweight is related to serious medical risks. Over $90 \%$ of obese children suffer from sleep abnormalities (Zametkin, 2004). As in adults, overweight is a risk factor for cardiovascular diseases in children. Obese children are twice as likely to develop cardiovascular disease compared with normal weight children. The younger the children are, the more overweight increases the risk of cardiovascular diseases later in life. Likewise, obesity in children is associated with hypertension and high cholesterol levels (Van Winckel \& Van Mil, 2001). More than $60 \%$ of the overweight children have hypertension or a high cholesterol level. 
A condition normally occurring in individuals older than forty years, type 2 diabetes, is now observed more and more frequently in children. About $85 \%$ of diabetes type 2 patients are obese (Schwartz \& Chadha, 2008).

It should be emphasized that diabetes mellitus, hypertension, cardiovascular diseases and strokes are, aside from cancer, AIDS and violence, the leading causes of morbidity and mortality in the developed world (Anderson, 2002).

In addition to physical implications, obesity comes with psychosocial consequences. One of the most prevalent psychological problems associated with obesity is depression: nearly half of all obese adults suffer from depression (Jansen, Havermans, Nederkoorn \& Roefs, 2008; Werrij, Mulkens, Hospers \& Jansen, 2006). Other consequences can include lower education, higher poverty rates and lower marriage rates (Jelalian \& Saelens, 1999; Kushner \& Aronne, 2004; Rhodes, Shimonda \& Waid, 1995; Stice, Presnell, Shaw \& Rohde, 2005; Zametkin, 2004). Gortmaker, Must, Perrin, Sobol and Dietz (1993) found that young obese women were far less likely to marry than their non-obese counterparts. Obesity stigmatizes young children even before adolescence (Puhl \& Brownell, 2004; Tanofsky-Kraff et al., 2004). When shown drawings of children of different sizes, children associate obesity with a variety of less desirable traits and they rank obese classmates as the least desirable playmates. Obese children are teased more frequently and experience more feelings of shame. In addition, they have problems in buying fashionable clothes, show deficits in social skills and have negative feelings about themselves (Foster et al, 1997; Puhl \& Brownell, 2004; Ramirez \& Rosen, 2001; Tanofsky-Kraff et al., 2004). Overweight children as young as age five can develop a low self-esteem and negative body image (Buddeburg-Fisher, Klaghofer \& Reed, 1999; Jelalian \& Saelens, 1999; Matz, Foster, Faith \& Wadden, 2002; Zametkin, 2004). Different studies have shown higher rates of anxiety and depression in obese children and adolescents than in normal weight children (Jelalian \& Saelens, 1999; Mokdad et al., 2003; Zametkin, 2004). Bearing in mind both the persistence of childhood obesity into adulthood and the many negative consequences of obesity, it is of major significance to challenge obesity early in life. 


\section{Treatment of obesity}

Treatment of overweight and obesity in adults leaves a lot to be desired.

Currently, there are three treatment options for obese adults: surgery, pharmacotherapy and behaviour therapy. Behaviour therapy produces a weight loss of about 10\% among the patients that complete treatment (Wing, 1998). Relapse occurs in most patients: nearly half of the lost weight is regained in the first year after treatment (Stalonas, Perri \& Kerzner, 1984; Wadden, Sternberg, Letizia, Stunkard \& Foster, 1989). A recent review by Douketis, Macie, Thabane and Williamsen (2005) confirms that the effects of dietary/lifestyle and pharmacological interventions provide modest weight loss (< 5kg within 2-4 years). Only surgical therapy appears to be successful; adults lose 25 to $75 \mathrm{~kg}$ (Douketis, Macie, Thabane \& Williamsen, 2005).

Since the effectiveness of obesity treatment is rather depressing, hope is placed in the treatment of obesity in childhood. The most effective way to treat childhood obesity is a multidisciplinary behaviour therapy, aimed at changing the eating- and exercise patterns of the child, which also involves the child's parents (Epstein, 1990). In a meta-analytic review by Wilfley, et al. (2007), 14 randomized controlled trials (RCT) were reviewed. Each reviewed study was a RCT of lifestyle interventions focused on weight loss or control for children, comparing a treatment to either a wait-list control or to an information only control. The average age was 11.5 years (range 2 - 19 years) Treatment duration ranged from 9 to 77 weeks, with an average of 18.3 sessions (Wilfley, et al., 2007). It was concluded that interventions aimed at changing eating habits and exercise patterns turn out to be efficacious at the end of treatment. Effect sizes were moderate (on average 0.75 ) at the end of treatment. This corresponds with an $8 \%$ decrease of percent overweight (whereas percent overweight increased with $2 \%$ in the control group). In addition, evidence was found that these effects endure in the long term; the mean effect size at follow up was 0.60. However, only three studies reported follow up measurements of 12 months or more from baseline. Although these findings show positive effects of interventions in 
children that focus on lifestyle improvement, the effects appear to diminish over time. Evidently, there is still room for improvement; especially the endurance of (relative) weight loss in the long term should be improved.

\section{Involvement of parents}

Characteristic for the majority of treatments for childhood obesity is the minor involvement of the children's parents. Parental involvement is an important factor in treating childhood obesity effectively (Epstein, 1990). Epstein and colleagues (1990) showed that children treated with a cognitive-behavioural and family-based approach maintained a substantial weight loss over a ten-year follow up. Parental involvement might not just be an effective addition; parents perhaps play a key role in effective treatment. Golan and Crow (2004a) also emphasized that parents are key players in treating childhood overweight. They found that targeting parents, by means of support and educational group sessions, results in greater weight loss than targeting children exclusively (14.6\% versus $8.4 \%$ after treatment and $29 \%$ versus $20.3 \%$ at 7 year follow-up; Golan \& (row, 2004b). A clinical study of West, Sanders, Cleghorn and Davies (2010) confirms the positive effects of parents as exclusive agents of change. In this study, a 12-week parent lifestyle intervention led to significant reductions in child BMI and weight-related problem behaviour. The effects were maintained at one-year follow-up. 


\section{The influence of parents in maintaining childhood overweight}

In general, obesity is caused by an imbalance between the intake and expenditure of energy (Wabitsch, 2000). Several factors may influence this imbalance. It is well known that obesity is influenced by genetic factors. Twin studies have shown that obesity is more common in relatives and that, with respect to body size, monozygotic twins are more alike than dizygotic twins. Also, it was found that $67 \%$ of the variation in body fat is genetically predisposed (Ravussin \& Bogardus, 2000). However, only $12 \%$ of this genetic predisposition is related to metabolism; the major part is related to the regulation of eating behaviour (Ravussin \& Bogardus, 2000). Besides genetic factors, environmental factors play a key role in the development of obesity. In our modern western society people are constantly surrounded by unlimited amounts of unhealthy kinds of food in all varieties and large portions. In addition, physical exercise is not promoted. This 'toxic' environment is put forward as a major factor in the development of obesity (Guerrieri, 2005). Besides the influence of our current society, children's eating behaviours are strongly affected by their parents. They have an important role in stimulating healthy eating behaviours in their children. Parental modeling has a consistent influence on the child's eating behaviour (Brown \& Ogden, 2004). Children, for example, imitate their parents in both food preferences and food avoidances (Guidetti \& Cavazza, 2008). Considering this, it is likely that eating behaviour in young children is a function of both parenting style and specific feeding practices.

\section{Parenting style}

The four classic parenting styles, described by Baumrind (1971) and modified by Maccoby and Martin (1983), are authoritative, authoritarian, permissive, and neglectful. Maccoby and Martin operationalized the construct of parenting style by defining it into 2 dimensions; demands for maturity or self-control and 
sensitivity/ emotional involvement. Authoritative parents have high demands for maturity and self-control from their children but also display high levels of sensitivity, emotional warmth, and involvement. The authoritative parenting style is often considered the ideal and has been associated with improved child outcomes, such as higher academic achievement, increased self-regulatory ability, frequent use of adaptive strategies, fewer depressive symptoms, and fewer risk-taking behaviours (Steinberg, Lamborn, Dornbusch \& Darling, 1992; Radziszewska, Richardson, Dent \& Flay, 1996). In contrast, authoritarian parents have high demands for self-control but low levels of sensitivity. They often are insensitive to the child's developmental needs, providing minimal emotional support, and are viewed as strict disciplinarians. The authoritarian parenting style has been associated with poorer outcomes among children, such as lower academic grades, compared with the authoritative style. Permissive parenting is characterized by low expectations for self-control and discipline in the setting of high sensitivity and warmth. Children from these families may be more selfconfident but often show lower levels of self-control (e.g., higher rates of drug use and school misconduct) than do children from authoritative or authoritarian homes (Lamborn, Mounts, Steinberg \& Dornbusch, 1991). Neglectful parenting is defined by low levels of both demands for self-control and sensitivity. Neglectful parenting is associated typically with unfavourable child outcomes, such as high rates of depression, smoking and poor school achievement and psychosocial development (Lamborn et al., 1991; Radziszewska et al., 1996).

In a study by Rhee, Lumeng, Appugliese, Kaciroti, and Bradley (2006), the association between parenting styles and children's overweight status in the first grade was examined. The authors found that mothers with an authoritarian parenting style were significantly more likely to have children who were overweight in the first grade, compared with mothers with an authoritative parenting style. Socio Economic Status (SES) did not alter the relationship between parenting style and weight status. Permissive and neglectful parenting styles also increased childhood overweight risk, relative to the authoritative style. 
In addition to the relationship with parenting style, specific parental feeding practices have been linked to an increased risk of overeating and thus overweight.

\section{Parental feeding practices}

In addition to being role models for their children and being in charge of purchasing and providing meals, parents also influence their children's eating patterns by using certain parenting techniques, like control. According to Birch et al. (2001), parental control in the domain of eating can be subdivided into pressuring the child to eat healthy kinds of food (e.g. fruit and vegetables) and restricting intake of unhealthy foods. However, overcontrolling a child's food intake potentially leads to adverse effects on food preferences and intake. t has been hypothesized that parents who are overcontrolling their children's food intake may interfere with their children's ability to self-regulate their intake. As a result, children would be more responsive to external cues (e.g. the smell and presence of food) as opposed to internal cues (e.g. hunger and satiety) (Faith, Scanlon, Birch, Francis and Sherry, 2004; Jansen et al., 2003). Consequently, this could lead to disturbed eating behaviours like eating in the absence of hunger, restrained eating and ultimately excess weight gain (Birch \& Fisher, 2000; Birch, Fisher \& Krahnstoever Davison, 2003; Robinson, Kiernan, Matheson \& Haydel, 2001).

Researchers have found pressuring to eat healthy kinds of food to be associated with lower fruit and vegetable consumption and picky eating in children (Galloway, Fiorito, Lee $\&$ Birch, 2005). The above studies being of a correlational nature, Galloway, Fiorito, Francis and Birch (2006) experimentally tested the influence of pressure to eat and found that normal weight children consumed more soup and made fewer negative comments when they were not pressured to eat. Thus, pressuring children to eat healthy indeed appears to result in adverse consequences. 
Evidence for the potential negative effects of restriction is, as mentioned above, largely correlational. Several researchers have found parents' restrictive behaviour to be associated with their children's weight status: the more restriction of food intake, the higher the weight (Birch et al., 2003; Constanzo \& Woody, 1984).

The assumption that restriction leads to overeating is in line with the dietary restraint theory (Polivy \& Herman, 1985). This theory states that dieting ultimately leads to overeating. The cause of overeating is supposed to lie in the fact that controlling food intake relies on cognitive processes: when these processes are disrupted, dieters are vulnerable to overeating (Polivy \& Herman, 1985). However, current research has shown that restrained eating and dieting cannot be viewed synonymously. Restrained eaters indeed increase their food intake after a high calorie preload (Herman \& Mack, 1975), but current dieters show an opposite reaction: they reduce their food intake (Lowe, Whitlow $\&$ Bellwoar, 1991).

Even though it might seem plausible that restriction by parents could result in disturbed eating behaviour and overweight, the alternative could be that parents start restricting the intake of palatable kinds of food as they observe their children becoming heavier. This problem of causality can be solved by manipulating restrictive behaviour in an experimental setting.

Past research in rats has shown that, even without depriving energy, restricting access to alcohol (Wayner, et al., 1972) or an optional high-fat food (Corwin, et al., 1998) leads to significant increases in the consumption of the restricted substance when it is subsequently made available. Fisher and Birch (1999) studied the influence of restriction of palatable foods in children. In this study, children participated in 8 group snack sessions: 4 unrestricted sessions, followed by 4 restricted sessions. The target food was a palatable snack food. The alternative was a food of lower preference. During the unrestricted sessions, both types of food were freely accessible during 15 minutes. During the restricted sessions, children had only one 5 minute period of free access to the restricted food. The results showed that children's behavioural response 
(requests for the food, attempts to obtain it or comments about liking it) to the palatable snack food was greater during restricted sessions than during unrestricted sessions (Fisher and Birch, 1999). Thus, restricting access to palatable foods increases children's desire to consume those foods.

\section{Research questions}

In this dissertation, two research questions are at the centre. The first research question is: 'What is the influence of control on children's eating behaviour?'

The second research question is: 'Is a treatment that targets parents exclusively effective in reducing childhood overweight/ obesity?'

The six chapters of the present thesis bear upon these two research questions.

\section{Outline of the present thesis}

The first part of the present thesis (chapters 2 to 5) addresses the role of control behaviour (more specifically restriction) in children's food preferences and consumption. In chapter 2, it is examined how children experience parental feeding control. In particular, it is studied whether children and their parents agree on the level of control the parents exert. The degree of parental control is measured using the Child Feeding Questionnaire (CFQ; Birch et al., 2001).

Chapters 3, 4 and 5 describe experimental studies into the effects of imposed control over eating in children. Chapter 3 inquires into the possible adverse effects of restriction of snacks. It is tested whether prohibiting palatable snacks will result in an increased desire for the formerly forbidden food followed by overeating. In chapter 4, a similar experiment is conducted. However, not only the effects of restricting palatable food are examined, but it is also tested whether restricting less attractive food (fruit) will yield similar effects. Chapter 5 compares restriction of fruit intake to enhancing visual appeal of fruit as potential methods to promote fruit consumption in children. 
The second part of the present thesis focuses on the role of parents in treating childhood obesity. In chapter 6, the merit of the Child Eating Disorder Examination-Questionnaire (ChEDE-Q; Decaluwé, 1999) as a measure of assessing eating disordered behaviour is evaluated. Therefore, the ChEDE-Q is modified in some ways and compared to the Child Eating Disorder Examination Interview (ChEDE; Bryant-Waugh et al, 1996), which is considered the gold standard. The goal of this chapter is to examine whether the ChEDE-Q is suitable for use in the treatment study described in chapter 7.

In chapter 7, a treatment for childhood obesity targeting parents exclusively is evaluated. The effectiveness of a short parental training on physical and psychological outcome measures in obese children and on BMI of their family members is described. 
Chapter 2 
How do children experience their parents' feeding practices?

\section{A study using the Dutch Child Feeding Questionnaire-child version}

\section{Published as:}

Jansen, E., Mulkens, S., Sanders, E., \& Jansen, A. (2011). How do children experience their parents' feeding practices? A study using the Dutch Child Feeding Questionnairechild version. Netherlands Journal of Psychology, 66, 26-32. 


\section{Abstract}

The Child Feeding Questionnaire (CFQ) is a self-report instrument that assesses the amount of parental control over child feeding. It is usually completed by parents, but social desirability, feelings of shame, and inadequate introspection or self-perception may cloud parents' self-reports. Children's experiences of parental control could be quite different from their parents' reports. In the current study it was considered how school-age children (8-12 years) perceive parental feeding control. In particular, the role of overweight and the correspondence to parents were examined.

For that purpose, a child version of the CFQ was constructed and the relationship between weight status and the experienced parental control was investigated. It was hypothesized that overweight children and children of overweight parents experience more control over child feeding than normal weight children and children of normal weight parents do. Moreover, the correspondence between parents' reports and children's experiences of parental control was examined.

The results indicated that weight status of child and parent did not play an important role in perceived child feeding control; no differences were found with respect to attitudes and practices. Regarding parent-child differences, children's perceptions differed from their parents' reports of control with respect to two out of six subscales. Weight status of the child did not influence the agreement between parent and child scores.

As parents and children correspond well on the Child Feeding Questionnaire, the Child version of this questionnaire should be further examined in order to determine its validity. 


\section{Introduction}

Obesity is considered one of the most serious threats to public health. In the United States, one in three adults is obese (Body Mass Index (BMI) $>30 \mathrm{~kg} / \mathrm{m}^{2}$ ) (Ogden, Carroll, Curtin, McDowell, Tabak \& Flegal, 2006). Among children, the prevalence of overweight is increasing as well. In the United States, about 17\% of all children and adolescents are overweight, whereas an additional $16.5 \%$ are at risk of becoming overweight (Ogden, et al., 2006). As childhood overweight and obesity often track into adulthood (Whitaker, Wright, Pepe, Seidel \& Dietz, 1997; Clarke \& Lauer, 1993; Serdula, Ivery, Coates, Freedman, Williamson, \& Byers, 1993), it is of great significance to challenge this health risk at a young age. Parents are believed to have a substantial influence when it comes to the development of their children's weight status (Birch \& Fischer, 1995). Besides acting as role models and being responsible for purchases and providing meals, parents may also influence their children's food preferences and intake by using control techniques. Parental control in the domain of eating can be subdivided into pressuring the child to eat healthy kinds of food and restricting the intake of unhealthy, palatable kinds of food (Birch, Fisher, Mackey, Grimm-Thomas, Sawyer \& Johnson, 2001). Nevertheless, overcontrolling children's intake might have adverse effects on food preferences and consumption. It has been hypothesized that parents who overcontrol their children's food intake may interfere with their children's ability to self-regulate intake. As a result, children would become more responsive to external cues (e.g. the smell and presence of food) as opposed to internal cues (e.g. hunger and satiety)( Faith, Scanlon, Birch, Francis \& Sherry, 2004; Jansen, Theunissen, Slechten, Nederkoorn, Mulkens \& Roefs, 2003). This could lead to disturbed eating behaviours like eating in the absence of hunger, restrained eating and eventually excessive weight gain (Birch, \& Fisher, 2000; Birch, Fisher \& Krahnstoever Davison, 2003; Robinson, Kiernan, Matheson, \& Hailed, 2001). According to the 'obesity proneness' model (Constanzo \& Woody, 1985), parents are likely to exert more control when they experience weight issues themselves or when they think their children are at risk 
for developing eating problems or overweight. So far, causal evidence for adverse effects of parental control is scarce. However, completely in line with the obesity proneness model, earlier research has found parental control in child feeding, as measured by the Child Feeding Questionnaire (CFQ; Birch, et al., 2001), to be correlated with children's weight status: a higher level of reported control was associated with a higher Body Mass Index (Birch, Fisher \& Krahnstoever Davison, 2003). The CFQ is an instrument for assessing parental control in child feeding and is administered to parents only. The CFQ is a valid and widely used measure of parental beliefs and practices regarding child feeding (Kaur, et al., 2006; Keller, Pietrobelli, Johnson \& Faith, 2006). Although CFQ scores and weight status indeed seem to be correlated, it can be questioned whether these CFQ data are reliable. After all, CFQ scores are self-reported. It is unknown whether parents have sufficient insight into their own behaviours to provide dependable answers. In addition, factors like social desirability and feelings of shame and guilt may be involved when inquiring after child feeding. Further, the perception of parental control by the child itself might be extremely relevant for eating behaviour. Apart from children's responses being less sensitive to social desirability (Gonzales, Cauce \& Mason, 1996; Paulson, 1994) and feelings of shame and guilt (Tagney, Wagne, Gavlas, \& Gramzow, 1991), the perception of experienced control might be a more important determinant of eating behaviour than the actual control or parents' perceptions of their control. After all, children are expected to act upon how they experience control, not upon parent's reports of control or the control that is objectively exerted. For the purpose of the current study, a child version of the CFQ was constructed.

The first aim of the study was to test the relationship between children's experiences of parental control and weight status. In line with the obesity proneness model (Constanzo \& Woody, 1985), it was hypothesized that overweight children would experience more parental control over child feeding than normal weight children would. In addition, children of overweight parents were expected to experience more parental control than children of normal weight parents. 
A second aim of the current study was to examine to what extent congruence existed between children's perceptions about parental control over child feeding and their parents' reports. Good agreement between children's experiences and parents' reports was expected. However, it was hypothesized that overweight children and their parents agreed less on parental control than normal weight participants. This was expected to be the result of the fact that parents of overweight children use ineffective parenting practices such as inconsistent discipline (Decaluwé, Braet, Moens \& van Vlierberghe, 2006; Johnson, Brownell, St. Jeor, Brunner \& Worby, 1997). For example, higher adaptability (e.g. constantly changing rules) is associated with an early onset of obesity and disturbed eating behaviour. With respect to child feeding, parents might restrict intake at one occasion, but may be permissive at another occasion. As a result, children do not know where they stand, possibly resulting in a discrepancy between parent and child with respect to CFQ scores.

\section{Method}

\section{Participants}

Ninety-four school-age children (45 boys) participated in this study. The age of the participating children ranged from eight to twelve years (mean age $=9.60$, $S D=1.30$ ). Forty-eight children had a normal weight (mean BMI percentile score of 48.49), 46 children were overweight (BMI percentile score > 90; $M=97.40$ ). See also table 1 for participant characteristics. The overweight participants were recruited from a waiting-list for multidisciplinary weight loss treatment in an ambulant setting. The normal weight participants were recruited from two primary schools in the same community. Their BMI percentile scores had to be between .15 and .85 . Response rates for both groups was 100\%.The parent who spent the most time with the child (in $87.8 \%$ of the cases this was the mother, in $12.2 \%$ it was the father) was approached and invited to fill out a questionnaire about her/ his child feeding behaviour. Their children were requested to fill out the child 
version of the questionnaire. Permission for participation was obtained from the children's parents. The study was approved by both the Atrium Medical Centre in Heerlen, and the ethical committee of the Faculty of Psychology and Neuroscience, Maastricht University, The Netherlands.

\begin{tabular}{lll} 
& Normal-weight children & Overweight children \\
& $(\boldsymbol{n}=\mathbf{4 8})$ & $(\boldsymbol{n}=\mathbf{4 6})$ \\
\hline Age (Mean (SD)) & $9.02(.96)$ & $10.20(1.34)$ \\
Gender (boys/girls) & $22 / 26$ & $23 / 23$ \\
Parents with normal weight & $68.8 \%$ & $21.7 \%$ \\
Overweight parents & $31.2 \%$ & $76.1 \%$
\end{tabular}

Table 1: Participant characteristics: normal-weight versus overweight children

\section{Measurements}

\section{Child Feeding Questionnaire}

Parents filled out the CFQ (Birch, et al., 2001). The original version of the CFQ was translated in Dutch with permission of the authors. The CFQ is a measure of parental attitudes, beliefs and practices of child feeding and obesity proneness. It is based on the above-mentioned obesity proneness model (Constanzo \& Woody, 1985). The CFQ comprises 31 items on seven subscales. These seven subscales can be classified into two categories. The category 'risk factors and concerns' includes the subscales 'perceived feeding responsibility', 'perceived parent overweight' (how parent classifies own weight), 'perceived child overweight' (how parent classifies child's weight) and 'concerns about child overweight'. The category 'control in child feeding: attitudes and practices' comprises the subscales 'restriction', 'pressure to eat' and 'monitoring' (keeping track of child's eating behaviour). Every item is scored on a scale from ' 1 ' to ' 5 '. Subsequently, subscale scores are calculated by averaging the corresponding item scores. The higher the score, the more parental control is exerted. 
The internal consistency of the seven subscales is good; all subscales have a Cronbach's alpha above .70. The CFQ has been proven valid in non-Hispanic Whites and Hispanic samples (Birch, et al., 2001).

\section{Child Feeding Questionnaire: Child version}

For the current study, the original CFQ was converted into a child version. All items were rephrased in such a way that the questions were asked from the child's perspective. For example the original item: 'I intentionally keep some foods out of my child's reach' was rephrased into 'My parents try to keep some foods out of my reach'. The subscale 'perceived parent overweight' was excluded from the child version of the CFQ, since children do not have insight in their parents' weight history. Considerable effort was put into preventing affection of the tenor of the original questions. See also Appendix A for the modified version of the CFQ. Although the original CFQ is also useful for parents of very young children (from the age of two onwards), the child version is suitable for children with sufficient reading skills. The reliability of the CFQ child version is good, Cronbach's alphas for the six subscales being .72, .74, .85, .69, .66 and .88 respectively in our sample.

\section{Body Mass Index}

Weight and height of the overweight children and their parents were measured (after completing the CFQ) by a research worker. Weight ( $\mathrm{kg}$ ) was measured by means of a digital scale. Height $(\mathrm{cm})$ was assessed with measuring tape which was applied to the wall. The research worker had undergone a short training in collecting this kind of information correctly.

Weight and height data of the normal-weight children and their parents were provided by the parents. BMI's and BMI percentiles were calculated subsequently (Children's BMI-percentile-for-age Calculator, USDA/ ARS Children's Nutrition Research Center). 


\section{Procedure}

Parents and children received an original (parent version) or a child-version of the CFQ, respectively. The overweight children and their parents received their questionnaires during the interview on admission to the weight loss treatment. They were instructed to individually fill out the questionnaire in situ. The normalweight participants and their parents received their questionnaires at school, and were instructed to complete the questionnaires at home, without consultation of the other participating family member. It was stressed that participants should depart from their own experiences.

\section{Data analyses}

A one way ANOVA on BMI percentile was performed to confirm the two groups (overweight children versus normal weight children) actually differed with respect to BMI percentile. In addition, one way ANOVAs on age and gender distribution were performed to preclude group differences at the start of the study. To test whether weight status of the children influenced their experiences of parental control (hypothesis 1), and whether weight status of the parent influenced their children's experiences of parental control (hypothesis 2), a MANOVA (child-CFQ subscale scores as dependent variables, both child's weight status and parental weight status as factors) was carried out. Both factors were entered in one analysis to examine possible interaction effects of child weight status and parental BMI on CFQ scores. Finally, to test agreement between the children and their parents (hypothesis 3), a repeated measures design with parent CFQ scores on Time 1, child CFQ scores on time 2, and weight status of the child as between subjects factor was carried out for every subscale of the CFQ. 


\section{Results}

One way ANOVA showed that the overweight children had significantly higher $\mathrm{BMI}$ percentiles than the normal weight children ( $F=128.39, \mathrm{p}<.001)$. In addition, the group of overweight children did not differ from the group of normal-weight children regarding gender distribution ( $F=.16, p=.69$ ), but the groups differed with respect to age $(F=24.01, P<.001)$, the overweight children being slightly older than the normal-weight children (10.20 years versus 9.02 years).

\section{Hypotheses 1 and 2:}

Overweight children perceive more parental control over child feeding than normal-weight children do and children from overweight parents perceive more parental control over child feeding than children from normal weight parents do.

In general, overweight children had higher child-CFQ total scores than normal weight children. In addition, results of the MANOVA showed that overweight children scored significantly higher than normal-weight children with respect to 'perceived child overweight' [F (1,90) = 38.47, p<.001], and 'concerns about child overweight' $[F(1,90)=40.88, p<.001]$. There were no significant differences on the other four subscales Parental weight status did not influence perceived parental control scores. With respect to interaction effects, no child weight status x parental weight status effects were found on child-CFQ scores. For the significant results, see also table 2 . 


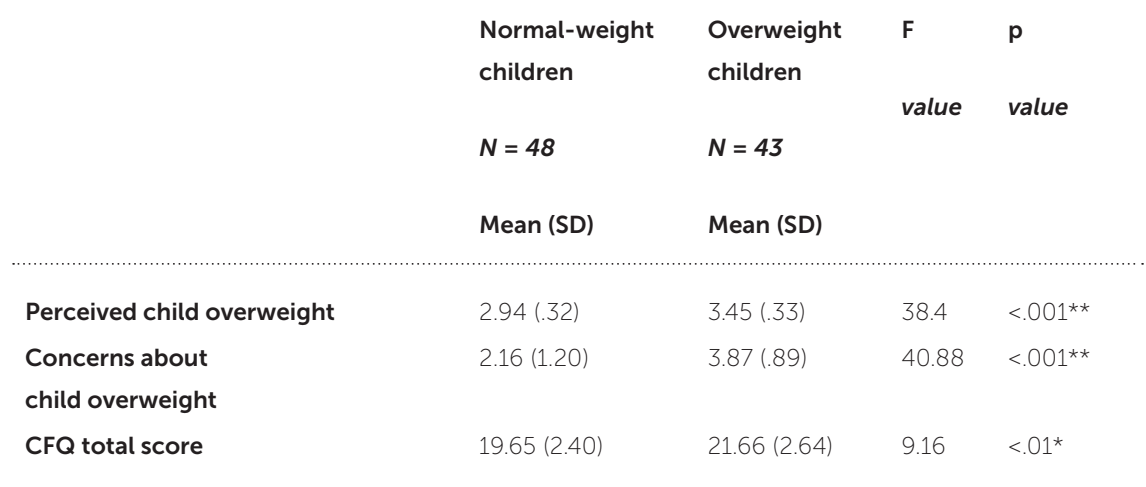

Table 2: Mean (SD) child-CFQ total score and subscale scores: normal-weight children versus overweight children

\section{Hypothesis 3:}

In general, parents and children agree well on (perceived) parental control over feeding, but there is more agreement between normal-weight children and their parents than between overweight children and their parents.

As hypothesized, the agreement between children and their parents was good. No differences were found between the parent CFQ total score and child-CFQ total score $[F(1,90)=2.45, p=.12]$. In addition no interaction effects were found between questionnaire version and weight status of the child; that is, overweight children did not differ from normal weight children in the agreement to their parents scores $[F(1,90)=.047, p=.83]$. With respect to the subscales, significant differences between parent and child scores were found on the subscales 'perceived feeding responsibility' and 'pressure to eat'. Regarding 'perceived feeding responsibility', parents score significantly higher than their children do $[F(1,92)=6.17, p<.05]$. Regarding 'pressure to eat', parents score significantly lower than their children do [F $(1,92)=24.89, p<.001]$. No significant differences were found on the other four subscales. As for any differences in agreement between normal weight children and overweight children; a significant questionnaire $x$ weight status interaction was found with respect to 'concerns about child overweight'. 
Overweight children scored significantly lower than their parents, whereas normal weight children scored significantly higher than their parents. See also table 3.

\begin{tabular}{|c|c|c|c|c|}
\hline & \multicolumn{2}{|c|}{$\begin{array}{l}\text { Main effect: } \\
\text { differences between } \\
\text { parent CFQ scores and } \\
\text { child CFQ scores }\end{array}$} & \multicolumn{2}{|c|}{$\begin{array}{l}\text { Interaction effect: } \\
\text { questionnaire version } x \\
\text { child weight status }\end{array}$} \\
\hline & $F$ & $p$ & $F$ & $p$ \\
\hline Total CFQ score & 2.44 & NS & .05 & NS \\
\hline Feeding responsibility & 6.17 & $<.05^{\star}$ & .008 & NS \\
\hline Perceived child overweight & .11 & NS & 2.33 & NS \\
\hline $\begin{array}{l}\text { Concerns about } \\
\text { child overweight }\end{array}$ & .87 & NS & 9.84 & $<.01^{\star}$ \\
\hline Restriction & .008 & NS & .92 & NS \\
\hline Pressure to eat & 24.89 & $<.001^{\star \star}$ & .84 & NS \\
\hline Monitoring & .11 & NS & .01 & NS \\
\hline
\end{tabular}

Table 3: Differences between child CFQ scores and parent CFQ scores ${ }^{*} p<.05,{ }^{* *} p<.001$

\section{Discussion}

The aim of the current study was to investigate how children perceive their parents' control over feeding, and whether child- and parent weight status influences perceived control in children. Moreover, the agreement between perceptions of children and their parents was examined. In addition, a possible interaction with weight status of the child was tested.

For this purpose, a child version of the CFQ was constructed and administered to 48 normal-weight children, 46 overweight children and their parents. In general, overweight children scored higher on the CFQ than normalweight children. However, these differences were, for the greater part, found in the subscales 'perceived child overweight' and 'concerns about child overweight'. It seems just plain logic that parents of overweight children are more 
concerned about their children's weight statuses as opposed to parents of normal weight children. In fact, when looking at the subscales in the category 'control in child feeding: attitudes and practices', no differences at all were found between the perceptions of overweight and normal weight children. Therefore, from this study, it cannot be concluded that overweight children experience more control over feeding than normal-weight children. In addition, parental weight status did not influence children's perceptions of parental control. However, in order to draw firmer conclusions about the causal relationship between parental control and overweight, experimental research is needed badly. Future research might focus on manipulating the level of control in normal weight children, to examine its effects on eating behaviour and weight status. A second aim of the study was to examine the possible differences between parents' reports and children's experiences concerning parental control. In general, children's perceptions correspond well with their parents' reports. Therefore, it might be useful to administer the child version of the CFQ in the future. However, with respect to the subscales 'perceived feeding responsibility' and 'pressure to eat', significant differences were found between child CFQ and parent CFQ scores. Children score lower than their parents do with respect to feeding responsibility, and they score higher than their parents with respect to pressure to eat (they experience more pressure than their parents claim to exert).

Weight status of the child did not influence agreement between child and parent scores as expected. Overweight children were expected to differ more from their parents than normal weight children. However, no such differences were found. The only interaction effect of child weight status $x$ questionnaire version was found with respect to 'concerns over child overweight'. Overweight children score lower than their parents, whereas normal weight children scored higher than their parents. The fact that overweight children score lower than their parents could possibly be explained by social desirability of the parent; when your child is overweight, you must be very concerned. 
The question which version of the questionnaire correlates highest with actual control behaviour is interesting. More research is necessary to determine whether the original CFQ or the child-CFQ is more valid and reliable. Nevertheless, the question remains whether it is really necessary to know objectively to what extent parental control is exerted. It seems more relevant to examine how experienced control and disturbed eating behaviours are related .

A limitation of this study concerns the use of the CFQ. Although the CFQ is a valid and widely used questionnaire, it has not yet been validated in an overweight sample. Further research should focus on validating the CFQ in a variety of large samples. Although further research is necessary to validate the CFQ Child version, the reliability of this questionnaire in the current sample is high, which is a promising starting point. 
Appendix A

Child Feeding Questionnaire: Child version

\section{Instruction}

Please circle one number for each question which best corresponds to your answer.

$\begin{array}{lll}\text { never seldom } & \begin{array}{l}\text { half } \\ \text { of time }\end{array} & \begin{array}{l}\text { most time } \\ \text { olways }\end{array}\end{array}$

1.

When you are at home, how often do your $\quad 1 \quad r \begin{array}{llll}2 & 3 & 4 & 5\end{array}$ parents feed you?

2.

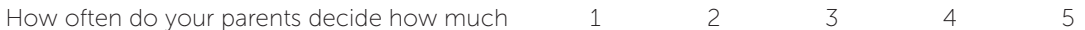
you eat?

3.

How often do your parents decide whether 1 2 3 4 5 you have eaten the right kind of food? 


\section{Instruction}

Please indicate how your weight was at each of these 6 periods. Circle only one number for each period.

$\begin{array}{lllll}\text { serious } & \text { under- average } & \begin{array}{l}\text { over- } \\ \text { weight }\end{array} & \begin{array}{l}\text { serious } \\ \text { over- } \\ \text { weight }\end{array} \\ \text { weight } & & & & \text { weight }\end{array}$

4.

$\begin{array}{llllll}\text { Your first year of life } & 1 & 2 & 3 & 4 & 5\end{array}$

5.

$\begin{array}{lllllll}\text { As a toddler } & 1 & 2 & 3 & 4 & 5\end{array}$

6.

$\begin{array}{llllll}\text { As a pre-schooler } & 1 & 2 & 3 & 4 & 5\end{array}$

7.

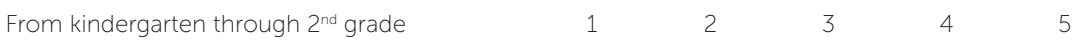

8.

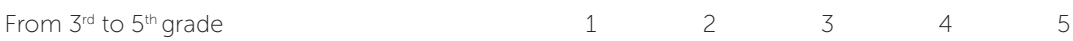

9.

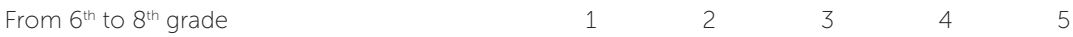

\section{Instruction}

Please circle one number for each question which best corresponds to your answer.

$\begin{array}{llll}\text { uncon- } & \text { little bit neutral } & \text { a little con- } \\ \text { cerned } & \text { uncon- } & \text { bit con- cerned } \\ & \text { cerned } & \text { cerned }\end{array}$

10.

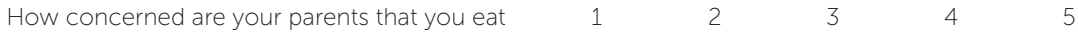
too much when they are not around?

11.

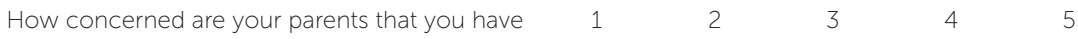

to diet to keep a healthy weight?

12.

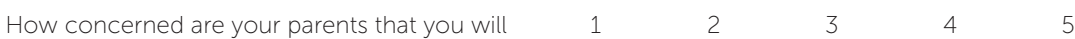

be overweight? 


\section{Instruction}

Please circle one number for each question which best corresponds to your answer

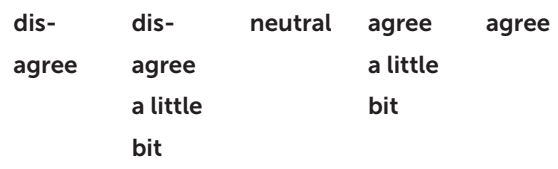

13.

My parents want to be sure that I do not eat 1 2 3 4 5 too many sweets (candy, ice cream, cake or pastries).

14.

My parents want to be sure that I do not eat $\quad \begin{array}{llllll}1 & 2 & 3 & 4 & 5\end{array}$
too many high fat foods.

15.

My parents want to be sure that I do not eat $\quad \begin{array}{llllll}1 & 2 & 3 & 4\end{array}$
too much of my favourite foods.

16.

My parents try to keep some foods out of my $\quad \begin{array}{llllll} & 1 & 2 & 3 & 4 & 5\end{array}$
reach

17.

My parents offer me sweets (candy, ice cream, $\quad 1 \quad 12 \quad 3 \quad 4 \quad 5$ cake, pastries) as a reward for good behaviour.

18.

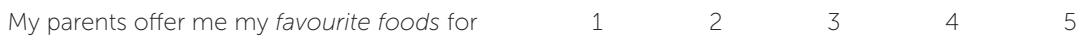
good behaviour.

19.

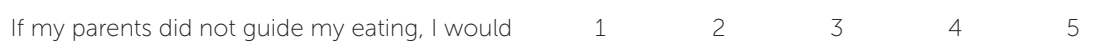
eat too many junk foods.

20.

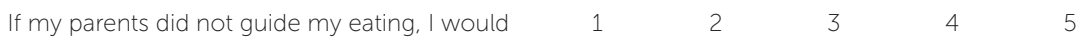
eat too much of my favourite foods. 


\section{1.}

\begin{tabular}{|c|c|c|c|c|}
\hline I should always eat all of the food on my plate. & 1 & 2 & 3 & 4 \\
\hline 22. & & & & \\
\hline $\begin{array}{l}\text { My parents have to be careful to make sure I } \\
\text { eat enough }\end{array}$ & 1 & 2 & 3 & 4 \\
\hline
\end{tabular}

23.

If I say "I'm not hungry", my parents try to make $\quad 1 \quad 2 \quad 3 \quad 4 \quad 5$
me eat anyway.

24.

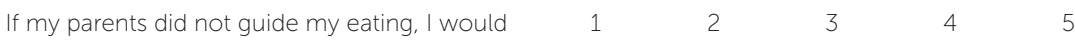
eat much less than I should.

\section{Instruction}

Please circle one number for each question which best corresponds to your answer.

never seldom some- most of always
times time

25.

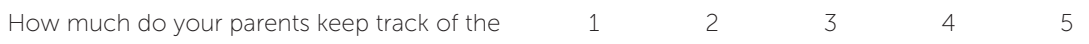
sweets (candy, ice cream, cake, pastries) that you eat?

26.

How much do your 1 2 3 4 5 parents keep track of the snack food (potato chips, Doritos, cheese puffs) that you eat?

27.

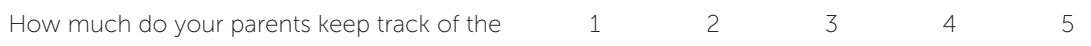
high fat foods that you eat? 
Chapter 3 


\section{Do not eat the red food!}

\section{Prohibition of snacks leads to their relatively higher consumption in children}

\section{Published as:}

Jansen, E., Mulkens, S., \& Jansen, A. (2007). Do not eat the red food! Prohibition of snacks leads to their relatively higher consumption in children. Appetite, 49, 572-577. 


\begin{abstract}
Overweight is becoming more prevalent in children. Parents' behaviours play an important role in children's eating behaviour and weight status. In addition to modeling and providing meals, parents also have an influence by using control techniques. One frequently used technique is restriction of intake. In this study, it was tested whether a prohibition of food in the first phase would lead to an increase in desire for the target food and overeating in the second phase. Sure enough, desire increased significantly in the prohibition group, whereas it remained constant in the no-prohibition group. Though no significant differences between groups were found in the absolute consumption of the target food, the proportion of consumed target food (target food intake/ total food intake) was significantly higher in the prohibition group. Finally, children whose parents imposed either very little or a lot of restriction at home consumed more kilocalories during the whole experiment, as opposed to children who were exposed to a moderate level of restriction at home. These data indicate that restriction can have adverse effects on children's food preference and caloric intake.
\end{abstract}

\title{
Introduction
}

Obesity is considered one of the most serious health issues of the century. In the Netherlands, $46 \%$ of all adults are overweight (body mass index (BMI) > $25 \mathrm{~kg} / \mathrm{m}^{2}$; CBS, 2006). Also among children, overweight is increasingly prevalent (Visscher, Kromhout \& Seidell, 2002). At present, one out of seven Dutch children is overweight (TNO, 2006). As childhood overweight often persists into adulthood (Clarke \& Lauer, 1993; Serdula et al., 1993), it seems of great importance to challenge this issue at a young age.

Parental behaviours are believed to play an important role in the development of children's weight status (see e.g., Birch \& Fisher, 1995). Besides being role models and being responsible for purchases and cooking, 
parents also influence their children's food intake by using control techniques. According to Birch et al. (2001) parental control in the domain of eating can be subdivided into pressuring the child to eat healthy kinds of food (e.g. fruit and vegetables) and restricting intake of unhealthy, palatable (fatty or sweet) kinds of food. Nevertheless, overcontrolling children's food intake might have adverse effects on food preference and intake. It has been hypothesized that parents who overcontrol their children's food intake may interfere with their children's ability to self-regulate their intake. As a result, children would be more responsive to external cues (e.g. the smell and presence of food, rewards) as opposed to internal cues (e.g. hunger and satiety) (Faith, Scanlon, Birch, Francis and Sherry, 2004). In turn, this could result in disturbed eating behaviours like eating in the absence of hunger, restrained eating and eventually excess weight gain (Birch \& Fisher, 2000; Birch, Fisher \& Krahnstoever Davison, 2003; Robinson, Kiernan, Matheson \& Haydel, 2001). With regard to pressuring children to eat healthy kinds of food, researchers found it to be associated with lower fruit and vegetable consumption and picky eating in children (Galloway, Fiorito, Lee $\&$ Birch, 2005). In a more experimental design, Galloway, Fiorito, Francis and Birch (2006) found that normal weight children consumed more soup and made fewer negative comments when they were not pressured to eat.

With regard to the effects of restriction, research in rats showed that, even without depriving energy, restricting access to alcohol can lead to significant increases in the consumption of alcohol when it is subsequently made available (Wayner, et al, 1972). These results were replicated using an optional high-fat food as the restricted substance (Corwin, et al., 1998).

So far, evidence for an adverse effect of restriction in humans is largely correlational. Several researchers have found parents' restraint over their children's food intake to be positively associated with children's weight status (Birch et al., 2003; Constanzo \& Woody, 1984). Although it may seem plausible that restriction behaviour by parents could lead to disturbed eating behaviour and subsequent overweight, the alternative could be that parents start restricting intake of palatable kinds of food when they observe their children becoming 
heavier. This problem of causality can be solved by manipulating restriction behaviour in a laboratory setting in normal weight participants.

A laboratory study by Mann and Ward (2001) examined the effect of food restriction in normal weight adults. Participants were assigned to either a forbid-choice condition or a forbid-reactance condition. All participants took part in three taste sessions of five minutes each. The first session was identical for both conditions: they were allowed to eat from all three kinds of candy, including a novel kind of candy. In the second taste session, the manipulation took place. Participants in the forbid-reactance condition were not allowed to eat from the novel kind of candy, whereas participants in the forbid-choice condition were asked not to eat much of the novel kind of candy, because it was scarce, but also told that they were free to do so anyway. Finally, the third taste session was identical to the first one. The results showed that desire for the forbidden food remained high in the forbid-reactance participants, whereas desire decreased in the forbid-choice participants. However, this constant level of desire did not lead to subsequent rebound eating in the forbid-reactance participants. Although palatable kinds of candy were used in the laboratory study, the forbidden food was a kind of candy that was novel to the participants. Therefore, one could argue that participants might not have had difficulties denying oneself this candy. It seems rational, thus, that rebound eating and increased desire do occur when participants are prohibited from well known palatable kinds of food that they are used to eat on a regular base.

Fisher and Birch (1999) studied the influence of restriction of palatable foods in children. In the experiment, 3-6 year old children participated in 8 group snack sessions: 4 unrestricted sessions, followed by 4 restricted sessions. The target food was a palatable snack food. The alternative was a food of lower preference. During the unrestricted sessions, both types of food were freely accessible during 15 minutes. During the restricted sessions, children had only one 5 minute period of free access to the restricted food. The results showed that children's behavioural response (requests for the food, attempts to obtain it or comments about liking it) to the palatable snack food was greater 
during restricted sessions that during unrestricted sessions (Fisher and Birch, 1999).

Summarized, research in adults shows an increased desire, but no rebound eating following restriction. Research in children shows that pressure to eat leads to a lower intake, thus an adverse effect. In addition, children show more behavioural responses when food is restricted. However, the effects of restriction in children have not been extensively tested yet. Considering the clinical relevance of mapping the effects of restriction, more experimental research in this area is highly desirable.

In their study, Fisher and Birch (1999) presented a less attractive food as the alternative for the restricted food. Although this design probably corresponds more to a real life situation, the current study aims to examine the pure effect of restriction by providing an alternative food that is equal in taste.

The current study focuses on the possible adverse effects of external restriction of food intake in children. In this study we tested whether prohibiting snacks would result in an increased desire for forbidden food followed by overeating. We expected desire for the forbidden snacks to increase after the prohibition phase in the prohibition group, whereas we hypothesized that it would remain constant or even decrease during that same period in the no-prohibition condition. Secondly, it was expected that participants in the prohibition condition would eat relatively more forbidden snacks (in comparison with control snacks) in the second phase of the experiment, whereas we expected no differences between the two phases in the no-prohibition condition. The third and final hypothesis was that the degree of restriction in the home situation influenced overall food intake during the experiment: the more a participant was restricted at home, the more he would consume during the taste sessions. 


\section{Method}

\section{Participants}

Seventy four participants were recruited from six different primary schools in the Netherlands, Germany and Belgium. Parents with children in primary school were approached and invited to let their children participate in the current study. Participants were told that the experimenter represented a sweets factory. As this factory was developing a new kind of sweet for children, the developers were very interested in how children evaluated existing snacks and sweets. The children were five and six year olds. The attraction of snacks is fairly strong in children, and we expected minimal social desirable behaviour concerning the eating of snacks in normal weight young children. Also, children in this age category are able to obey prohibitions (Piaget, 1965). Beside the fact that children under the age of 5 might not understand the content of a restriction, we also expected difficulties in assessing taste and levels of desire in children that young. In addition, older children could possibly experience feelings of shame and guilt to a greater extent than younger children.

Permission was obtained from the participating schools as well as from the children's parents. Although the parents were not presented with the formulated hypotheses, they were told the study examined effects of prohibition. They were requested not to share this information with their children prior to their participation in the study. The study was approved by the ethical committee of the Faculty of Psychology, Maastricht University. Cooperating schools received a gift certificate afterwards. Participant characteristics are summarized in table 1. 


\section{Prohibition group No-prohibition group}

N

Nationality distribution of participants

Age (mean (SD))

Gender (boy/girl)

BMI (mean (SD))

BMI percentile (mean (SD))
36

14 German

14 Dutch

8 Belgium

$5.44(.5)$

$19 / 17$

$15.8(3.3)$

$59.07(33.0)$
38

14 German

15 Dutch

9 Belgium

$5.58(.6)$

$18 / 20$

$15.0(3.1)$

$47.14(32.1)$

Table 1

Age, gender, nationality and BMI percentiles of the prohibition group versus the no-prohibition group

There were no significant differences between groups regarding age, BMI percentile, nationality or gender distribution

\section{Design}

Participants were randomly assigned (though controlled for gender) to one of two conditions: a prohibition condition and a no-prohibition condition (between subjects factor). The experiment consisted of two phases (within subjects factor; during the first phase the prohibition manipulation took place, phase two was an "all you can eat" phase for both groups). Dependent variables were food intake in kilocalories, proportion of consumed prohibited snacks and desire for prohibited snacks. 


\section{Measurements}

\section{Child Feeding Questionnaire}

Along with an informative letter about the study and an informed consent form, parents received the Dutch Child Feeding Questionnaire (CFQ: Birch, et al., 2001, translated with permission of the authors) to fill in. The CFQ is a measure of parental attitudes, beliefs and practices of child feeding and obesity proneness. The CFQ comprises 34 items spread over 7 factors, namely 'perceived feeding responsibility', 'perceived child overweight', 'perceived parent overweight', 'concerns about child overweight', 'restriction', 'pressure to eat' and 'monitoring'. Every item is scored on a scale from 1 to 5. The higher the score, the more parental control is exerted. The internal consistency of the 7 subscales is good; all 7 subscales have a Cronbach's alpha above.70. As yet, the validity of the CFQ is unknown.

For the current study we were especially interested in the 'restriction' scale of the $C F Q$, considering our hypotheses. Therefore, only data from the 'restriction' scale were analyzed.

\section{Snacks}

In this study, M\&M's chocolates and crisps were presented to the participants, both in colours red and yellow. Participants in the prohibition condition were prohibited from eating the red foods during phase 1 . We chose to forbid only a certain colour of food instead of prohibiting one kind of food, because Sensory Specific Satiety (SSS; Rolls \& Rolls, 1996) alone could account for an increased interest in other kinds of food. SSS refers to the 'decrease in pleasantness of a food after it has been eaten to satiety and other food not eaten to satiety remains relatively pleasant'. Instead we used two different kinds of snacks (sweet and salty), both presented in two colours: red and yellow. The two colours did not differ in taste, and therefore SSS could not account for an increased interest in the forbidden food. 
The snacks were presented in four identical bowls: the bowls with crisps contained 45 grams each; the bowls with MEM's contained 400 grams each.

\section{Desire to eat, taste and satiety}

To measure the desire to eat a particular kind of food, a Visual Analogue Scale (VAS) was used. The left extreme represented 'no desire to eat at all' and the right extreme represented 'a very large desire'. Emoticons were used to clarify these terms. Taste of the food types was measured with a five point rating scale (ranging from 'not tasty at all' to 'very tasty'). Finally, satiety was measured with a VAS-scale (marking the left extremity meaning 'their tummy was totally empty' and marking the right extremity meaning 'their tummy was completely full'). Taste and satiety were measured before phase 1 to assure that the participants from the different groups did not differ in their taste ratings and were equally satiated before the experiment started. Desire was assessed at three moments: before phase 1 and after phases 1 and 2 .

\section{Body Mass Index}

Participating children's weight and height were measured once at the end of the session. Participants had their clothes on, coats and shoes off. Weight in kilograms, rounded off to one decimal, was measured by means of a digital scale. Height in centimetres, rounded off to one decimal, was assessed with measuring tape which was applied on the wall. The experimenters had undergone a short training in collecting this kind of information correctly. BMI's and BMI percentiles were calculated subsequently (Children's BMI-percentile-for-age Calculator, USDA/ ARS Children's Nutrition Research Center). 


\section{Procedure}

All children were individually tested. To this end, they were picked up from their class rooms (one by one) and asked to sit down in a quiet room where they were not distracted by other children or noises. The experimenter then introduced herself as a staff member of a sweet factory. The children were told that they had to answer various questions and taste different kinds of food. Then the actual experiment started. Through a structured interview, the current levels of satiety, taste of and desire for all four types of food were assessed. Additionally, they were asked about the frequency of eating snacks and sweets at home and whether they had to ask their parents for permission to eat snacks. After answering these questions the first phase began. Four bowls filled with snacks (one for each type of food) were presented during this phase. In both conditions, two different snacks (sweet and salty), were offered, each presented in two colours (red M\&M's, yellow M\&M's, red crisps and yellow crisps). A glass of water was placed on the table along with the snacks.

Children in the control condition were allowed to eat all types of food during this phase. Children in the prohibition condition were instructed not to eat the red kinds of food. The children were left alone during the actual tasting. After five minutes, the experimenter returned to the room and took away the bowls which were weighed secretly in another room. Then, levels of desire for the different kinds of food were assessed. Photographs of the different types of food were placed in front of the child as a helping hand. Subsequently, the second phase started. During this phase, both conditions received the same instruction: they could eat as much as they wanted from all kinds of food. Again, the experimenter left the room during the tasting. After five minutes, the experimenter returned, took the food outside the room and weighed the respective bowls. Finally, the child's weight and height were measured. The child was then guided back to the classroom. Afterwards, parents received a debriefing form which informed them about the hypotheses and expected results. 


\section{Results}

Data for all 74 children were used in the analyses.

Taste ratings and satiety levels before phase 1 did not differ between groups. Mean and SD's are listed in table 2.

Prohibition group No-prohibition group

\begin{tabular}{|c|c|c|c|}
\hline & Mean (SD) & Mean (SD) & $\begin{array}{l}\mathrm{P} \\
\text { value }\end{array}$ \\
\hline $\begin{array}{l}\text { Satiety before phase } 1 \\
(\min 1-\max 10)\end{array}$ & 4.1 (3.1) & $4.1(2.7)$ & NS \\
\hline $\begin{array}{l}\text { Taste red food } \\
(\min 0-\max 4)\end{array}$ & $3.1(1.12)$ & $3.21(1.22)$ & NS \\
\hline $\begin{array}{l}\text { Taste yellow food } \\
(\min 0-\max 4)\end{array}$ & $3.0(1.21)$ & $3.16(1.22)$ & NS \\
\hline $\begin{array}{l}\text { Desire for red food } \\
\text { before phase } 1 \\
(\min 1-\max 10)\end{array}$ & $6.5(3.0)$ & $6.9(2.0)$ & NS \\
\hline $\begin{array}{l}\text { Desire for red food } \\
\text { after phase } 1 \\
(\min 1-\max 10)\end{array}$ & $7.6(2.5)$ & $7.1(2.0)$ & NS \\
\hline $\begin{array}{l}\text { Intake in kilocalories from } \\
\text { red food in phase } 2\end{array}$ & $69.7(37.2)$ & $63.7(32.67)$ & NS \\
\hline $\begin{array}{l}\text { Intake in proportion of } \\
\text { red food in phase } 2\end{array}$ & $.61(.18)$ & $.50(.19)$ & $P<.05$ \\
\hline
\end{tabular}

Table 2 Control measures, desire and intake: prohibition group versus no-prohibition group 


\section{Hypothesis 1:}

Desire for the forbidden food increases during phase 1 in the prohibition group as compared to the non-prohibition group.

Difference scores for desire (desire after phase 1 minus desire before phase 1) were calculated for all 74 participants. To determine whether a difference between groups regarding change in desire existed, a 2 (Group: prohibition versus no prohibition) x 2 (Phase: 1 versus 2) ANOVA was carried out. Further, simple effects were examined using t-tests.

The results showed a marginal significant interaction of group and phase regarding the course of desire $(F(1,72)=2.22, p=0.07$, one-tailed). T-tests of simple effects show that desire roughly remained at the same level in the control group (t $(37)<1$ ), whereas desire increased significantly during phase 1 in the prohibition condition (t $(35)=2.24, p<.05$ ). See also table 2 .

\section{Hypothesis 2:}

Children in the prohibition condition consume more forbidden snacks in phase 2.

For the second hypothesis we used a MANOVA to measure the differences between the two groups in the second phase regarding consumed kilocalories and proportion of red food (red food in grams divided by total amount of food in grams).

With respect to consumed amount in kilocalories no significant differences between groups were found (see also table 2). However, the MANOVA indicated a significant difference between the two groups with respect to the proportion of consumed red snacks in phase $2(F(1,72)=6.4, p<0.05)$. Children in the prohibition condition consumed a larger proportion of red snacks $(M=.61, S D=.18)$ than children in the control condition $(M=.5, S D=.19)$ during that same phase. 


\section{Hypothesis 3:}

Children, whose parents are more restricting at home, consume more kilocalories during the experiment.

Hypothesis 3 was investigated using linear regression. Both the 'restriction' scale of the CFQ and a quadratic term of this scale were entered in the regression. Dependant variable was total food intake in kilocalories.

Analysis of the third hypothesis showed a curve linear effect: regression analysis indicated that children of parents reporting a low level of restriction, as well as children of parents reporting a high level of restriction consumed more kilocalories during the whole experiment than children of parents reporting a moderate level of restriction at home $\left(p<.000, R^{2}=.212\right)$. See also figure 1. This means that $21 \%$ of the variance in the amount of consumed snacks can be explained by the (self-reported) restricting behaviour of the parents at home.

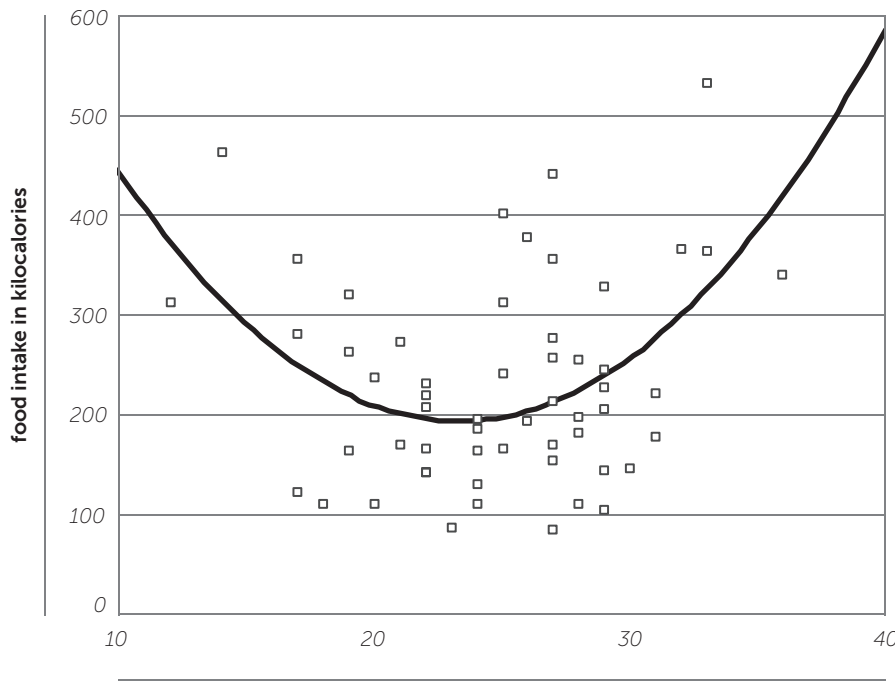

$\mathrm{CFQ}$ restriction score 


\section{Discussion}

The aim of this study was to test whether restricting children's snack intake would result in an increased desire for the forbidden food and subsequent overeating. To this end, we had 5- and 6-year-old children participate in a taste experiment in which they were either or not prohibited to eat a certain colour of snacks. It was expected that the children in the prohibition group would develop an increased desire for the forbidden food during the first phase. Also, they were expected to eat more from the formerly forbidden food in the second phase of the experiment during which the prohibition was no longer operative, as opposed to the children in the no-prohibition group.

The present results show that the desire to eat the forbidden food indeed increased after a prohibition. Next, although the absolute intake of the forbidden food did not differ between groups, the consumed proportion of forbidden snacks (compared to the control snacks) was significantly higher in children in the prohibition group. This means that children who were prohibited from eating the red snacks in the first phase of the experiment ate relatively more from this food in the second phase than from the other (yellow) foods. Thus, our prediction that a prohibition of a certain snack would lead to a relatively greater consumption of this snack afterwards, came true. The formerly prohibited snack was indeed consumed relatively more often than the unforbidden one, as compared to the control group. The desire data support this behavioural outcome. The findings thus suggest that forbidden 'fruit' becomes more attractive.

The fact that desire already increased after a 5 minute prohibition, is interesting. Despite the fact that these children did not consume more kilocalories from red snacks after the prohibition, it could very well be that they develop some kind of obsessive interest for the forbidden food. In the current study, children in the prohibition group were offered similar attractive alternatives for the forbidden snacks (identically the same snacks, yet in a different colour), whereas in a home situation, parents often provide a far less attractive alternative (e.g. 
fruit) or no alternative at all. This could probably lead to other effects of the prohibition itself, including overeating.

Our third hypothesis regarded the relationship between parental restriction at home and snack intake during the experiment. Interestingly, parental restriction at home could predict overall food intake, regardless of the experimental condition of the child. It appeared that children whose parents imposed either very little or a lot of restriction at home consumed more kilocalories throughout the experiment, as opposed to children who were exposed to a moderate level of restriction at home. Though a causal relationship cannot be deduced from these data, this finding clearly is in line with earlier research on the relationship between restriction and weight status. In our study, however, only children with a normal weight participated. Replication and further research in this domain seem certainly worthwhile.

The findings of the current study support previous evidence for the idea that parents should be careful with restricting children's food intake in a rigid way, as it makes them more eager for that food. It might even be the case that children eat more from those kinds of food, although the latter is based upon correlational data. Still, restricting children's food intake might not be an effective strategy when challenging overweight. Parents need to be enlightened about these adverse effects of restriction and provided with better alternatives. A difficulty that arises when advising parents, is determining how moderate or normal control is defined or characterized. Further research seems necessary before guidelines can be formulated definitively.

A final point is that restricting food intake might also be used for positive purposes. If palatable foods can be made even more attractive by prohibiting them, it would be interesting to study whether the same holds true for less palatable kinds of food like vegetables and fruits. As a lot of children have difficulties consuming the daily recommended amounts of vegetables and fruits, it would be valuable to develop a method to promote their consumption.

The experimental nature of the current study makes the results a worthwhile addition to the current knowledge in this area. As this study was carried 
out in an experimental setting, it was possible to control more variables than would have been possible in a field study. Although we found relatively small group differences, these differences are significant and systematic. In addition, this experimental study allows us to cautiously determine the causal relation between restriction and food consumption. Therefore, the results can contribute to the comprehension of the development of overweight. 
coneres 6 
Chapter 4 
From the Garden of Eden to the land of plenty

Restriction of fruit and sweets intake leads to increased fruit and sweets consumption in children

\section{Published as:}

Jansen, E., Mulkens, S., Emond, Y., \& Jansen, A. (2008). From the Garden of Eden to the land of plenty. Restriction of fruit and sweets intake leads to more fruit and sweets consumption in children. Appetite, 51, 570-575. 


\begin{abstract}
Overweight is increasing rapidly in children, compelling researchers to seek for determinants of adverse food intake. In a previous experiment it was found that manipulating the restriction of attractive snacks increased the desirability and intake of these snacks. In the present study, we tested whether this paradoxical restricting effect is also seen in relatively less attractive but healthy food, i.e. fruit. Will fruit become more desirable through restriction, and will children eat more forbidden fruit than non-forbidden fruit?

Two groups of young children were forbidden to eat fruits and sweets respectively, whereas a control group was invited to eat everything. Desire for sweets remained high in the sweets-prohibition condition, whereas it decreased in the fruit-prohibition and no-prohibition conditions. No group differences were found regarding the desire for fruit. With respect to intake, children in both the fruit- and the sweets-prohibition condition consumed more of the formerly forbidden food during a taste session as compared to the no-prohibition condition. In addition, total food intake was higher in the two prohibition conditions than in the no-prohibition condition. These data indicate that the adverse effects of restriction apply to both attractive unhealthy and relatively less attractive but healthy food.
\end{abstract}

\title{
Introduction
}

Overweight and obesity are becoming alarmingly prevalent in the Western society. In the Netherlands, 46\% of all adults are overweight (Body Mass Index $(B M I)>25 \mathrm{~kg} / \mathrm{m}^{2}$; CBS, 2006), whereas over $10 \%$ are obese $\left(\mathrm{BMI}>30 \mathrm{~kg} / \mathrm{m}^{2}\right.$; CBS, 2006). In the United States, the figures are even more shocking: one in every three adults is obese (Ogden et al., 2006). Also, overweight and obesity in children have increased to exceptional proportions. At present, one out of seven Dutch children is overweight (Van den Hurk et al., 2006). In the United States, about $17 \%$ of all children and adolescents are overweight, whereas an additional 
$16.5 \%$ are at risk of becoming overweight (Ogden et al., 2006). Obesity is diagnosed in $3 \%$ of all Dutch children. As childhood overweight generally tracks into adulthood (Whitaker, Wright, Pepe, Seidel \& Dietz, 1997; Clarke \& Lauer, 1993; Serdula et al., 1993), it is of major significance to challenge overweight early in life.

In general, obesity is caused by an imbalance between the intake and the expenditure of energy (Wabitsch, 2000). Current food patterns do not only show substantial increases in snack intake compared to 25 years ago (St-Onge, Keller \& Heymsfield, 2003), they also indicate that children do not consume enough fruit and vegetables. Even though the Dutch National Food Council recommends that children eat at least two portions of fruit a day (HealthCouncil-of-the-Netherlands, 2002), Dutch children eat less than one portion of fruit (Dutch Food Consumption Survey, 1998). As fruit consumption protects against overweight (McCrory et al., 1999), increasing fruit intake is just as important as decreasing the intake of unhealthy kinds of food.

Parents leave their mark on the development of their children's weight status (see e.g. Birch \& Fisher, 1995). They have an important role in stimulating healthy eating behaviour in their children and parental modeling has a consistent influence on the child's eating behaviour (Brown \& Ogden, 2004). It was, for example, found that children imitate their parents in both food preferences and food avoidances (Guidetti \& Cavazza, 2008). Considering all of this, it seems obvious to keep children away from certain unhealthy kinds of food, and to encourage them to eat healthy food. In addition to being role models for their children and being in charge of purchasing and providing meals, parents may also influence their children's eating patterns by using control techniques. According to Birch et al. (2001) parental control in the domain of eating can be subdivided into pressuring the child to eat healthy kinds of food (e.g. fruit and vegetables) and restricting intake of unhealthy, palatable (fatty or sweet) kinds of food. Overcontrolling a child's food intake potentially leads to adverse effects on food preference and intake. It has been hypothesized that parents overcontrolling their children's food intake may interfere with their children's ability to self- 
regulate their intake. As a result, children would be more responsive to external cues (e.g. the smell and presence of foods) as opposed to internal cues (e.g. hunger and satiety) (Faith, Scanlon, Birch, Francis and Sherry, 2004; Jansen et al., 2003). In turn, this could lead to disturbed eating behaviours like eating in the absence of hunger, restrained eating and ultimately excess weight gain (Birch \& Fisher, 2000; Birch, Fisher \& Krahnstoever Davison, 2003; Robinson, Kiernan, Matheson \& Haydel, 2001).

Researchers have found pressuring to eat healthy kinds of food to be associated with lower fruit and vegetable consumption and picky eating in children (Galloway, Fiorito, Lee \& Birch, 2005). In an experimental design examining the influence of pressure to eat, Galloway, Fiorito, Francis and Birch (2006) found that normal weight children consumed more soup and made fewer negative comments when they were not pressured to eat. Thus, pressuring children to eat indeed appears to result in adverse consequences.

Evidence for the potential negative effects of restriction is largely correlational. Several researchers have found parents' restrictive behaviour to be associated with their children's weight status: the more restriction of food intake, the higher the weight (Birch et al., 2003; Constanzo \& Woody, 1984). Although it might seem plausible that restriction by parents could result in disturbed eating behaviour, the alternative could be that parents start restricting the intake of palatable kinds of food as they observe their children becoming heavier. This problem of causality can be solved by manipulating restriction behaviour in an experimental setting. Past research in rats has shown that, even without depriving energy, restricting access to alcohol (Wayner, et al., 1972) or an optional high-fat food (Corwin, et al., 1998) leads to significant increases in the consumption of the restricted substance when it is subsequently made available. Fisher and Birch (1999) studied the influence of restriction of palatable foods in children. In this study, children participated in 8 group snack sessions: 4 unrestricted sessions, followed by 4 restricted sessions. The target food was a palatable snack food. The alternative was a food of lower preference. During the unrestricted sessions, both types of food were freely accessible during 15 min- 
utes. During the restricted sessions, children had only one 5 minute period of free access to the restricted food. The results showed that children's behavioural responses (requests for the food, attempts to obtain it or comments about liking it) to the palatable snack food were greater during restricted sessions that during unrestricted sessions (Fisher and Birch, 1999).

Jansen, Mulkens and Jansen (2007) also studied the influence of restriction in children. It was tested whether a prohibition of attractive snacks would lead to an increased desire for that food and overeating at a later moment in time. Children in the experimental group were not allowed to eat red M\&M's and red crisps in the first phase of the experiment (but were allowed to eat the yellow versions of these same snacks), whereas children in the control group were allowed to eat from both red and yellow snacks in the first phase. The second phase of the experiment was an 'all you can eat' phase for both groups. Desire for and intake of red food increased in the experimental group, whereas desire and intake of red foods remained constant in the control group. From this study it was concluded that restricting the intake of attractive snacks in children actually has adverse effects on food preference and intake. Moreover, it was found that parental restriction, measured among parents with the restriction scale of the Child Feeding Questionnaire (CFQ; Birch, et al., 2001), was associated with snack intake during the taste sessions. Both children of parents reporting either low or high levels of restriction consumed significantly more snacks during the experiment than children of parents reporting a moderate level of restriction.

As restricting the intake of attractive snacks increases the desirability of these snacks (Jansen, Mulkens, \& Jansen, 2007), it would be useful to examine whether it is also possible to make relatively less attractive kinds of food (e.g. fruit) more desirable by the use of restriction. Therefore, the current study focuses on the effects of restriction of both attractive and less attractive food. In this study we test whether prohibiting either sweets or fruit will result in an increased desire for the forbidden food followed by an increased consumption. Desire for and consumption of the forbidden food is expected to increase after 
prohibition, regardless of which type of food is forbidden. Further, it is hypothesized that the degree of restriction at home will be associated with overall energy intake during the experiment: the more a child is restricted at home, the more it is expected to consume during the taste sessions.

\section{Method}

\section{Participants}

Seventy children were recruited from two primary schools in the Netherlands. Participants were told that the experimenter was interested in what kind of tastes children like. The participating children were five to seven year olds (mean age $=$ $5.57, \mathrm{SD}=.55)$. In this age group, minimal social desirable behaviour concerning eating was expected. Older children, or adolescents, could possibly experience feelings of shame and guilt to a greater extent than younger children. In addition, children in this age category are able to obey prohibitions (Piaget, 1965). Permission for participation was obtained from the participating schools as well as from the children's parents. Parents were requested not to share information concerning the content of the study with their children. The study was approved by the ethical committee of the Faculty of Psychology, Maastricht University. Cooperating schools received a gift certificate afterwards. Participant characteristics are summarized in table 1. 


\begin{tabular}{|c|c|c|c|c|c|}
\hline & $\begin{array}{l}\text { No- } \\
\text { prohibition } \\
\text { condition }\end{array}$ & $\begin{array}{l}\text { Fruit- } \\
\text { prohibition } \\
\text { condition }\end{array}$ & $\begin{array}{l}\text { Sweets- } \\
\text { prohibition } \\
\text { condition }\end{array}$ & value & value \\
\hline & Mean (SD) & Mean (SD) & Mean (SD) & & \\
\hline$N$ & 22 & 25 & 23 & & \\
\hline Age & $5.36(0.49)$ & $5.72(0.54)$ & $5.61(0.58)$ & 2.62 & NS \\
\hline Gender (boy/girl) & $13 / 9$ & $16 / 9$ & $14 / 9$ & 0.06 & NS \\
\hline BMI percentile & 77.15 (20.95) & $60.11(26.28)$ & $81.36(23.67)$ & 5.38 & $<0.01$ \\
\hline
\end{tabular}

Table 1: Age, gender and BMI characteristics of the three conditions

One way ANOVAs showed no significant differences between conditions regarding age and gender distribution. However, groups differed significantly regarding BMI (Body Mass Index) percentile.

\section{Design}

Participants were randomly assigned to one of three conditions:

a no-prohibition condition, a fruit-prohibition condition and a sweets-prohibition condition (between subjects factor). The experiment consisted of two phases (within subjects factor); during the first phase the actual manipulation (prohibition yes/no) took place, phase two was an 'all you can eat' phase for all groups. Dependent variables were intake of both fruit and sweets in grams and desire for the prohibited food on a 5-point Likert scale. 


\section{Measurements}

\section{Child Feeding Questionnaire}

Along with an informative letter about the study and an informed consent form, parents received the 'restriction' scale of the Dutch Child Feeding Questionnaire (CFQ: Birch, et al., 2001, translated with permission of the authors) to fill in. The CFQ is a measure of parental attitudes, beliefs and practices of child feeding and obesity proneness. The 'restriction' scale of the CFQ comprises 8 items on restrictive practices (for instance 'I intentionally keep some foods out of my child's reach'). Every item is scored on a scale from 1 to 5 . The higher the score, the more parental restriction is expected to be exerted. The internal consistency of this subscale is good; (Cronbach's alpha $=.72$ ) As yet, the validity of the CFQ is unknown. Nevertheless, a high agreement between parents and children was found (Jansen, Mulkens, Sanders \& Jansen, 2011).

\section{Fruit and sweets}

In this study, banana slices (550 gr. per bowl) and pineapple pieces (750 gr. per bowl) were presented as fruits. M\&M's chocolates (750 gr. per bowl) and Haribo ${ }^{\circledR}$ fruit gums (700 gr. per bowl) represented the sweets category. All four kinds of food were presented to all participants. Participants in the fruit-prohibition condition were prohibited from eating all fruits in phase 1, whereas participants in the sweet-prohibition condition were not allowed to eat the sweets in phase 1. Children in the no-prohibition condition were allowed to eat from all four kinds of food in phase 1.

All kinds of food were presented in identical bowls. Red or green sheets were placed underneath the bowls to indicate whether it was in the forbidden category (red sheet) or the allowed category (green sheet). 


\section{Desire to eat, palatability and satiety}

To measure the desire to eat a particular kind of food, a 5 point rating scale, ranging from 0 ('I do not want to eat this at all') to 4 ('I want to eat this really bad') was used. Palatability of the food was measured with a $10 \mathrm{~cm}$ Visual Analogue Scale (VAS). The left extremity $(0)$ represented 'not palatable at all' and the right extremity (10) represented 'very palatable'. Finally, satiety was measured with a $10 \mathrm{~cm}$ VAS (0:'my tummy is totally empty', 10:'my tummy is completely full'). Palatability and satiety were measured before phase 1 to assure that the participants from the different conditions did not differ in their palatability ratings and were equally satiated before the experiment started. Desire was assessed both before and after phase 1 .

\section{Body Mass Index}

Participating children's weight and height were measured once at the end of the session. Participants had their clothes on, coats and shoes off. Weight in kilograms, rounded off to one decimal, was measured by means of a digital scale. Height in centimetres, rounded off to one decimal, was assessed with measuring tape which was applied on the wall. The experimenters had undergone a short training in collecting this kind of information correctly. BMI percentiles were calculated subsequently (Children's BMI-for-age Calculator, USDA/ ARS Children's Nutrition Research Center).

\section{Procedure}

All children were individually tested. They were picked up from their class rooms one by one and asked to sit down in a quiet room where they were not distracted. The experimenter then introduced herself and told the participant that he/ she would have to answer various questions and taste different kinds of food. The actual experiment then began. Current levels of satiety, palatability and 
desire for all to be presented foods were assessed. Then the first taste session started. During this five minute taste session, the children were left alone with the food. Four bowls, one for each type of food (banana, pineapple, M\&M's and fruit gums) were presented during this phase. All participants had the same four bowls in front of them. Children in the no-prohibition condition were allowed to eat all types of food during this phase. This was underlined by the green sheets underneath all four bowls. Children in the sweets-prohibition condition were instructed not to eat from the M\&M's or the fruit gums. This was visualized by the red sheets underneath the bowls filled with sweets. However, they were allowed to eat from the bowls with fruit, indicated by green sheets underneath those bowls. Likewise, children in the fruit-prohibition condition were instructed not to eat from the banana slices or the pineapple pieces. Yet, they were permitted to eat from the bowls filled with sweets. They were left alone, and after five minutes the experimenter returned to take away the food, which was weighed in another room. Levels of desire for the foods were then assessed. Next, in the second phase, which also took five minutes, all participants received the same instruction: they could eat as much as they liked from all four bowls. This was underlined by the green sheets underneath all bowls. The participant was left alone for five minutes. Then the experimenter returned and took the food away, and the bowls were again weighed outside the room. Finally, the child's weight and height were measured. The child then returned to the classroom. Parents received a debriefing letter about the experiment afterwards.

\section{Statistical analyses}

One-way ANOVAs on desire, palatability and satiety were performed to preclude group differences at the start of the experiment.

In order to analyze the effects of the restriction- manipulation on desire, difference scores for desire for fruit and desire for sweets were calculated (desire after prohibition phase minus desire at start experiment). To test whether the conditions differed in desire change, a MANOVA was carried out entering 
difference scores for both desire for fruit and desire for sweets as dependant variables and condition as factor.

To determine the effects of the restriction manipulation on intake in phase 2, another MANOVA was performed (intake of fruit in phase 2 and intake of sweets in phase 2 as dependant variables, group as factor). Finally, hypothesis 3 was tested by means of linear regression. The 'restriction' scale of the CFQ was entered as a predictor in the regression. The dependent variable was total food intake in kilocalories.

\section{Results}

One-way ANOVAs showed no group differences with respect to desire, palatability and satiety ratings before phase 1. However, conditions differed significantly regarding BMI (Body Mass Index) percentile. Therefore, the reported analyses included BMI percentile as a covariate. Means, SD's, F- and P-values are listed in table 2. Paired sample t-tests show that participants preferred the taste of sweets over fruit [t (69) $=-4.55, \mathrm{p}<.001$ ] and displayed a larger desire for sweets as opposed to fruit at the start of the experiment [t (69) $=4.44, p<.001$ ].

\section{Hypothesis 1:}

Desire for the forbidden food increases during phase 1 in the two prohibition conditions as compared to the no-prohibition condition

The MANCOVA showed no significant group effect for the course of desire for fruit. However, regarding the course of desire for sweets a significant group effect was found $[F(3,66)=3.26, p<.05]$. Post hoc independent samples t-tests showed that the desire for sweets decreased stronger in the fruit-prohibition group than in the sweets-prohibition group [t (33.6) $=4.26, p<.001$ ]. See also table 2. 


$\begin{array}{lllll}\begin{array}{l}\text { No- } \\ \text { prohibition }\end{array} & \begin{array}{l}\text { Fruit- } \\ \text { prohibition } \\ \text { condition }\end{array} & \begin{array}{l}\text { Sweets- } \\ \text { prohibition } \\ \text { condition }\end{array} & \begin{array}{l}\mathrm{F} \\ \text { value }\end{array} & \text { value } \\ N=22 & N=25 & N=23 & \\ \text { Mean (SD) } & \text { Mean (SD) } & \text { Mean (SD) } & \end{array}$

\begin{tabular}{|c|c|c|c|c|c|}
\hline \multicolumn{6}{|l|}{ Before phase 1} \\
\hline $\begin{array}{l}\text { Desire fruit } \\
(0-4)\end{array}$ & $2.41(1.45)$ & $2.52(1.13)$ & $2.43(1.24)$ & 0.05 & $<1.0$ \\
\hline $\begin{array}{l}\text { Desire sweets } \\
(0-4)\end{array}$ & $3.18(1.02)$ & $3.50(0.65)$ & 3.09 (1.24) & 1.16 & $<0.4$ \\
\hline $\begin{array}{l}\text { Palatability fruit } \\
(1-10)\end{array}$ & $5.75(3.12)$ & $6.50(2.60)$ & $5.67(2.75)$ & 0.63 & $<0.6$ \\
\hline $\begin{array}{l}\text { Palatability sweets } \\
(1-10)\end{array}$ & $7.80(2.10)$ & $8.34(1.57)$ & 7.59 (2.44) & 0.86 & $<0.5$ \\
\hline $\begin{array}{l}\text { Satiety } \\
(0-10)\end{array}$ & $6.10(2.71)$ & $5.68(2.64)$ & $6.26(2.16)$ & 0.34 & $<0.8$ \\
\hline
\end{tabular}

\begin{tabular}{|c|c|c|c|c|c|}
\hline \multicolumn{6}{|l|}{ After phase 1} \\
\hline $\begin{array}{l}\text { Increase in } \\
\text { desire fruit }\end{array}$ & $-0.64(1.42)$ & $-0.08(0.98)$ & $-0.39(1.11)$ & 1.34 & $<0.3$ \\
\hline $\begin{array}{l}\text { Increase in } \\
\text { desire sweets }\end{array}$ & $-0.59(1.75)$ & $-1.10^{a}(1.13)$ & $-0.04^{b}(0.50)$ & 4.45 & $<0.05^{\star}$ \\
\hline
\end{tabular}

\begin{tabular}{|c|c|c|c|c|c|}
\hline \multicolumn{6}{|l|}{ Phase 2} \\
\hline $\begin{array}{l}\text { Fruit intake } \\
\text { (gr.) }\end{array}$ & $22.77^{\mathrm{a}}(28.23)$ & $44.72^{\mathrm{b}}(45.12)$ & $17.09^{a}(18.11)$ & 4.74 & $<0.05^{*}$ \\
\hline $\begin{array}{l}\text { Sweets intake } \\
\text { (gr.) }\end{array}$ & $22.95^{\mathrm{a}}(23.90)$ & $27.88^{\mathrm{a}}(21.58)$ & $43.83^{b}(29.77)$ & 4.26 & $<0.05^{*}$ \\
\hline $\begin{array}{l}\text { Intake } \\
\text { (kcal) }\end{array}$ & 117.20 (87.31) & $153.56(83.68)$ & $193.01(121.66)$ & 3.32 & $<0.05^{\star}$ \\
\hline
\end{tabular}

Table 2 


\section{Hypothesis 2:}

Children in both prohibition conditions consume more of the formerly forbidden food in phase 2 as compared to the no-prohibition group

The MANCOVA showed a significant difference between groups with respect to the intake of fruit in phase $2[F(3,66)=4.73, p<.05]$. Post hoc independent samples t-tests showed that the fruit-prohibition condition consumed more fruit than the no-prohibition condition [t $(40.9)=2.02, p=.05$ ] and the sweetsprohibition condition [t $(32.1)=2.83, p<.01$ ] as soon as the prohibition was neutralized. Similar results were found regarding the intake of sweets in phase 2 : the three groups differed significantly $[F(3,66)=3.92, p<.05]$. Consistent with the expectations, post hoc independent samples t-tests showed that participants in the sweets-prohibition condition consumed more sweets than the noprohibition condition [t (43) $=2.59, \mathrm{p}<.05$ ] and the fruit-prohibition condition [t $(46)=2.14, p<.05]$ as soon as the prohibition was no longer operative. In addition, not only the intake of the formerly forbidden food was higher, total food intake (in kilocalories, as sweets and fruit differ in energy density) in phase 2 was also higher in the prohibition conditions as opposed to the no-prohibition condition $[\mathrm{F}(3,66)=3.18, \mathrm{p}<.05]$.

\section{Hypothesis 3 :}

Children, whose parents are more restricting at home, consume more kilocalories during the experiment.

The regression analysis showed no significant predicting effect of restriction scores on energy intake ( $\left.p=0.44, R^{2}=0.01\right)$. The analysis was then repeated with total sweets intake in grams as dependent variable. Again, no effect was found ( $p=0.28, R^{2}=0.02$ ) 


\section{Discussion}

The objective of the current study was to examine whether the effects of restricting attractive snacks, as earlier found by Jansen et al. (2007), would also be applicable to relatively less attractive kinds of food. Therefore, 5- to 7-year-old children participated in a taste experiment in which they were either prohibited from eating fruit, prohibited from eating sweets or not prohibited at all. A second taste session followed, during which the earlier imposed prohibitions were no longer operative; all children could eat as much as they wanted. As predicted, children in both the fruit and the sweet prohibition condition consumed more of the earlier forbidden food during the second taste session as compared to the no-prohibition condition. In addition, total food intake was higher in the two prohibition conditions than in the no-prohibition condition. Thus, the data show that restriction indeed results in higher intake, not only when it concerns attractive, unhealthy food, but also when it concerns relatively less attractive, healthy kinds of food (such as fruit).

The increased intake was accompanied by a lack of a reduction in desire. It was found that the desire to eat sweets decreased in the two conditions that were allowed to eat them, whereas desire for sweets remained constant in the sweets-prohibition group. As for the desire to eat fruit, no differences between groups were found. Nevertheless, children in the fruitprohibited condition ate more fruit in phase 2. The data suggest that the desireeffects of restricting sweets are stronger than the desire-effects of restricting fruit. With respect to consumption, the results strongly supported our expectations: children in the fruit-prohibition condition consumed more fruit than children in the other two conditions as soon as the prohibition was neutralized. Similar results were found regarding the intake of sweets: participants in the sweets-prohibition condition consumed more sweets than participants in the other two conditions as soon as the prohibition was no longer operative. In addition, not only the intake of the earlier forbidden food was higher, total food intake (in kilocalories) in phase 2 was also higher in both prohibition conditions as opposed to the no-prohibition condition. Thus, from these data 
it can be concluded that restricting the intake of either attractive or moderately attractive kinds of food leads to more consumption of that food at a later time point. On top of that, the extra intake of the formerly forbidden food at this later moment is not compensated for by eating less of the other presented kinds of food.

It could be argued that the results can be explained by Sensory Specific Satiety (SSS; Rolls \& Rolls, 1996). SSS refers to the 'decrease in pleasantness of a food after it has been eaten to satiety and other food not eaten to satiety remains relatively pleasant'. However, there are some arguments against the SSS explanation in this case. First, all four types of food that were presented have a sweet taste. If the SSS effect was so strong, it would have carried over from the fruit to the sweets and vice versa (Rolls, Rolls, Rowe \& Sweeney, 1981), resulting in a decrease of pleasantness of the prohibited foods as well. Possibly, no results would have been found at all, then. Secondly, the data on intake in phase 2 suggest that children in the prohibition conditions consumed a similar amount of the (during phase 1) alternative food as children in the control condition. If SSS could explain all results, children in the prohibition conditions would have eaten less of the (during phase 1 ) alternative food in phase 2.

Like previous research indicated, these findings suggest once more that restricting intake could lead to unintentional consequences. Whereas parents may try to tone down their children's preferences for sweet and high fat foods by restricting them, it could be (among other things) precisely this restriction that makes children want and eat the unhealthy kinds of food even more.

The finding that the effects of restriction may be generalized to fruit (at least with respect to intake) is promising. However, implications of this finding are perhaps confusing. On the one hand, it is hopeful that the consumption of fruit can easily be increased by imposing a prohibition first. On the other hand, it seems quite counter-intuitive to instruct parents to restrict their children's fruit intake. Restricting the intake of fruit might well lead to an increase in subsequent fruit intake, but the current research does not provide any information about what happens to fruit preferences and intake in the long term. The chances are that fruit should be available at home, in order for children to eat it. As pres- 
suring children to eat fruit and vegetables seemed to result in adverse effects (Galloway, Fiorito, Lee \& Birch, 2005), it is certainly worthwhile to further examine how fruit consumption in the long term can be realized. Even though the adverse effects of prohibiting sweets were found once more in the current study, it is recommendable to examine the long term effects of restriction of sweets as well. When the effects of restriction will still be present after a longer period of time, parents should be advised not to restrict sweets intake completely.

In general, more research should be done with regard to educational recommendations for parents. Though the adverse effects of complete restriction suggest dismissing this control technique, giving children complete freedom over their intake does not seem right either. An optimal compromise between controlling and letting go is still groping in the dark.

With respect to our third hypothesis, no appreciable results were found. The CFQ restriction scale could not be correlated to energy intake during the experiment. As the results of earlier research were promising (Jansen et al, 2007), the nature of the relationship between the CFQ and intake should be investigated in future research.

A limitation of the current study concerns a methodological issue. Fact is that in the current study, restriction was enforced by a stranger in a school setting. Therefore, the results cannot unthinkingly be generalized to restrictive parental practices at home. Perhaps, parents provide their children with a more thorough explanation of why they cannot eat a particular food. On the other hand, by providing an alternative to the forbidden food, it was attempted to resemble a real life situation as much as possible. Another way of testing the effects of restriction could be to instruct parents to restrict (or not restrict) their child at home and investigate what happens. However, several (important) parameters such as whether the children really leave the forbidden food alone at home and outside their homes cannot be controlled completely then. The strength of the current study lies in the fact that the effects of restriction were manipulated experimentally, which can tell us something about the causal relationship between restriction and eating behaviour. 
Chapter 4

(a)

(n)

75. 
Chapter 5 


\section{How to promote fruit consumption in children: visual appeal versus restriction}

\section{Published as:}

Jansen, E., Mulkens, S., \& Jansen, A. (2010). How to promote fruit consumption in children: visual appeal versus restriction. Appetite, 54, 599-602. 


\begin{abstract}
The prevalence of overweight is increasing dramatically in children. A protective factor against the development of overweight is a sufficient intake of fruit and vegetables. However, the consumption of fruit and vegetables in children is far from ideal these days. Therefore, it is important to examine how the intake of fruit and vegetables can be promoted. In this study, the effects of two fruit promoting techniques were evaluated in 4 to 7 year-old children: presenting fruit in a more visually appealing manner versus restricting the intake of fruit. Two presentations of fruit (regular and visually appealing) were offered to the participants. In a first taste session participants were either allowed to eat from both fruit presentations (no-prohibition group) or prohibited from eating one of the two presentations (regular fruit prohibited group/ visually appealing fruit prohibited group). In a second taste session all participants were allowed to eat from both fruit presentations. The results indicated that visual appeal had a strong effect on consumption of the fruit. With respect to restriction, no effects were found. Parents, schools, supermarkets and food producers should take advantage of these results, and offer children fruit and vegetables that are presented in a visually appealing manner.
\end{abstract}

\title{
Introduction
}

Obesity and overweight are sizeable health threats. Among children, the prevalence of weight problems has increased to exceptional proportions. Currently, one out of seven Dutch children is overweight (Van den Hurk et al., 2006) whereas $3 \%$ of the Dutch children are obese. These numbers are alarming in light of the grave consequences of overweight and obesity. Besides genetic factors, environmental factors play a key role in the development of obesity. In our modern western society we are constantly surrounded by unlimited amounts of unhealthy kinds of food in all varieties and, above all, vast portions. In addition, physical exercise is not promoted. This so-called 'obesogenic' 
environment is put forward as a major factor in the development of obesity (Guerrieri, 2005). Besides the influence of our current society, children's eating behaviours are strongly affected by their parents. Parents do not only serve as role models for their offspring (Brown \& Ogden, 2004), they are also responsible for purchasing groceries and doing most of the cooking. On top of that, parents influence their children's food preferences and intake by using control techniques like restriction of intake and pressure to eat (Birch et al., 2001).

In order to tackle the obesity problem it is not only important to put the brakes on unhealthy eating behaviours, but also to promote healthy eating behaviours, like fruit and vegetable intake. Fruit and vegetables have positive influences on our health. For instance with respect to the prevention of cardiovascular disease, the beneficial effect of fruit intake has been proven (Hung et al., 2004). In addition, fruit also protects against overweight (Roblin, 2007; Epstein et al., 2001; McCrory et al., 1999). Therefore, it seems self-evident to examine how their intake can be increased. Current food patterns indicate that children do not consume enough fruit and vegetables. Even though the Dutch National Food Council recommends that children eat at least two portions of fruit a day (Health-Council-of-the-Netherlands, 2002), Dutch children eat in fact less than one portion of fruit a day on average (Dutch Food Consumption Survey, 1998).

Now, the crucial question is how to encourage children to eat more fruit. For many parents, a chosen method seems to be pressuring their children to eat them. However, previous research has demonstrated that pressuring children to eat healthy foods results in adverse effects: children in fact eat less fruit and vegetables when they are forced to eat them. In addition they may become picky eaters (Galloway, Fiorito, Lee \& Birch, 2005). When we take a closer look at the attractiveness of sweets again, children's strong attraction to sweets might partly result from the fact that the intake of sweets is often restricted. Earlier research has already shown that not only the restriction of sweets leads to higher intake in children (Jansen, Mulkens $\&$ Jansen, 2007), the restriction of fruit yields similar effects (Jansen, Mulkens, Emond \& Jansen, 2008). In this latter study, the intake of either fruit or sweets 
was prohibited during a first taste session. A third (control) group received no prohibition during this first taste session. In a second taste session, the prohibitions were removed, and all participants could eat both sweets and fruit. It was found that both the restriction of sweets and fruit during the first taste session led to an increase in intake of the respective forbidden food during the second taste session, as opposed to the control group. Therefore, prohibiting the intake of fruit was one of the promotion techniques that were examined during the current study. It was hypothesized that children would eat more fruit when the taste session had been preceded by a prohibition to eat the presented fruit.

Next, availability (whether the food is present) and accessibility (e.g. form) of fruit were found to facilitate its consumption (Hearn et al., 1998). Bönnhoff, Eissing, Baumann and Kuß (2002) examined whether the accessibility of fruit and vegetables could increase the intake in children. They presented children with different kinds of fruit and vegetables (apples, bananas and carrots) in two different forms: the control group received whole raw and washed fruit and vegetables; the experimental group received cut up pieces of the same fruit and vegetables. It was found that children in the experimental group ate almost twice as much fruit and vegetables as opposed to children in the control group. It was concluded that children will eat more fruit and vegetables if these are easier to consume.

Visual appeal falls outside the scope of accessibility, but is expected to influence consumption positively as well. For instance, the majority of all sweets are visually appealing, for example by their colour or shape. Fruit consumption in children is expected to increase when the presented fruit is made more visually appealing. The second promotion technique that was examined in the current study therefore was manipulating the visual appeal of fruit. Finally, an interaction between restriction and visual attractiveness was expected. That is, it was hypothesized that the largest increase in fruit consumption would occur in the group were the visually appealing fruit was prohibited before. 


\section{Method}

\section{Participants}

Ninety-four children were recruited from six primary schools in the Netherlands and Belgium. Parents of children in primary school were approached by means of a letter and invited to let their children participate in the current study. Participants were told that the experimenter was interested in what kind of fruit children like. The participating children were four- to seven-year-olds (mean age $=5.48, \mathrm{SD}=.58$ ). In this age group, minimal social desirable behaviour concerning eating was expected. In addition, children of this age category are able to obey prohibitions (Piaget, 1965). Permission was obtained from the participating schools as well as from the children's parents. Parents were requested not to share information concerning the content of the study with their children. The study was approved by the ethical committee of the Faculty of Psychology and Neuroscience, Maastricht University. Cooperating schools received a gift certificate afterwards.

\section{Design}

Participants were randomly assigned to one of three groups: a no-prohibition group, a regular fruit prohibition group and a visually appealing fruit prohibition group (between subjects factor). The experiment consisted of two phases (within subjects factor; during the first phase the actual manipulation took place, phase two was an 'all you can eat' phase for all three groups). Dependant variables were regular fruit intake in grams, visually appealing fruit intake in grams and desire for the prohibited food. 


\section{Measurements}

\section{Fruit}

In a pilot study, 30 children were asked to name their favourite kind of fruit. The three kinds of fruit mentioned most often in this pilot study were used in the main study. By doing so, we tried to make sure that every participant had a taste for at least one kind of fruit that would be presented. Seedless grapes (175 grams per presentation), apple pieces (125 grams per presentation) and strawberries (150 grams per presentation) were presented to the children. These three kinds of fruit were presented in two different ways and offered to the participants simultaneously. The 'visually appealing' fruit was a mix of the above-mentioned fruits, pierced with flagged cocktail sticks and stuck into a watermelon. The 'regular' fruit was an identical mix of these fruits, simply offered on a white plate. To rule out any differences concerning the time children would need to consume the different presentations of fruit, the fruit in the 'regular' presentation was also skewered, but presented with a regular cocktail stick. In all 3 the conditions and in both phases, both the 'regular' fruit and the 'visually appealing' fruit were presented.

\section{Desire to eat, tastiness and satiety}

To measure the desire to eat a particular kind of fruit, a five point rating scale ranging from 0 ('no desire to eat at all') to 4 ('a very large desire') was used. Tastiness of the different kinds of fruit was measured with a ten point rating scale ranging from 1 ('not tasty at all') to 10 ('very tasty'). Finally, satiety was measured with a Visual Analogue Scale (marking the left extremity meaning 'their tummy was totally empty and marking the right extremity meaning 'their tummy was completely full'). Tastiness and satiety were measured before phase 1 to assure the participants from the different groups did not differ in their taste ratings and were equally satiated before the experiment started. Desire was assessed at two moments: before phase 1 and after phase 1. 


\section{Procedure}

All children were tested individually. They were picked up from their class rooms and asked to sit down in a quiet room without any distracters. The experimenter then introduced him/herself and told the child that he/she would have to answer various questions and taste different kinds of food. The actual experiment then began. The two presentations of fruit were placed in front of the participant. Current levels of satiety, tastiness and desire for all to be presented foods were assessed. Then the first taste session started, during which the child was left alone. During this first taste session, participants in the 'regular fruit prohibition group' were prohibited from eating fruit from the regular presentation, whereas they were allowed to eat as much as they wanted from the visually appealing presentation. This was precisely the other way around for participants in the 'visually appealing fruit prohibition group'. Children in the no-prohibition group were allowed to eat fruit from both the regular and the visually attractive presentation. After five minutes, the experimenter returned and took away the food, which was weighed in another room. Levels of desire for the different kinds of fruit were then assessed. Next, the second phase started. During this phase, all participants received the same instructions: they could eat as much fruit as they liked from both the regular and the visually appealing presentation. After five minutes, the experimenter returned and took the food away. Again, the fruit was weighed outside the room. The child then returned to the classroom. Parents received a debriefing letter about the experiment afterwards.

\section{Results}

Data for all 94 children were used in the reported analyses ${ }^{1}$. One way ANOVAs showed no group differences with respect to desire, tastiness and satiety ratings before phase 1.

\footnotetext{
1 When participants who did not comply with the instructions of the experimenter $(n=11)$ were excluded from the analyses, the reported findings were not affected. Therefore, the analyses with all 94 participants were reported.
} 


\section{Hypothesis 1:}

Children in the 'regular fruit prohibition group' show an increased desire for the regular fruit and consume more regular fruit during phase 2 as compared to the other two groups.

Difference scores for desire for regular fruit were calculated (desire after prohibition phase minus desire at start experiment). To test this first hypothesis (the pure effect of restriction), a MANOVA (difference score for desire for regular fruit and intake of regular fruit in phase 2 as dependent variables, group as factor) was carried out. No significant differences between the three groups were found with respect to desire. Desire for regular fruit actually decreased slightly in all groups (mean $=-.32(S D=.98)$ for the 'regular fruit prohibition group' versus mean $=-.25(S D=.78)$ for the 'no prohibition group' and mean $=-.23(S D=.91)$ for the 'visually appealing fruit prohibition group'). With respect to the intake of regular fruit in phase 2 , no differences were found (23.30 grams (SD $=26.97$ ) for the 'regular fruit prohibition group' versus 34.03 grams (SD = 37.51) for the 'no prohibition group' and 21.66 grams (SD = 24.15) for the 'visually appealing fruit prohibition group').

\section{Hypothesis 2:}

The intake of visually appealing fruit will be larger than the intake of regular fruit.

To test this hypothesis, the data of participants in the no-prohibition condition alone were analyzed, as we wanted to examine the pure effect of visual appeal (e.g. without the potential effects of prohibition). A paired sample t-test was carried out, with total intake of regular fruit and total intake of visually appealing fruit as the paired variables. The results showed a significant effect of visual appeal on intake (t (35) =3.69, p = .001). As expected, the total intake of the visually appealing fruit was larger than the intake of regular fruit (mean $=135.37$ grams $(S D=78.64)$ versus mean $=73.34$ grams $(S D=67.24)$. 


\section{Hypothesis 3:}

Children in the 'visually appealing fruit prohibition group' show an increased desire for the visually appealing fruit and consume more visually appealing fruit during phase 2 as compared to the other two groups.

Difference scores for desire for visually appealing fruit were calculated (desire after prohibition phase minus desire at start experiment). To test the third hypothesis (interaction effect of visual appeal and restriction) a MANOVA (difference score for desire for visually appealing fruit and intake of visually appealing fruit in phase 2 as dependent variables, group as factor) was carried out. Regarding desire, no significant differences between the three groups were found. (Mean $=-.17$ (SD = .76) for the 'visually appealing fruit prohibition group' versus mean $=-.06(S D=1.18)$ for the 'no prohibition group' and mean $=-.18$ $(S D=1.34)$ for the 'regular fruit prohibition group'). With respect to the intake of visually appealing fruit in phase 2, no differences were found (63.31 grams $(S D=43.73)$ for the 'visually appealing fruit prohibition group' versus 62.60 grams (SD $=53.93)$ for the 'no prohibition group' and 70.97 grams (SD $=59.50$ ) for the 'regular fruit prohibition group').

\section{Discussion}

The aim of the current study was to examine how fruit consumption in children may be increased. Two different promotion techniques were evaluated: prohibiting the fruit prior to the actual intake and presenting fruit in a more visually appealing manner. To this end, 94 four- to seven-year-old children participated in a taste experiment in which they were either prohibited from eating regular fruit, prohibited from eating visually appealing fruit or not prohibited at all. A second taste session followed, during which the earlier imposed prohibitions were no longer operative; all participants could eat as much as they wanted from both kinds of fruit. Three hypotheses were formulated.

First, children were expected to consume more fruit when the taste session had been preceded by a prohibition to eat fruit. However, no group 
differences were found regarding the intake of regular fruit during the second taste session. Therefore, these data do not support any influence of restriction on subsequent fruit intake.

Secondly, it was hypothesized that children would consume more fruit when it was presented in a visually appealing manner. The results show that the consumption of visually appealing fruit was indeed significantly larger than the consumption of regular fruit: children in the 'no prohibition group' ate nearly twice as much of the visually appealing fruit mix as opposed to the regular fruit mix. From these data it can be concluded that presenting fruit in a more visually appealing manner actually promotes fruit consumption in children.

Finally, an interaction effect of visual appeal and restriction was expected. However, no group differences were found regarding the intake of visually appealing fruit during the second taste session. It can be concluded that there is no support for an interaction effect of restriction and visual appeal in the current study.

In general, the current study found support for a main effect of visual appeal on intake, whereas restriction was not supported as a promotion technique.

A limitation of the current study is that where intake data evidently show the promoting effect of visual appeal on intake, this is not supported by desire scores; the desire for visually appealing fruit scores do not differ from desire for regular fruit scores. That could implicate that the use of desire rating scales is not suitable for young children. However, these desire ratings were successfully used before in a comparable age group (Jansen, Mulkens \& Jansen, 2007). Another possibility is that, because there were only 5 rating options, (0-4), there was not enough dispersion of the scores to result in significant differences.

The effects of visual appeal on fruit intake cannot be explained by debriefing the participating children. They could not explain why they ate more from the visually attractive fruit than from the regular fruit. They knew very well that both the visually attractive fruit and the regular fruit tasted identical, but still they consumed more from the visually attractive fruit. Perhaps it was not about 
taste, but about fun. Even though the effect of visual appeal cannot be explained, the promoting effect of visual appeal on fruit consumption seems rather logical. When children (or people in general) can choose between two options it seems quite obvious that they choose the (visually) most attractive option. The effect of visual appeal on fruit consumption appears to be a rather robust effect.

Implications of this finding seem quite simple. Parents should present fruit in a more appealing manner in order to stimulate their consumption in their children. In addition, food producers, schools and supermarkets can take an active part in developing and proffering more appealing alternatives. A number of Dutch chains of supermarkets recently introduced the so-called 'snack fruits'; bite-size raw vegetables or pieces of fruit in an attractive pack-aging. Although these healthy snacks are not especially developed for children, it is certainly a valuable initiative. Perhaps adding a little toy (like the toy that comes with a Happy Meal) to the packaging could make this kind of snack even more appealing. On the other hand, it cannot be predicted for how long a new, more visually appealing presentation of fruit remains interesting for children. When children are exposed to a new kind of fruit presentation for a number of times, they might lose their interest in the fruit. Therefore, in the long term, it is probably necessary for parents and food producers to remain innovative. Future research should focus on evaluating other methods that can be used to make fruit more appealing. In addition, future research should also focus on whether the consumption of vegetables could be increased in a similar way, as vegetables are generally less liked than fruit.

With respect to restriction as a method to promote consumption, more research is recommended as well. As mentioned before, earlier research did find effects of restriction on subsequent fruit intake (Jansen et al., 2008). Even though no effects of restriction on fruit intake were found in the current study, it cannot be ruled out that restriction has any influence at all. Future research will have to provide us with a definite answer on the role of restriction. 
Chapter 6 
Assessing eating disordered behaviour in overweight children and adolescents: bridging the gap between a self-report questionnaire and a gold standard interview

\section{Published as:}

Jansen, E., Mulkens, S., Hamers, H., \& Jansen, A. (2007). Assessing eating disordered behaviour in overweight children and adolescents: bridging the gap between a self-report questionnaire and a gold standard interview. Netherlands Journal of Psychology, 63, 102-106. 


\begin{abstract}
The current study compared two measurements assessing eating disorder psychopathology in overweight children and adolescents: an interview and a self-report questionnaire. An adjusted version of the Child Eating Disorder Examination Questionnaire (ChEDE-Q) was compared to the Child Eating Disorder Examination interview (ChEDE), which is considered the gold standard. 38 overweight children and adolescents (age 8-14) participated in the study. Regarding objective bulimic episodes, the current study found that using smaller chunks of information decreased the discrepancy between interview and questionnaire. The chances are that the gap between ChEDE-Q and ChEDE can be reduced when paying more attention to children's abilities concerning the understanding of complex concepts.
\end{abstract}

\title{
Introduction
}

Overweight and obesity are becoming the most significant public health issues of the 21 st century. In the Netherlands, $46 \%$ of all adults are overweight, of which $11 \%$ are obese. At the same time, overweight and obesity are increasingly prevalent in children and adolescents. Currently, one out of eight Dutch children is overweight or obese (CBS, 2005; Visscher, Kromhout \& Seidell, 2002). Because of severe physical and psychological health consequences, treatment is necessary. However, prior to treatment, it is important to assess potentially disordered eating behaviours like binge eating and purging, as the occurrence of these behaviours complicates treatment (Elfhag \& Rossner, 2005).

Among the adult overweight population, binge eating seems a common behaviour. Research suggests that 20 up to $46 \%$ of all treatment seeking obese adults report eating binges (Bruce \& Wilfley, 1996; de Zwaan \& Mitchell, 1992). In addition, binge eating episodes are reported by 20 to 30\% of obese children (Decaluwé, Braet $\&$ Fairburn, 2003). An eating binge is defined as eating an amount of food that is larger than most people would eat during a discrete period of time during which loss of control is experienced (APA, 1994). 
Binge eating is an ambiguous concept and therefore hard to diagnose (Fairburn \& Wilson, 1993; Jansen, van den Hout \& Griez, 1990).

At present, various instruments are used to diagnose eating disorders and binge eating. The Eating Disorder Examination (EDE; Fairburn \& Cooper, 1993) is considered the gold standard for assessing specific eating psychopathology. As the EDE should be administered by a trained interviewer (Cooper \& Fairburn, 1987), this method is far more time-consuming and more expensive than, for example, a self-report questionnaire (Black \& Wilson, 1996). Another disadvantage might be that a semi-structured interview like the EDE allows less anonymity, which might lead to a lower degree of honesty, especially when it comes to delicate issues (Carter, Aimé \& Mills, 2001). The Eating Disorder Examination Questionnaire (EDE-Q; Fairburn \& Beglin, 1994) was developed as a possible substitute for the EDE. A study of Luce and Crowther (1999) suggests that the subscales of the EDE-Q have high levels of internal consistency (Cronbach's alpha ranged from 0.78 to 0.93). However, the EDE-Q proved to have difficulties in identifying more complex conceptual issues, like binge eating (Black \& Wilson, 1996; Fairburn \& Beglin, 1994).

The same problems arise when the children's versions of these instruments are compared. In a study by Decaluwé and Braet (2004), the child version of the EDE (ChEDE; Bryant-Waugh et al, 1996) and the child version of the EDE-Q (ChEDE-Q; Decaluwé, 1999) were compared. It was found that the four subscales of the ChEDE correlated significantly with the corresponding subscales of the ChEDE-Q (r ranging from .42 to .76). However, scores on the ChEDE-Q subscales were found to be consistently higher than scores on the ChEDE subscales. When comparing the ChEDE and the ChEDE-Q in assessing objective bulimic episodes the researchers did not find any significant correlation between the two instruments. The ChEDE-Q produced significantly higher scores with respect to binge eating. The discrepancy between the ChEDE and ChEDE-Q thus concerns binge eating behaviour in particular. The probable cause for these results lies in the fact that it is very difficult to identify bulimic episodes and the concepts involved. 
Because of the major advantage of saving expenses and time when using questionnaires, improving the ChEDE-Q seems to be of great value. With respect to a complex conceptual issue like binge eating, the consistency between the two instruments might well be improved by explaining ambiguous concepts in the questionnaire.

Passi, Bryson and Lock (2003) examined whether adding information for adults led to a smaller discrepancy between EDE and EDE-Q. This research showed that adults studied the extra information and used it when filling in the questionnaire. Yet, because of the small number of participants $(n=28)$, no firm conclusions could be drawn.

In the current study we attempt to further reduce the gap between the EDE interview and questionnaire for children by appending information explaining ambiguous concepts like 'binge eating', 'loss of control' and 'large amounts of food'. It is hypothesized that the addition of this information results in a smaller discrepancy between the two instruments in children, especially with respect to objective bulimic episodes.

If it appears possible to increase the agreement between the two instruments, the ChEDE-Q might be welcomed as a useful alternative for the time-consuming and costly ChEDE.

\section{Method}

\section{Participants}

38 children and adolescents (30 girls and 8 boys) participated in the current study. Mean age of the participants was 11.3 years ( $S D=1.43$, range $8-14$ years) with a mean $\mathrm{BMI}$ percentile of 94.49 (SD = 5.81, range 75.2 -99.6).

All children had been participating in a free out-patient treatment program for overweight, provided by Maastricht University. The current research was integrated in one of the follow-up measurements. Informed consent was obtained from the children's parents. After completing the measurements, the children were allowed to choose a small present. 


\section{Measurements}

\section{Child Eating Disorder Examination}

The ChEDE (Bryant-Waugh, Cooper, Taylor \& Lask, 1996) is a child adapted version of the adult EDE (Fairburn \& Cooper, 1993). It consists of four subscales; 'restraint', 'eating concern', 'shape concern' and 'weight concern'. Furthermore, the ChEDE measures overeating ('objective bulimic episodes', 'subjective bulimic episodes' and 'objective overeating episodes') and methods of weight control ('self-induced vomiting', 'laxative misuse', 'diuretic misuse' and 'intense exercising'). The ChEDE consists of 35 items that are scored on a 7-point (0-6) rating scale. Higher scores indicate greater seriousness or frequency of the given feature.

\section{Child Eating Disorder Examination Questionnaire}

The Child Eating Disorder Examination Questionnaire (ChEDE-Q; Decaluwé, 1999) is based on the Eating Disorder Examination Questionnaire (EDE-Q; Fairburn \& Beglin, 1994) for adults. It is a self-report questionnaire measuring the existence and frequency of eating disorder psychopathology. The EDE-Q consists of 30 items, each corresponding to an item of the original EDE. The ChEDE-Q also consists of 30 items, using a 7-point rating scale.

For the current study, some adjustments were made to the ChEDE-Q. The adjusted questionnaire did not make use of 7 response possibilities, but of 28: each of 28 boxes represented one of the past 28 days the questionnaire inquires after. This was done to visually enhance children's notion of the past 28 days. The children had to colour the number of boxes (that is, days) on which they had experienced the inquired feature. The researcher afterwards transcribed these scores into the original 7-point rating scores. Furthermore, another important change was the insertion of definitions of the ambiguous concepts used in the ChEDE-Q: 'loss of control', 'eating binge', 'eating in secret', 'large amount of food' and 'intense exercising'. 
In the present study the Cronbach alpha coefficients for each subscale were 0.53 for 'Restraint', 0.65 for 'Eating Concern', 0.57 for 'Weight Concern' and 0.83 for 'Shape Concern' respectively. These are comparable to alphas found in other studies (Decaluwé \& Braet, 2004).

\section{Procedure}

The interview and questionnaire were both administered during the same follow-up measurement and therefore related to the same preceding 28-day period. As Decaluwé and Braet (2004) recommended, a 28-day diary was used to enhance recall during the administration of both the questionnaire and the interview. The adapted version of the ChEDE-Q was administered at the beginning of the measurement. Subsequently, the child completed a number of other questionnaires which were irrelevant for this study. Then, the ChEDE was administered. Finally, the child was measured and weighed. The order in which the ChEDE-Q and ChEDE were administered was not counterbalanced. As previous studies (Black \& Wilson, 1996; Decaluwé and Braet, 2004; Fairburn $\&$ Beglin, 1994) have argued, administering the interview first could elucidate key concepts and consequently influence scores on the adjusted ChEDE-Q.

\section{Results}

\section{Data reduction and analysis}

To establish the degree of correspondence between the ChEDE and ChEDE-Q, first the subscale scores of both measures were calculated. Correlations and t-tests were computed to compare the subscale scores, the global score as well as overeating and compensatory behaviour. The level of agreement was also calculated for all these variables. Agreement is met when the ChEDE-Q score lies within a 1-scale point range of the ChEDE score. With respect to the ChEDE-Q, an eating binge can be diagnosed in two ways. 
Item 8 comprises both the concepts of eating a large amount of food and the loss of control in a single question ('Have you had episodes of binge eating?'), whereas items 16 and 17 address these two concepts separately (item 16 focuses on eating a large amount of food whereas item 17 inquires after loss of control).

Consequently, an eating binge can be diagnosed by an affirmative response to item 8 or by affirmative responses to both items 16 and 17 . Regarding the results of the present study we examined both ways of diagnosing eating binges.

\section{Subscales}

Table 1 shows the scores of both the interview and the questionnaire. The four subscales of the ChEDE and ChEDE-Q were all significantly correlated, with correlations ranging from 0.40 to 0.78 . Comparisons of the subscales show that scores on the interview and the questionnaire are significantly different with respect to 'Eating concern' and 'Shape concern'; questionnaire scores are significantly higher than interview scores. Regarding the other two subscales, 'Restraint' and 'Weight concern', there were no significant differences between interview and questionnaire. The level of agreement is considerably high for all four subscales, ranging from $73 \%$ to $92 \%$ agreement within one scale-point. 


\begin{tabular}{|c|c|c|c|c|c|c|}
\hline & $\begin{array}{l}\text { ChEDE } \\
M(S D)\end{array}$ & $\begin{array}{l}\text { ChEDE-Q } \\
M(S D)\end{array}$ & $\begin{array}{l}\text { M (SD) of } \\
\text { Difference } \\
\text { between } \\
\text { ChEDE-Q } \\
\text { and ChEDE }\end{array}$ & $\mathbf{R}$ & $t$ & $\begin{array}{l}\% \\
\text { agree- } \\
\text { ment } \\
\text { within } \\
\text { 1-scale } \\
\text { point }\end{array}$ \\
\hline Restraint & $1.18(0.97)$ & $1.20(0.85)$ & $0.016(1.00)$ & $0.40 *$ & -0.10 & 77.9 \\
\hline Eating concern & $0.25(0.26)$ & $0.47(0.55)$ & $0.324(0.46)$ & $0.55^{\star \star}$ & $-4.29 * \star$ & 92.1 \\
\hline Weight concern & $1.53(0.99)$ & $1.62(1.05)$ & $0.137(0.68)$ & $0.78^{\star \star}$ & -1.19 & 73.4 \\
\hline Shape Concern & $0.73(0.79)$ & $1.29(1.05)$ & $0.557(0.69)$ & $0.75^{\star * *}$ & $-4.90 * *$ & 76.7 \\
\hline $\begin{array}{l}\text { Objective Bulimic } \\
\text { episodes }^{1}\end{array}$ & $(0.00)$ & $1.03(2.37)$ & & & & 76.3 \\
\hline $\begin{array}{l}\text { Objective Bulimic } \\
\text { episodes }^{2}\end{array}$ & $0.0(0.00)$ & $0.26(0.89)$ & & & & 94.7 \\
\hline
\end{tabular}

Table 1: Comparison of the ChEDE and ChEDE-Q $(n=38)$ ${ }^{*} p<.05,{ }^{* *} p<.01$

${ }^{1}$ An objective bulimic episode was scored when the response to item 8 was affirmative.

${ }^{2}$ An objective bulimic episode was scored when both eating large amounts of food and loss of control were reported (both affirmative responses to item 16 as well as item 17)

\section{Objective bulimic episodes}

Table 1 shows the binge eating scores of the interview and questionnaire. Because the ChEDE did not determine any binge eating episodes in all 38 participants, no correlation with ChEDE-Q scores could be calculated nor could a t-test be executed. However, it is eye-catching that the results indicate an evident difference between the two scoring methods of the ChEDE-Q. When binge eating is assessed by ChEDE-Q items 16 and 17 instead of item 8 , the scores resemble ChEDE scores to a higher degree, resulting in less false positives. 


\section{Discussion}

The aim of the current study was to improve the ChEDE-Q (Decaluwé, 1999) by providing clarification of complex concepts used in questions and modifying the response possibilities. To determine whether these alterations were actually improvements, the ChEDE-Q scores were compared to the ChEDE scores in 38 overweight or obese children.

Earlier research findings showed that there is a substantial discrepancy between the interview and questionnaire: scores on all four subscales differ significantly between the two measures. In addition, the most salient difference between the two measurements is found with respect to the assessment of objective bulimic episodes: the questionnaire approves to overestimate the number of eating binges in comparison with the interview (Decaluwé \& Braet, 2004).

By adapting the ChEDE-Q in the current study through exemplifying certain concepts, inserting definitions and adapting the response format, this discrepancy decreased. When the questionnaire and the interview were compared, the four subscales were all significantly correlated. The obtained correlations are comparable to those found by Decaluwé and Braet (2004). That is, in general, scores on the questionnaire appeared higher than scores on the interview. With regard to the subscales 'Eating concern' and 'Shape concern', these differences were significant. However, the discrepancy found in the current study is not as considerable as the discrepancy found by Decaluwé and Braet (2004), who found that all four subscales differed significantly between interview and questionnaire. With respect to objective bulimic episodes, it was shown that the discrepancy between interview and questionnaire was reduced from 1.03 to 0.26 points when an eating binge was scored based on affirmative responses both on item 16 (eating large amounts of food) and 17 (loss of control) instead of on item 8 (episodes of binge eating) solely. Agreement between the two measures was $76.3 \%$ based on item 8 and $94.7 \%$ based on the combination of items 16 and 17 . 
These results indicate that the adjustments made are indeed improvements to the ChEDE-Q, in a way that the scores resemble ChEDE scores to a larger extent. Concerning the future use of self-report questionnaires measuring eating disordered behaviour (in children, but possibly also in adults), it would be recommended to further examine the effects of clarifying vague concepts, questioning these concepts in manageable and meaningful chunks (for example splitting binge eating into loss of control and eating large amounts of food) and modifying response possibilities.

Obviously, this study shows some limitations. First, the results are based on a fairly small sample $(n=38)$. Therefore, these findings need to be replicated in a larger sample. Secondly, being an allied problem, none of the participating overweight or obese children were diagnosed with objective bulimic episodes according to the gold standard. A larger sample size could probably solve this problem as well. A third limitation, which is connected to the previous, might be that the study was carried out with children that had already completed treatment. It would be better to carry out this research before participants start treatment. Yet, the question is whether this really causes problems for interpreting the results as within group differences implicate an improvement when questions are subdivided into smaller chunks.

In conclusion, the current study found that adjustments to the ChEDE-Q reduced the gap between interview and self-report questionnaire. Adding up that self-report questionnaires are less time consuming, do not require a trained interviewer, cost less, possibly result in more sincere answers to delicate issues and do not bring about an instrumentation effect, it seems worthwhile to consider investing time and money in further improving and refining the ChEDE-Q. 
Chapter 7 


\section{Tackling childhood overweight: treating parents exclusively is effective}

\section{Published as:}

Jansen, E., Mulkens, S., \& Jansen, A. (2011). Tackling childhood overweight: treating parents exclusively is effective. International Journal of Obesity, 35, 501-509. 


\section{Abstract}

In general, treatment of childhood obesity focuses on treating the obese child. The results of child directed treatments are disappointing in the long run. In the current study, it was tested whether a treatment aimed solely at obese children's parents results in positive effects on the child's weight status. In addition, potential predictors of treatment success were identified.

The parents of 98 overweight or obese children (age 7-13) were randomly assigned to either the (8 sessions) cognitive-behavioural group treatment or the waiting list control group.

With respect to child BMI percentile, the parent treatment was successful in reducing overweight from pre-treatment to post treatment: BMI percentile decreased significantly with $2.4 \%$ in the treatment group whereas there was no change in the waiting list control group. There was no significant relapse at follow up (3 months). Child BMI percentile did not decrease in the waiting list control group. In addition, significant main effects of time were found for both groups with respect to eating psychopathology (decrease), self-esteem (increase) and negative thoughts (decrease). Finally, parental BMI decreased significantly only in the treatment group. With respect to treatment success, four predictors were identified; lower socioeconomic status, younger age of the child, higher parental attendance and lower BMI percentile of the child before treatment.

The parent treatment had significant effects on child- and parent BMI. Long-term endurance of these positive effects needs to be studied. Striking are the positive effects of time in the waiting list control group for some psychological outcome measures; obviously, waiting for treatment already affects psychological processes (but not behaviour) in the children. 


\section{Introduction}

Childhood obesity and overweight are sizeable health threats. Among children, the prevalence of weight problems has increased to exceptional proportions (Dietz \& Robinson, 2005). In the United States, about 17\% of all children and adolescents are overweight, whereas an additional $16.5 \%$ are at risk of becoming overweight (Ogden et al., 2006). Currently, one out of seven Dutch children is overweight (Van den Hurk et al., 2006) whereas 3\% of the Dutch children are obese. These numbers are alarming in light of the grave consequences of obesity. As childhood overweight generally tracks into adulthood, and treatment for adults is hardly effective on the long run, it is of major significance to challenge overweight early in life (Whitaker, Wright, Pepe, Seidel \& Dietz, 1997; Clarke \& Lauer, 1993; Serdula et al., 1993).

At present, the most effective treatment is behaviour therapy, aimed at changing the eating and exercise patterns of the child, which also involves the child's parents (Epstein, 1994). In a meta-analytic review by Wilfley et al. (2007), 14 randomized controlled trials were reviewed. It was concluded that interventions aimed at changing eating habits and exercise patterns, turn out to be efficacious in the short term. Effect sizes of these interventions were on average 0.75 at the end of treatment. In addition, there is some evidence that these effects endure in the long term; the mean effect size at follow up (mean = 15 months) was 0.60 (Wilfley et al., 2007). Likewise, from a recent meta-analysis by Oude Luttikhuis et al. (2009), it was concluded that combined behavioural lifestyle interventions can result in significant and clinically relevant overweight reduction in children. Although these findings show positive effects of weight loss interventions in children, there is still room for improvement.

In the current study, the role of parents in the treatment of childhood obesity is emphasized. Parental behaviours are believed to play an important role in the development of children's weight status (see e.g., Birch \& Fisher, 1995). They have an important role in stimulating healthy eating behaviours in their children. Parental modeling has a consistent influence on the child's eating 
behaviour (Brown \& Ogden, 2004). Children, for example, imitate their parents in both food preferences and food avoidances (Guidetti \& Cavazza, 2008). In addition, parents are responsible for purchasing foods and preparing meals. Furthermore, they can influence their children's eating behaviour by both parenting style and specific feeding practices, for example the use of restriction.

In the majority of weight loss interventions, parents are involved, but only indirectly (for example attending education meetings about healthy food). Mostly, they are less involved than their children. In a treatment study, Mulkens, Jansen and Jansen (2004) found evidence that the attendance of parents at the parental meetings (in which parents were informed about their children's progress, and taught how to support their children, how to cook healthy and how to promote exercise) predicted weight loss in children. Golan and Crow (2004a) also emphasize that parents are key players in treating childhood overweight. They found that targeting parents exclusively, by means of support and educational group sessions, resulted in greater weight loss (both in the short and the long term) than targeting children exclusively (Golan \& Crow, 2004b). In addition, a parent-only treatment would also be favourable with respect to cost efficiency (Golan, Kaufman \& Shahar, 2006). There is only limited support for the efficacy of interventions targeting parents exclusively. Recent support was provided by a study by West, Sanders, Cleghorn and Davies (2010). They found that a 12 week intervention for parents of 4- to 11-year-old children significantly reduced child BMI and weight related problem behaviour. The intervention included nutrition strategies, physical activity strategies and positive parenting strategies. Although the outcomes of parentfocused treatments are positive so far, the evidence is not conclusive. The aim of the current study is to investigate whether a treatment that aims at parents exclusively (by targeting eating and exercise behaviour, and supporting self-esteem of the child in a cognitive behavioural manner) would be successful in reducing their children's overweight. Such a treatment might lead to better results than treatments focusing on children, since parents play such an important role in their children's eating and exercising behaviour, and in promoting their self-esteem. 
It is hypothesized that treating parents only will have a favourable effect on the child's BMI in comparison with a waiting-list control group. In addition, it is hypothesized that the parent treatment will improve healthy eating behaviours, decrease eating psychopathology, increase the frequency of exercise, decrease negative thoughts and increase self-esteem in the children (as opposed to the waiting- list control group). Finally, the treatment is expected to result in healthier BMI's of the parents and siblings, as well. A second goal of the current study is to identify predictors of treatment success.

In a recent study by Moens, Braet and van Winckel (2010) it was found that age of the child, baseline BMI and self-worth were significant predictors of treatment success after 8 years. In the current study, it was hypothesized that a younger age of the child (Braet, 2006), the absence of parental overweight (Golan \& Crow, 2004; Wrotniak, Epstein, Paluch \& Roemmich, 2004), higher BMI percentile of the child before treatment (Braet, 2006), higher socio economic status (Epstein \& Wing, 1987), higher motivation and greater parental attendance would positively influence treatment outcome.

\section{Method}

\section{Participants}

Participants were the parents of 98 overweight or obese children (aged 7-13 years). They signed up for a training to help their child to attain a healthy weight. The mean age of their children was 9.72 years $(S D=1.6)$. Parents were recruited by different means; advertisements in local newspapers, posters in doctor's practices and pharmacies, information leaflets at primary schools, and finally referral by general practitioners. Parents participated in the treatment voluntarily. To be included in the study, their children's percentage of overweight had to be at least 130\% (van Wieringen, 1985). The children's mean Body Mass Index (BMI) percentile was 96.48 (SD = 3.13) (Children's BMI-for-age Calculator, USDA/ ARS Children's Nutrition Research Center). 
From 63 families, both parents participated in the study. In addition, 35 single parent families took part in the study (24 mothers and 11 fathers). In total, 87 mothers (mean age $=40.31$, SD $=5.16$, range 29 to 50) and 74 fathers (mean age $=43.18, \mathrm{SD}=5.62$, range 27 to 64 ) participated. Of the mothers, $64.4 \%$ were overweight (mean BMI of all mothers $=27.99, \mathrm{SD}=5.83$ ) and $83.3 \%$ of all fathers were overweight (mean BMI of all fathers $=29.74$, $\mathrm{SD}=5.41)$.

\section{Design}

Parents were randomly assigned to either the treatment group or the waitinglist control group. The treatment group immediately started the training after pre-testing, whereas families in the waiting-list control group waited six months first. After the waiting period of six months, they were also offered the parent training. As only 9 of the 48 families in the waiting-list control group eventually decided to participate in the treatment after the waiting period, it was decided to include these 9 families in the treatment group, and to disregard their data from the waiting period. These 9 families did not differ from the original treatment group or the control group. There were three main reasons for parents to withdraw from treatment; no more need for treatment (these parents reported lifestyle improvement), no time for treatment, or intending to engage in another treatment program. In the treatment group, measurements were scheduled before the start of treatment, after completing the treatment and 3 months post treatment. In the waiting-list control group, the measurements were scheduled at the same time points as the treatment group.

The measurements took place at home. A psychologist guided the family through the different questionnaires, and assessed binge eating and eating behaviours by means of an interview. If the psychologist had the impression that the child or other members of the family were emotionally affected by the questions, they were emotionally counselled. In practice, this was never necessary. 


\section{Treatment}

The training entitled 'Finger in the pie' was a cognitive behavioural treatment and was carried out according to a protocol, written by the first and the second author (the second author being a cognitive behavioural therapist). Treatment was provided in groups (parents of 5-8 overweight children) and carried out by trained cognitive behavioural therapists. Participants were offered eight twohours (evening)sessions spread over ten weeks. Treatment took place in one of three locations (a community health centre in Sittard, a university building in Maastricht and a community centre in Heerlen). The therapists were counterbalanced over the three locations. Each session addressed a different theme associated with childhood overweight (see also table 1). The purpose was not purely to present information, but to teach parents to think of alternatives and possible solutions themselves. This way, future coping abilities were addressed. The following themes were included; creating realistic expectations concerning the development of their children's weight status, modifying eating- and exercising habits, knowledge on how parents can influence the behaviour of their children (for example by modeling, and by the use of control and rewards), information on the development of overweight, handling feelings of guilt and recognizing and handling a child with low self-esteem. So, instead of purely focusing on nutrition and physical activity, a substantial part of the treatment was devoted to enhancing parenting tactics (for example teaching parents to ignore undesirable behaviours and to reward desirable behaviours). This aspect of the treatment combined with extensively discussing parental control make the current intervention distinguishing.

Of the two-hour sessions, the first hour was interactive (for example discussions on provocative propositions were held). One of the main goals of this first hour was to identify wrong thought patterns and challenging these patterns as is done in cognitive therapy. The second hour of each session was more informative and practical by nature. 


\section{Session number \& theme Contents}

S1 The part that $\quad$ Parents' expectations and motivations
parents play
Thought exploration: 'parents are the ones to blame'
Training overview
Clarification of reward system
Winding up/ evaluation

S2 Eating behaviour Experiences

Thought exploration: 'breakfast is unnecessary'

Education: regularity

Thought exploration: 'My child does not eat too much'

Education: amounts and type of food

Practical tips

Homework

Winding up/ evaluation

S3

Physical exercise Experiences

Thought exploration: 'television makes you fat'

Education: physical exercise

Practical tips

Homework

Winding up/ evaluation

S4 Parental control

Experiences

Thought exploration: 'parents should be strict'

Education: parental control

Practical tips

Homework

Winding up/ evaluation

Experiences

Thought exploration: 'Thoughts and feelings do not matter!' Education: self-esteem and bullying

Practical tips

Homework

Winding up/ evaluation 
S6 Food and party
Experiences

Thought exploration: 'On holidays my child can eat anything'

Education: parties and holidays

Practical tips

Homework

Winding up/ evaluation

\section{Experiences}

Thought exploration: 'We will probably relapse after the training'

Education: relapse prevention + repetition

Practical tips

Homework

Winding up/ evaluation

S8 Responsibility

Thought exploration: 'My child can do it alone now!'

Education: responsibility + repetition

Practical tips

Homework

Evaluation training

Table 1: Overview of the parent treatment sessions

\section{Measurements}

\section{Weight Parameters}

Weight (kilograms) and height (meters) were measured and BMI percentile (Children's BMI-for-age Calculator, USDA/ ARS Children's Nutrition Research Center) was calculated for each child of the participating parents, thus including the target children and their siblings. With respect to the parents,

BMI was calculated. 


\section{Socio Economic Status (SES)}

Before treatment, parents filled out a questionnaire with demographic items. Socio Economic Status was derived from family income. Family income was measured on a 5 point rating scale (1 representing $<12.000$ euro's and 5 representing $>38.000$ euro's). Scores ranged from 1 to 5 , with a mean score of 3.90 .

\section{Eating psychopathology: Child Eating Disorder Examination Questionnaire (ChEDE-Q)}

The Child Eating Disorder Examination Questionnaire (ChEDE-Q; Decaluwé, 1999) is based on the Eating Disorder Examination Questionnaire (EDE-Q; Fairburn \& Beglin, 1994) for adults. It is a self-report questionnaire measuring the existence and frequency of eating disorder psychopathology. The ChEDE-Q consists of four subscales; 'restraint', 'eating concern', 'shape concern' and 'weight concern'. Furthermore, the ChEDE-Q measures overeating ('objective bulimic episodes', 'subjective bulimic episodes' and 'objective overeating episodes') and methods of weight control ('self-induced vomiting', 'laxative misuse', 'diuretic misuse' and 'intense exercising'). The ChEDE-Q consists of 30 items that are scored on a 7-point (0-6) rating scale. Higher scores indicate greater seriousness or frequency of the given feature. In the current study, Cronbach's alphas of the ChEDE-Q subscales ranged from .48 to .82 . Since the ChEDE-Q is not very reliable regarding the assessment of binge eating (Decaluwé \& Braet, 2004), binge eating was assessed by means of an interview, as it is done in the ChEDE. The ChEDE-Q was filled out by the overweight child, in the presence of a parent and a trained interviewer. 


\section{Eating behaviours}

With respect to eating behaviours, two types of information were collected by interview before and after treatment, and at 3 month follow up. First the regularity of the children's eating pattern was examined (for example: How many eating moments are there on a typical weekend day?). Scores for regularity range from 0 to 7 , a higher score indicating a more regular eating pattern. Secondly, it was registered how many unhealthy food items (that is, 'red' food items according to the traffic light system, provided by The Netherlands Nutrition Centre, The Hague) the children consumed per day. Therefore, the children were asked to recall every food and drink item they consumed the day before the measurement. In case that day was not representative for an average day, the children were asked to recall their consumption of an earlier day. One of their parents was present to add or correct information if necessary. The Netherlands Nutrition Centre composed a list of frequently consumed food items, and categorized them into three categories: green (healthiest food items, to be used preferably), orange (less healthy options, advised to consume moderately) and red (high in fat and/ or sugar; to be eaten by exception).

\section{Physical activity}

Current physical activity was assessed by means of the Baecke Questionnaire (Baecke, Burema \& Frijters, 1982), which was filled out by the overweight child (in presence of a parent and the interviewer). This Questionnaire consists of three components: work activity, sports activity and leisure activity. An index score for the three components is calculated, ranging from 1 to 5, with higher index scores reflecting higher levels of activity. The Baecke Questionnaire was adapted for use with children by replacing 'work activity' with 'school activity' (including similar questions). The validity and test-retest reliability of the original Baecke Questionnaire are good (Baecke, Burema \& Frijters, 1982). 


\section{Self-esteem}

Perceived competence was measured with the translated version of the Self-Perception Profile for Children (Harter, 1985): CBSK (Veerman, 1989). The overweight child filled out the questionnaire (in presence of a parent and the interviewer). The CBSK comprises six subscales ('scholastic competence', 'social acceptance', 'athletic competence', 'physical appearance', 'behavioural conduct' and 'global self-worth') each consisting of six items, formulated as opposite pairs. Each answer is scored between 1 (most competent) and 4 (least competent). For the current study we were particularly interested in the subscales 'physical appearance' and 'global self-worth'. The CBSK has been validated for Dutch children (Van Dongen-Melman, Koot \& Verhulst, 1993).

\section{Negative thoughts}

Negative thinking concerning weight and body issues was measured with the self-composed Heavy Thoughts Questionnaire, which was completed by the overweight child (in presence of a parent and the interviewer). This questionnaire maps the frequency of negative weight related thoughts in overweight children. The questionnaire comprises 20 items (for example 'I am worthless because I am overweight'). Scores range from 1 ('I never have this thought') to 5 ('I always have this thought'). In the current study, Crohnbach's alpha $=0.88$.

\section{Knowledge test}

By means of a knowledge test, a manipulation check was carried out to examine whether parents learned from the training. Before and after treatment, they completed a test consisting of 29 multiple-choice items (for example: 'In what category (green, orange or red) does this food item belong: a boiled egg?' or 'How can you motivate your child to engage in physical activity?'), covering the subject matter of the training. 1 point was awarded for every 
correct answer, resulting in a maximum score of 29 points. In order to preclude a learning effect, two comparable versions of this knowledge test were constructed. The order in which the tests were administered was balanced: half of the parents started with version A before treatment, the other half started with version B before treatment.

\section{Motivation}

The motivation of the participating parents was assessed by the therapist. The therapists rated the parents' active participation during the sessions, their performance on homework assignments and their general motivation. A motivation score was calculated by averaging the therapist ratings on these 3 questions, resulting in a score ranging from 0 to 10. In the current sample, scores ranged from 3.25 to 10 . The mean motivation score was 7.12 (SD=1.38).

\section{Statistical Analysis}

First, one-way ANOVAs on child BMI status, parental BMI (if BMI data from both parents were available, their average BMI was used in the analyses), sibling's BMI, eating behaviour, physical activity, self esteem and cognitions were performed to test for pre treatment group differences. Then, a 2 (time: pre treatment vs. post treatment) $\times 2$ (group: treatment vs. waiting list control) ANOVA on knowledge test scores was carried out as a manipulation check.

In order to analyse the effects of the parent treatment, 3 (Time: pre treatment vs. post treatment vs. follow up) $\times 2$ (group: treatment vs. waiting list) repeated measures ANOVAs were carried out for all outcome measures (BMI percentile child, BMI parent, BMI percentile siblings, ChEDE-Q subscales, eating behaviour, physical activity, self-esteem and cognitions). The results section is structured according to our hypotheses. For significant interactions, post-hoc analyses were conducted. Finally, to identify predictors of treatment success, a linear regression analysis was carried out. The dependent variable was 
treatment success (represented by decrease of child BMI percentile from pre treatment to 3 month follow up). The hypothesized predictors (age, parental BMI before treatment, child BMI percentile before treatment, socio economic status, motivation and parental attendance) were entered as predictors in the regression.

\section{Missing data}

The missing values at the follow up meeting were replaced by the last observation carried forward. The missing in-between values (post treatment) were replaced by the average of the values before treatment and at 3 month follow up. In total, 98 families engaged in the study. 59 families started treatment. From these 59 families, 10 families did not finish treatment (These families attended less than 3 of the 8 sessions). However, 5 of these families were willing to continue their participation in the post treatment and follow up measurements. In the waiting list control group, 39 families participated in the first measurement session. Data of 34 of these families was available after three and six months.

\section{Results}

Data are provided in table 2 (page 116-117).

One-way ANOVAs showed no pre test group differences with respect to age, BMI values, eating behaviour, physical activity, self-esteem and cognitions.

\section{Knowledge test manipulation check}

With respect to the knowledge test, a significant interaction of time $x$ group was found, $F(2,75)=7.96, p<0.01$. As expected, paired sample t-tests showed that scores of parents in the treatment group on the knowledge test increased from pre to post treatment, $t(1,51)=3.56, p<0.01$, whereas scores of parents in the waiting list control group remained constant, $t(1,24)=0.99, p=0.33$. 


\section{Hypothesis 1:}

BMI percentile of the overweight children will decrease over time in the treatment group, whereas it will remain constant or increase in the waiting list control group.

The analyses showed a significant time $x$ group interaction with respect to BMI percentile of the overweight children, $F(2,95)=5.53, p<0.01$. Post-hoc paired sample t-tests showed that BMI percentiles of children whose parents engaged in the treatment decreased significantly from pre to post treatment, $t(1,58)=3.7, p<0.001$, and from pre treatment to 3 month follow up, $t(1,58)=3.8, p<0.001$. No significant differences were found between post treatment and 3 month follow up. Similar post-hoc analyses for the waiting list control group showed no significant differences in child BMI percentile. See also figure 1.

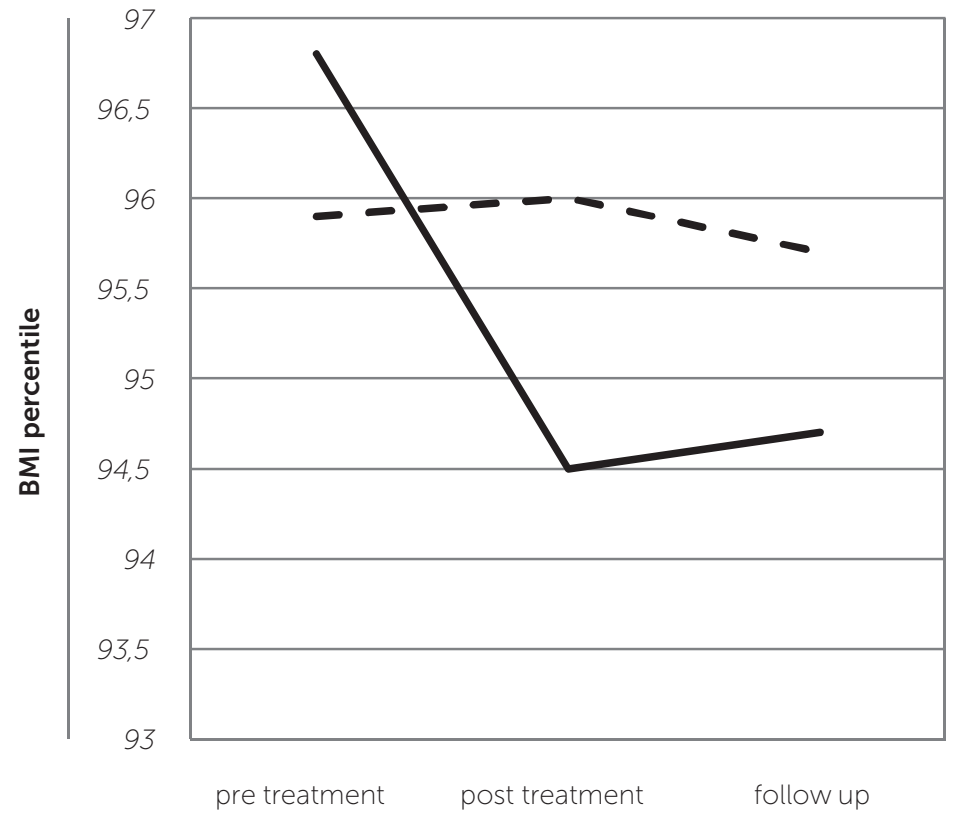

- waiting list control group $\longrightarrow$ treatment group 
Treatment group

$N=59$

T1

T2

$M(S D)$

$M(S D)$

M (SD)

M (SD)

$M(S D)$

BMI percentile child

$96.8(2.93) \quad 94.5(6.52)$

$947(6.58)$

$96.0(3.64) \quad 95.7(3.90)$

\section{EDEQ}

$\begin{array}{lllllll}\text { Restraint } & 0.62(0.67) & 1.09(1.09) & 0.58(0.69) & 0.83(0.94) & 0.71(0.74) & 0.72(0.74) \\ \text { Eating concerns } & 0.45(0.41) & 0.40(0.52) & 0.27(0.39) & 0.66(0.82) & 0.67(0.80) & 0.52(0.68) \\ \text { Weight concerns } & 1.67(0.84) & 1.41(1.07) & 1.38(0.95) & 1.46(1.11) & 1.28(1.20) & 1.21(1.13) \\ \text { Shape concerns } & 1.26(0.96) & 1.04(1.19) & 0.97(0.89) & 1.07(0.97) & 1.08(1.09) & 0.92(1.01)\end{array}$

Eating behaviour

\begin{tabular}{|c|c|c|c|c|c|c|}
\hline Regularity & $5.67(0.94)$ & $5.65(1.06)$ & $5.65(0.80)$ & $5.49(0.95)$ & $5.80(0.69)$ & $5.21(0.90)$ \\
\hline Unhealthy items & $6.84(2.81)$ & $5.77(2.95)$ & $6.03(3.22)$ & $7.08(2.40)$ & $6.76(2.16)$ & $6.52(2.53)$ \\
\hline hysical activity & $9.16(1.25)$ & $9.16(1.18)$ & $9.16(1.20)$ & $8.92(1.28)$ & $8.76(1.12)$ & $8.68(1.27)$ \\
\hline \multicolumn{7}{|l|}{ Self esteem } \\
\hline Physical appearance & $14.87(4.52)$ & $15.87(5.04)$ & $15.98(5.25)$ & $15.16(4.34)$ & $16.11(4.69)$ & $15.74(4.72)$ \\
\hline Global self-worth & $18.43(4.14)$ & $18.79(4.20)$ & $19.02(4.86)$ & $19.79(4.02)$ & $20.26(4.23)$ & $20.16(4.14)$ \\
\hline legative thoughts & $43.9(13.55)$ & $41.8(14.53)$ & $41.1(14.66)$ & $44.6(14.42)$ & $41.8(14.74)$ & $40.8(15.99)$ \\
\hline MI parents & $28.30(4.53)$ & $28.01(4.53)$ & $28.13(4.58)$ & $29.35(6.33)$ & $29.43(6.22)$ & $29.49(6.24)$ \\
\hline MI percentile siblings & $73.8(24.30)$ & $71.6(24.63)$ & $73.1(24.17)$ & $69.4(23.40)$ & $68.8(22.16)$ & $69.1(22.21)$ \\
\hline Knowledge test & $15.1(2.50)$ & $17.1(3.69)$ & & $15.3(1.89)$ & $14.8(2.02)$ & \\
\hline eisure activity s & $18(0.59)$ & $3.35(0.51)$ & $3.38(0.55)$ & $.24(0.57)$ & $23(0.56)$ & $20(0.64)$ \\
\hline
\end{tabular}




$\begin{array}{lll}\text { Main effect } & \text { Main effect } & \text { Time } \mathrm{x} \text { group } \\ \text { time } & \text { group } & \text { interaction }\end{array}$

\begin{tabular}{|c|c|c|c|c|c|}
\hline F & {$\left[\eta_{p}^{2}\right]$} & $\mathbf{F}$ & {$\left[\eta_{p}^{2}\right]$} & $\mathrm{F}$ & {$\left[\eta_{p}^{2}\right]$} \\
\hline $6.58^{* *}$ & {$[0.11]$} & 0.30 & {$[0.00]$} & $5.53^{* *}$ & [0.09] \\
\hline $4.06^{\star}$ & {$[0.04]$} & 0.02 & {$[0.00]$} & $6.74^{* *}$ & {$[0.07]$} \\
\hline $3.67^{*}$ & {$[0.04]$} & $5.79^{*}$ & {$[0.06]$} & 0.12 & [0.00] \\
\hline $5.81^{* *}$ & {$[0.06]$} & 0.72 & {$[0.01]$} & 0.09 & {$[0.00]$} \\
\hline $3.12^{*}$ & [0.03] & 0.13 & {$[0.00]$} & 0.88 & [0.01] \\
\hline 2.44 & {$[0.04]$} & 0.47 & [0.01] & 2.45 & [0.04] \\
\hline 2.92 & [0.03] & 1.70 & [0.02] & 0.67 & [0.01] \\
\hline 0.99 & {$[0.01]$} & 2.53 & [0.03] & 0.97 & [0.01] \\
\hline $5.02^{*}$ & {$[0.07]$} & 0.01 & [0.00] & 0.38 & $0.01]$ \\
\hline 2.35 & {$[0.04]$} & 1.33 & [0.02] & 0.25 & [0.00] \\
\hline $6.26^{* *}$ & [0.08] & 0.00 & {$[0.00]$} & 0.16 & [0.00] \\
\hline 1.04 & [0.01] & 1.38 & [0.01] & $3.50^{\star}$ & {$[0.04]$} \\
\hline 0.77 & {$[0.01]$} & 0.43 & [0.01] & 0.29 & [0.00] \\
\hline 3.06 & {$[0.04]$} & $4.02^{*}$ & [0.05] & $7.96^{\star *}$ & {$[0.10]$} \\
\hline 1.98 & [0.02] & 0.56 & [0.01] & $3.31^{*}$ & [0.04] \\
\hline
\end{tabular}




\section{Hypothesis 2:}

The parent treatment will decrease eating psychopathology, improve healthy eating behaviours, increase exercise, decrease negative thoughts and increase self-esteem in the overweight children of the trained parents, as opposed to overweight children of parents in the waiting- list control group.

With respect to eating psychopathology, main effects of time were found for all four subscales of the ChEDE-Q; children reported less eating concerns, less weight concerns and less shape concerns over time, regardless of whether their parents received the training or not. In addition, a significant time $x$ group effect was found on the restraint scale scores of the ChEDE-Q, $F(2,90)=6.74$, $p<0.01$. Tests of within subject contrasts show an interaction, $F(1,90)=10.45$, $p<0.01$. Post-hoc paired sample t-tests showed that restraint in children whose parents engaged in the treatment increased significantly from pre to post treatment, $t(1,54)=3.3, p<0.01$, and decreased significantly from post treatment to 3 month follow up, $t(1,55)=3.9, p<0.001$. No significant differences were found between pre treatment and follow up. Similar post-hoc analyses for the waiting list control group showed no significant differences in restraint.

With respect to healthy eating behaviours (regularity and the consumption of unhealthy food items) and physical activity, no significant effects were found.

Concerning self-esteem, a main effect of time was found on the 'physical appearance' scale, $F(2,63)=5.02, p<0.05$. Post-hoc paired sample t-tests in all children show significant increases in physical appearance selfesteem from pre to post treatment, $\mathrm{t}(1,64)=3.27, \mathrm{p}<0.01$, and from pre treatment to 3 month follow up, t $(1,64)=2.68, \mathrm{p}<0.01$.

Finally, with respect to negative thoughts, a main effect of time was found, $F(2,71)=6.26, p<0.01$. Post-hoc paired sample t-tests in all children show significant decreases of negative thoughts from pre to post treatment, $t(1,72)=2.86, p<0.01$ and from pre treatment to 3 month follow up, $t(1,72)=2.79, p<0.01$ 


\section{Hypothesis 3:}

Parents and siblings in the treatment group show healthier BMI's over time than parents and siblings in the waiting list control group.

Regarding the BMI's of family members, a significant time $x$ group effect was found in parental BMI, F $(2,96)=3.50, p<0.05$. Post- hoc paired sample t-tests show that parents in the treatment group show a decrease in BMI from pre to post treatment, $t(1,58)=2.75, p<0.01$. No significant differences were found from post treatment to 3 month follow up or from pre treatment to 3 month follow up. Similar post-hoc analyses for the waiting list control group showed no significant differences in parent BMI.

With respect to siblings, no significant effects were found.

\section{Hypothesis 4:}

lower age of the child, lower parental BMI, less severe overweight of the child, higher socio economic status, higher motivation and higher parental attendance are expected to positively influence treatment outcome.

All six potential predictors of treatment success were entered in a linear regression analyses (Backward method). After excluding the non-significant variables, four significant predictors of treatment success remained in the final regression model. See also table 3. The strongest predictor of treatment success was BMI percentile of the child. However, contrary to what was expected, the lower the child's pre treatment BMI percentile, the more treatment success. In addition, parental attendance predicted treatment success in the hypothesized way (more parental attendance leads to more BMI loss). Third, age of the child predicted treatment success as expected; younger children showed larger BMI percentile decreases. Finally, socioeconomic status contributed to treatment success, however, not in the expected direction: lower income families took more advantages of the treatment than higher income families. 
B

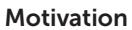

BMI parent before treatment

Socio economic status

Age of the child

Parental attendance

BMI child before treatment
.03

$-.09$

$-.90$

$-.75$

.83

$-1.24$
$\mathrm{T}$

20

.80

1.99

2.14

2.52

6.81 p

.84

.43

.05

.04

.02

.00

Table 3: Regression coefficients of potential predictors of treatment success

\section{Discussion}

In the present study, the effects of a treatment targeting parents of overweight children were examined. To this end, a parental treatment program was compared to a waiting list control group. With respect to the effects of the parent treatment, it was found that BMI percentile of the overweight children in the treatment group decreased significantly compared to children in the waiting list control group. At 3 month follow up, no significant relapse occurred. Even though the decrease in BMI percentile seems clinically modest, the fact that an 8-session parent treatment - without treating the children - results in significant weight loss in their overweight children is very promising. In addition, the effect size of BMI change in the overweight children is medium to large (Cohen's $f=0.31$ ). This is comparable to the mean effect size reported in the meta- analyses of Wilfley, et al. (2007). More specific, $22 \%$ of the children from parents in the treatment group, that were overweight at pre treatment, were no longer overweight at post treatment. In addition, $8.7 \%$ of the children went from being obese before treatment to being overweight at post treatment.

Besides affecting the child's weight status, BMI of the participating parents also decreased significantly from pre to post treatment. The finding that the whole family profits from the intervention is valuable. A third treatment effect was found with respect to the restraint subscale of the ChEDE-Q. Children in the treatment group reported increased levels of restraint after treatment. 
Clearly, the parents were able to induce a functional restraint in their children that helped them to decrease weight. In line with earlier findings of Stice, Martinez, Presnell and Groesz (2006), the increased restraint did not lead to an increase in eating disorder symptoms like concerns and increased intake of unhealthy foods. Increased restraint was related to decreased concerns and less unhealthy food intake. Although restraint levels decreased to baseline levels at follow-up, BMI, concerns and unhealthy food intake did not increase. Striking is the finding that main effects of time were found for most psychological measurements. In both the treatment- and the waiting list control group, concerns about eating, weight and shape decreased, self-esteem improved and negative thinking diminished. Apparently, waiting for overweight treatment by itself, already seems to affect one's thinking about the problems. The prospect of dealing with the overweight might lead the children to trivialize their concerns with respect to their overweight, or postpone their worries. Perhaps these results can also be explained by repetition of the questions.

Unfortunately, no significant effects of treatment were found with regard to actual (self-reported) eating behaviour, or on actual (self-reported) physical activity. A possible explanation for the absence of effects on eating regularity is the possibility of ceiling effects. That is, pre treatment scores were already high: on average almost 6 where the maximum was 7. Another explanation might be the way we measured both, i.e. by self-reports. Although actual behaviour might have changed, people might have judged their behaviour as better or healthier but less realistic before treatment and more realistic after treatment - ending up at the same levels.

Inconsistent with the expectations, general physical activity did not increase in the treatment group. In this study, physical activity was self-reported with the Baecke questionnaire. As well as the common difficulties with selfreport measurements, a specific feature of the used questionnaire might have distorted the results. As described earlier, the physical activity score is composed by school activity, sports activity and leisure activity. As school activity and sports activity are pretty stable throughout the year, only leisure activity could be in- 
creased. Leisure activity would have to increase substantially in order to significantly affect the general physical activity score. This explanation for the results was tested post hoc. Indeed, a time $x$ group interaction was found with respect to leisure activity (see also table 2). However, for future research, it is recommended to include a more objective method of registering physical activity, for example by using an accelerometer (Bonomi, Plasqui, Goris $\&$ Westerterp, 2009).

With respect to the knowledge test results, a remark should be made. Even though the test distinguished groups significantly (which means that the 'manipulation', that is the treatment, indeed increased knowledge in the treatment group), the post treatment scores in the treatment group are not very high: on average parents scored $59 \%$ of the questions correctly versus $52 \%$ pre treatment. On the one hand these data represent a learning effect, on the other hand these numbers illustrate that (also after treatment) parents still have a lot of ground to cover.

In general, the effects of the parent treatment are very promising. The relatively short intervention led to very useful results. Furthermore, an intervention that focuses on parents exclusively is, compared to the common child and parent focused interventions, cost-reducing, as fewer treatment sessions are required. With respect to the (cost) effectiveness of a parent treatment, we can join the point of view described in the work of Golan and Crow (2004a); if parent-sessions alone yield the same effects as a combination of both child- and parent-sessions, this means that fewer sessions are needed to reach the same goal, thus resulting in a less expensive treatment.

A second goal of the study was to identify potential predictors of treatment success. No effects were found with respect to motivation and parental BMI. Contrary to our expectations, lower Socio Economic Status (SES) was associated with greater treatment success. Other studies have found exactly the opposite: higher SES being associated with greater treatment success (Epstein \& Wing, 1987; Langnäse, Asbeck, Mast \& Müller, 2004; Müller, Danielzik \& Pust, 2005). Perhaps, the treatment evaluated in the current study was 
particularly easily accessible and not pedantic by nature. Further research is necessary to find out from what components in treatment different SES groups profit. In addition to SES, age of the overweight child was a significant predictor; the younger the child was at the start of treatment, the larger the BMI decrease. It seems obvious that the younger the child, the more influence parents have on the eating- and exercise habits of the child. As a child becomes older, parents are no longer their most important role models: peers take over that role (Shroff \& Thompson, 2006).

Furthermore parental attendance predicted treatment success in the expected direction: the more sessions were attended, the more treatment success. Total attendance of the families that completed treatment was high: on average, parents attended 6.49 sessions $(S D=1.42)$. The fact that more attendance leads to greater BMI decrease is a very logical finding. Finally, BMI percentile of the overweight child before treatment was the strongest predictor of treatment success: the lower BMI percentile at the start of treatment; the larger the decrease in $\mathrm{BMI}$ percentile. On the one hand this is unexpected, as children with higher BMI percentiles at start have more room for improvement. But, on the other hand, this finding might implicate that the kind of treatment that was evaluated in the current study (relative short and not very intensely) works best for children that are not morbidly obese yet. Possibly, the more severe cases will profit more from a longer enduring and more intensive form of treatment. Future research is needed to determine which families particularly benefit from a treatment that focuses on parents exclusively. 



\section{General discussion}




\section{Aim of the dissertation}

Two main research questions were addressed in the present dissertation. The first part of this dissertation aimed to investigate the influence of (parental) control behaviour on children's eating behaviour. In the second part of this dissertation, the role of parents in the treatment of childhood obesity was examined.

Here, the main findings of the different studies in this dissertation are discussed. Suggestions for future research and implications for the clinical practice are put forward.

\section{Summary and discussion of the findings}

The first part of this doctoral thesis (chapters 2 through 5) addressed the relationship between control behaviour (more specifically, restriction) and children's weight status, food preferences and actual food consumption. In chapter 2, the main goal was to find out whether parental control, as experienced by the child, and child weight status were positively associated. Earlier research showed such a positive correlation between parental Child Feeding Questionnaire (CFQ) scores and child weight status; that is, the higher the level of (parents' selfreported) exerted parental control, the heavier their child was (Birch, Fisher \& Krahnstoever Davison, 2003). The results of the study in chapter 2 indicated that neither the weight status of the child, nor that of the parent(s) was associated with perceived child feeding control as measured by a child version of the CFQ. No differences were found between normal weight and overweight children with respect to (self-reported) perceived feeding attitudes and practices (by their parents). Whereas earlier research showed that parents of overweight children exerted more control than parents of normal weight children, in chapter 2 no evidence was found that overweight children experience more control. In addition, it was found that parents' reports about control and their children's perceptions corresponded well. The study in the second chapter was explorative and 
the results are of a correlational nature. Therefore, nothing can be concluded about a possible causal relationship between exerted parental control and child weight status; only experimental research in which the level of exerted control is manipulated in healthy, normal weight children can throw light on this matter. Therefore, the studies described in chapters 3 and 4 had an experimental design. Chapter 3 inquired into the possible adverse effects of restriction of snack intake in children. It was tested whether prohibiting palatable snacks would result in an increased desire for the formerly forbidden food followed by overeating in 5- and 6-year-old children. The results showed that, as hypothesized, desire for the target food increased significantly in the prohibition group, whereas it remained constant in the no-prohibition group. No significant differences between groups were found with respect to the absolute consumption of the target food. However, the proportion of consumed target food (target food intake/ total food intake) was significantly higher in the prohibition group. Thus, imposing restriction in normal weight young participants led to greater desire and relatively higher intake of the restricted food. These results are promising, especially since the participants were offered alternatives (yellow MEM's and yellow crisps) that were identical in almost every aspect (taste, attractiveness, caloric value) to the forbidden food types (red M\&M's and red crisps) at the start of the manipulation: only the colour of the alternative food items differed. Translating the results into real life situations, alternatives to unhealthy food may be offered likewise. Parents will for example offer their children fruit or raw vegetables as alternatives for snacks or sweets; perhaps they do not even give an alternative at all.

Still, the offered alternative is likely to be far less attractive for the child than the restricted food is. Relying on these data, parents should not completely restrict attractive foods. However, future research will have to show to what level parents should restrict intake of unhealthy foods in their children.

Finally, in the study in chapter 3, it was found that children whose parents imposed either very little or, on the contrary, a lot of restriction at home consumed more kilocalories during the whole experiment, as opposed to children who were exposed to a moderate level of restriction at home. 
The correlation between parental restriction and caloric intake is confirmed in different experimental studies in this dissertation. The results of this study indicate that restriction can have adverse effects on children's food preferences.

The aim of the study in chapter 4 was to replicate and expand these findings. Therefore, an experiment that was similar in design was conducted. However, here not only the effects of restricting palatable food were examined, but it was also tested whether restriction of relatively less attractive food (in this case, fruit) would yield similar effects. In the first phase of this experiment, two groups of children were forbidden to eat fruits and sweets respectively, whereas a control group was allowed to eat both foods. During the second phase of the experiment, children in all three groups were allowed to eat from both the fruits and the sweets. It was found that children who were prohibited to eat the sweets in phase 1 reported an unchanged, high level of desire for sweets, whereas desire for sweets decreased in the fruit-prohibition and noprohibition groups. No group differences were found regarding the desire for fruit. With respect to intake, it was found that children in both the fruit- and the sweets-prohibition groups consumed more of the formerly forbidden food during the second taste session as compared to the no-prohibition group. In addition, total food intake was higher in the two prohibition groups than in the no-prohibition group.

These data thus replicate the results that were earlier found and described in chapter 3; restricting attractive unhealthy food types leads to a higher desire for and an increased intake of the formerly forbidden food. In addition, the adverse effects of restriction can - to a large extent- be generalized to relatively less attractive food (in this case fruit). The fact that total intake in the prohibition groups was also higher than in the control group is interesting as well. It seems as if the concept of restriction results in a state of letting oneself go, not only with respect to the formerly forbidden food, but with respect to everything that is available. Again, it shows that the consequences of restriction are undesirable. Therefore, parents (but also practitioners like dieticians and physicians) should be informed about the unwanted side effects of restriction. 
These two chapters clearly indicate a causal relationship between restriction and food preference- and intake. In the last chapter of the first part of this thesis, chapter 5 , the concept of restriction was applied and examined in a totally different setting than in the earlier chapters. That is, in chapter 3 and 4 the negative effects of restriction were emphasized, whereas in chapter 5 it was examined whether restriction can also be used as a successful strategy to promote fruit consumption. It was already shown in chapter 4 that restricting fruit intake led to an increased intake of fruit at a later stage. In the study in chapter 5 , the effects of restricting fruit intake were compared to any possible effects of visual appeal on fruit consumption in children. Two types of presentations of fruit (regular and visually appealing) were offered to the participating children. In a first taste session participants were either allowed to eat from both fruit presentations (no-prohibition group) or prohibited from eating one of the two presentations (regular fruit prohibited group/ visually appealing fruit prohibited group). In a second taste session all participants were allowed to eat from both fruit presentations. The results indicated that visual appeal had a strong positive effect on fruit consumption. However, contrary to our expectations with respect to restriction, no effects were found on fruit intake. Naturally, the practicability of restricting fruit intake would have been dubious anyhow, but theoretically it is an interesting matter. To promote fruit consumption in real life, parents, schools, supermarkets and food producers should focus more on the visual appeal of fruit and vegetables.

The second part of the present thesis focused on the role of parents in the treatment of childhood obesity. First, in chapter 6 , the merit of the Child Eating Disorder Examination-Questionnaire (ChEDE-Q; Decaluwé, 1999) as a measure of assessing eating disordered behaviour was evaluated. Therefore, the ChEDE-Q was modified in some ways and compared to the Child Eating Disorder Examination Interview (ChEDE; Bryant-Waugh et al, 1996), which is considered the gold standard. The goal of this chapter was to examine whether the ChEDE-Q was suitable for use in the treatment study described in chapter 7. Earlier research findings showed that there is a substan- 
tial discrepancy between the interview and questionnaire: scores on all four subscales differ significantly between the two measures. Children report higher levels of eating disorder psychopathology when using the questionnaire as opposed to the interview. In addition, the most salient difference between the two measurements is found with respect to the assessment of binge eating episodes: the questionnaire approves to overestimate the number of eating binges in comparison with the interview (Decaluwé \& Braet, 2004).

By adapting the ChEDE-Q in this study through exemplifying certain concepts, inserting definitions and adapting the response format, this discrepancy decreased. The results indicate that the adjustments made were indeed improvements to the ChEDE-Q, in a way that the scores resemble ChEDE scores to a larger extent. Concerning the future use of questionnaires measuring eating disordered behaviour, it was recommended to further examine the effects of the alterations. Considering these results, it was decided to use the CHEDE-Q items in the treatment study described in chapter 7 , but to question binge eating episodes by means of an oral interview.

Finally, in chapter 7, a treatment for childhood obesity targeting parents exclusively was evaluated. The parents of 98 overweight or obese children were randomly assigned to either the treatment group or the waiting list control group. With respect to child BMI percentile, the parent treatment was successful in reducing overweight from pre-treatment to post treatment. In addition, there was no significant relapse at follow up (3 months). As expected, child BMI percentile did not decrease in the waiting list control group. In addition, significant main effects of time were found for both groups with respect to eating pathology (decrease), self-esteem (increase) and negative thoughts (decrease). Finally, parental BMI decreased significantly only in the treatment group. It was concluded that the parent treatment had significant effects on child- and parent BMI. Somewhat unexpected were the positive effects of time in the waiting list control group on some psychological outcome measures; obviously, waiting for treatment already affects psychological processes (but not behaviour) in the children. In general, the effects of the parent treatment are promising. 
The relatively short intervention led to useful results. Furthermore, an intervention that focuses on parents exclusively is probably, compared to common child and parent focused interventions, cost-reducing, as less treatment sessions are required.

A second goal of chapter 7 was to identify predictors of treatment success. Regression analyses identified four significant predictors of BMI decrease: Socio Economic Status (SES), age of the child, parental attendance and $\mathrm{BMI}$ percentile of the child at start influenced treatment outcome. As expected, the higher parental attendance and the younger the overweight child, the more successful the treatment was. However, unlike our expectations, a lower SES predicted more BMI decrease during treatment. Finally, BMI percentile of the overweight child before treatment was the strongest predictor of treatment success: the lower BMI percentile of the child at start, the larger the decrease in BMI percentile. On the one hand this is unexpected, as children with higher BMI percentiles at start have more room for improvement. On the other hand, this finding might implicate that the kind of treatment that was evaluated in the current study (relative short and not very intensely) works best for children that are not yet morbidly obese. Possibly, the more severe cases will profit more from a longer enduring and more intensive form of treatment. 


\section{Conclusions}

Five main conclusions can be drawn from the research in this thesis:

1. The prohibition of both attractive and moderately attractive types of food subsequently leads to a higher desire for and an increased intake of the formerly forbidden food. This conclusion was strongly supported by the results of chapters 3 and 4 .

2. Enhancing visual appeal is an effective strategy in promoting fruit intake in children (chapter 5). Children consumed almost twice as much from a visually appealing fruit presentation as opposed to a regular presentation.

3. The gap between the CHEDE-Questionnaire and the gold standard CHEDE-Interview can be reduced (for example by explaining ambiguous concepts). However, the CHEDE remains more reliable and valid than the questionnaire, and is therefore the preferable measure (chapter 6).

4. Treating parents exclusively is effective in reducing BMI percentiles in overweight or obese children (chapter 7).

5. Moderators of parent-treatment success are (lower) Socio Economic Status, (lower) age of the child, (higher) parental attendance and (lower) $\mathrm{BMI}$ percentile of the child before treatment (chapter 7 ).

\section{Future research}

With respect to the first part of this thesis (the effects of restriction on children's food preferences and intake) some interesting research questions remain. First, in the described studies, the adverse effects of one single prohibition were observed after a fairly short time interval; children's intake of the formerly forbidden food increased within minutes after the prohibition was neutralized. No follow-up measurements to examine the persistence of these effects were carried out. 
After all, the main goal of the described studies was to find out whether any effects of restriction could be experimentally elicited at all. Further research could further investigate how long the effects of restriction on food preferences and intake will persist. And in addition: what are the long term effects of consistently restricting intake of particular (or even multiple) food items? A longitudinal research design would be necessary to examine these long term effects. However, ethical and practical issues could be raised.

Another interesting question in the domain of restriction is whether the child's relationship to the person imposing the restriction influences the effects of restriction itself. In the described studies, the prohibition to eat was imposed by an unknown experimenter, whereas one can imagine that the effects of parents restricting their children to eat particular food items might differ. It is well known that children obey strangers with less resistance than their own parents (Landauer, Carlsmith \& Lepper, 1970). Assuming that, it can be hypothesized that children will react even stronger to a prohibition imposed by their own parents. In addition, also age of the restricted child could influence the effects of restriction.

Finally, and clinically relevant, it seems worthwhile to further research the ideal level of control parents should exert with respect to eating behaviour of their children. From the research that was described in the first part of this thesis it seems obvious that using high levels of control (and in particular restriction, as other methods of control were not discussed), has adverse effects on food preferences and intake. On the other hand, it seems very logical (though this was only supported by correlational data in chapter 3 ) that imposing no restrictions on a child's eating behaviour at all would not be desirable either. The question remains what the ideal level of control / restriction is, and what kind of behaviours go with that optimum. To investigate that question, a first study could have a design similar to the design described in chapter 3, but with multiple conditions in phase 1 ( the red food is restricted completely, the red food is allowed without limitation, 1 red food item is allowed, and 5 red food items are allowed). The answers to these questions will possibly shed more light on the relationship between restriction and eating behaviour. 
Regarding the second part of this thesis, there are some suggestions for future research as well. With respect to treating parents of overweight children, especially the long term effectiveness of treating parents exclusively needs to be established. It is clear that parents play a key role in guiding their children to a normal, healthy lifestyle and ditto weight status. However, more research needs to be done to find out what components in parent treatment may be especially effective, and what components may not.

In addition, it seems clinically relevant to further examine not only whether families profit from a parent directed intervention, but rather what kind of families benefit from this type of intervention. In chapter 7 several predictors of treatment success were considered, but the findings are very preliminary. Future research should focus on identifying predictors and moderators of treatment success, and applying the obtained knowledge in the intake- or selection procedure of patients. Some families might benefit optimally from a short, parent directed intervention, whereas other families might profit more from a more intensive, child- and parent focused intervention. Earlier studies have identified some predictors of treatment success in obese children. For example Reinehr, Brylak, Alexy, Kersting and Andler (2003) found that previous participation in exercise groups predicted treatment success. Impulsivity is another factor that has been found to influence the success of obesity treatment in children: the more impulsive children were, the less successful they were in reducing their weight (Nederkoorn, Jansen, Mulkens \& Jansen, 2007). Impulsivity was not measured in the children participating in the described treatment study, thus on the basis of the available data nothing can be said. However, future research should focus on whether impulsive children benefit from standard obesity treatment, and on additions to standard treatment that result in more effectiveness in impulsive children (for example training impulse control or the use of medication).

An interesting moderator of treatment success is BMI change in parents; the more weight parents lose, the more the children benefit from treatment (Wrotniak, Epstein, Paluch, \& Roemmich, 2004). Although parental 
weight loss cannot be predicted before treatment, it might be useful to pay more attention to parental weight loss during the intervention itself. It is important to identify the underlying factor that leads to success. Motivation does not lead these families to be more successful. Perhaps, these families actually cook healthier meals and become more active. Further research is especially recommended with respect to parent and family characteristics as potential predictors of treatment success; the family structure (single parent versus two parents, etcetera), relationships and finally genetic components may play an important role in optimizing childhood obesity treatment in the near future. 
Childhood overweight: parents in control?

136. 
Summary 
Childhood overweight and obesity have become alarmingly prevalent in the Western society. In the USA, $17 \%$ of all children are overweight and an additional $31 \%$ are at risk of becoming overweight (Ogden et al., 2006). Among Dutch children, the prevalence of overweight problems is just as serious: between 12 and $21 \%$ of the children are overweight and 2 to $5 \%$ are obese (Schokker et al., 2007).

Generally, childhood overweight and obesity have serious consequences, both physically and psychologically. Bearing in mind both the persistence of childhood obesity into adulthood and the many negative consequences of obesity, it is of major significance to challenge obesity early in life.

Currently, the most effective way to treat childhood obesity is a multidisciplinary behaviour therapy, aimed at changing the eating- and exercise patterns of the child, which also involves the child's parents (Epstein, 1990). Characteristic for the majority of treatments for childhood obesity is the minor involvement of the children's parents. Parental involvement is an important factor in treating childhood obesity effectively (Epstein, 1990).

Parental involvement might not just be an effective addition; parents perhaps play a key role in effective treatment. In the first place, parents are the most important role models for their children and they are in charge of purchasing and providing meals. In addition, parents also influence their children's eating patterns by using certain parenting techniques, like control. It has been hypothesized that parents who are overcontrolling their children's food intake may interfere with their children's ability to self-regulate their intake. Consequently, this could lead to disturbed eating behaviours like eating in the absence of hunger, restrained eating and ultimately excess weight gain (Birch \& Fisher, 2000; Birch, Fisher \& Krahnstoever Davison, 2003; Robinson, Kiernan, Matheson \& Haydel, 2001). Thus far, evidence for the potential negative effects of restriction is largely correlational.

The first part of this thesis focuses on the relationship between restriction and children's weight status, food preferences and actual food consumption. In chapter 2, the main goal was to find out whether parental control (experienced by the child) and child weight status were positively associated. 
Earlier research showed such a positive correlation between parental Child Feeding Questionnaire (CFQ) scores and child weight status; that is, the higher the level of (parents' self-reported) exerted parental control, the heavier their child was (Birch, Fisher \& Krahnstoever Davison, 2003). However, the results in chapter 2 indicate that neither the weight status of the child, nor that of the parent(s) was associated with perceived child feeding control as measured by a child version of the CFQ. In addition, it was found that parents' reports about control and their children's perceptions corresponded well. The study in the second chapter was explorative and the results are of a correlational nature. Therefore, nothing can be concluded about a possible causal relationship between exerted parental control and child weight status. Only experimental research, in which the level of exerted control is manipulated in healthy, normal weight children, can throw light on this matter. Therefore, the studies described in chapters 3 and 4 have an experimental design. Chapter 3 inquires into the possible adverse effects of restriction of snack intake in children. It was tested whether prohibiting palatable snacks would result in an increased desire for the formerly forbidden food followed by overeating in 5- and 6-year-old children. The results showed that desire for the target food increased significantly in the prohibition group, whereas it remained constant in the no-prohibition group. No significant differences between groups were found with respect to the absolute consumption of the target food. However, the relative intake of target food (target food intake/ total food intake) was significantly higher in the prohibition group. Thus, imposing restriction in normal weight young participants led to greater desire and relatively higher intake of the restricted food.

Finally, in the study in chapter 3, it was found that children whose parents imposed either very little or, on the contrary, a lot of restriction at home consumed more kilocalories during the whole experiment, as opposed to children who were exposed to a moderate level of restriction at home. The results of this study indicate that restriction can have adverse effects on children's food preferences. 
The aim of the study in chapter 4 was to replicate and expand these findings. Therefore, an experiment that was similar in design was conducted. However, not only the effects of restricting palatable food were examined.

In addition, it was tested whether restriction of relatively less attractive food (in this case fruit) would yield similar effects. In the first phase of this experiment, two groups of children were forbidden to eat fruits and sweets respectively, whereas a control group was allowed to eat both foods. During the second phase of the experiment, children in all three groups were allowed to eat from both the fruits and the sweets. It was found that children who were prohibited to eat the sweets in phase 1 reported an unchanged, high level of desire for sweets, whereas desire for sweets decreased in the fruit-prohibition and no-prohibition groups. No group differences were found regarding the desire for fruit. With respect to intake, it was found that children in both the fruit- and the sweets-prohibition groups consumed more of the formerly forbidden food during the second taste session as compared to the no-prohibition group. In addition, total food intake was higher in the two prohibition groups than in the no-prohibition group. These data thus replicate the results that were earlier found and described in chapter 3; restricting attractive unhealthy food types leads to a higher desire for and an increased intake of the formerly forbidden food. In addition, the adverse effects of restriction can be generalized to relatively less attractive food (in this case fruit). These two chapters clearly indicate a causal relationship between restriction and food preference- and intake. In the last chapter of the first part of this thesis, chapter 5, the concept of restriction was applied and examined in a totally different setting than in the earlier chapters. That is, in chapter 3 and 4 the negative effects of restriction were emphasized, whereas in chapter 5 it was examined whether restriction can also be used as a successful strategy to promote fruit consumption. In chapter 5 , the effects of restricting fruit intake were compared to possible effects of visual appeal on fruit consumption in children. Two types of presentations of fruit (regular and visually appealing) were offered to the participating children. In a first taste session participants were either allowed to eat from both fruit 
presentations (no-prohibition group) or prohibited from eating one of the two presentations (regular fruit prohibited group/ visually appealing fruit prohibited group). In a second taste session all participants were allowed to eat from both fruit presentations. The results indicated that visual appeal had a strong positive effect on fruit consumption. However, with respect to restriction, no effects were found on fruit intake.

The second part of the present thesis focuses on the role of parents in the treatment of childhood obesity. First, in chapter 6 , the merit of the Child Eating Disorder Examination-Questionnaire (ChEDE-Q; Decaluwé, 1999) as a measure of assessing eating disordered behaviour is evaluated. The ChEDE-Q was modified in some ways and compared to the Child Eating Disorder Examination Interview (ChEDE; Bryant-Waugh et al, 1996), which is considered the gold standard. Earlier research showed that there is a substantial discrepancy between the interview and questionnaire: scores on all four subscales differ significantly between the two measures. Children report higher levels of eating disorder psychopathology when using the questionnaire as opposed to the interview. In addition, the most salient difference between the two measurements is found with respect to the assessment of binge eating episodes: the questionnaire approves to overestimate the number of eating binges in comparison with the interview (Decaluwé \& Braet, 2004).

By adapting the ChEDE-Q in this study through exemplifying certain concepts, in serting definitions and adapting the response format, this discrepancy decreased. The results indicate that the adjustments made were indeed improvements to the ChEDE-Q, in a way that the scores resemble ChEDE scores to a larger extent. Considering these results, it was decided to use the CHEDE-Q items in the treatment study described in chapter 7 , but to question binge eating episodes by means of an interview.

Finally, in chapter 7, a treatment for childhood obesity targeting parents exclusively is evaluated. The parents of 98 overweight or obese children were randomly assigned to either the treatment group or the waiting list control group. 
With respect to child BMI percentile, the parent treatment was successful in reducing overweight from pre-treatment to post treatment. In addition, there was no significant relapse at follow up (3 months). As expected, child BMI percentile did not decrease in the waiting list control group. In addition, significant main effects of time were found for both groups with respect to eating pathology (decrease), self-esteem (increase) and negative thoughts (decrease). Finally, parental BMI decreased significantly only in the treatment group. It was concluded that the parent treatment had significant effects on child- and parent BMI. In general, the effects of the parent treatment are promising. The relatively short intervention led to useful results. Furthermore, an intervention that focuses on parents exclusively is probably, compared to common child and parent focused interventions, cost-reducing, as less treatment sessions are required.

A second goal of chapter 7 was to identify predictors of treatment success. Regression analyses identified four significant predictors of BMI decrease: Socio Economic Status (SES), age of the child, parental attendance and $\mathrm{BMI}$ percentile of the child at start influenced treatment outcome. As expected, the higher parental attendance and the younger the overweight child, the more successful the treatment was. However, unlike our expectations, a lower SES predicted more BMI decrease during treatment. Finally, BMI percentile of the overweight child before treatment was the strongest predictor of treatment success: the lower BMI percentile of the child at start, the larger the decrease in BMI percentile. On the one hand this is unexpected, as children with higher BMI percentiles at start have more room for improvement. On the other hand, this finding might implicate that the kind of treatment that was evaluated in the current study (relative short and not very intensely) works best for children that are not yet morbidly obese. Possibly, the more severe cases will profit more from a longer enduring and more intensive form of treatment.

To recapitulate, the studies in the first part of this thesis support the hypothesis that restriction of intake leads to paradoxical effects like increased desire for and higher consumption of the restricted food. The second part of this thesis demonstrated that treating parents exclusively is effective in reducing overweight in children. 
Childhood overweight: parents in control?

144. 
Samenvatting 
Het aantal kinderen met overgewicht of obesitas in de Westerse wereld is alarmerend toegenomen. In de Verenigde Staten heeft 17\% van alle kinderen overgewicht, en nog eens 31\% loopt het risico in de nabije toekomst te zwaar te worden (Ogden et al., 2006). In Nederland is het probleem van overgewicht bijna net zo omvangrijk: tussen de 12 en 21\% van de kinderen is te zwaar en 2 tot 5\% kampt met obesitas (Schokker et al., 2007).

Overgewicht en obesitas hebben ernstige gevolgen, zowel op fysiologisch als op psychologisch vlak. Wanneer we rekening houden met het feit dat obese kinderen vaak obese volwassenen worden en met het feit dat obesitas veel negatieve gevolgen met zich meebrengt, is het van groot belang om obesitas op jonge leeftijd aan te pakken.

Op het moment behelst de meest effectieve behandelmethode een multidisciplinaire gedragstherapie, gericht op het veranderen van eet- en beweegpatronen bij het kind. Daarnaast blijkt het betrekken van de ouders bij de behandeling een belangrijke factor in het effectief behandelen van kinderen (Epstein, 1990). Echter, kenmerkend voor de meerderheid van de behandelingen voor obesitas bij kinderen is de geringe betrokkenheid van de ouders.

Wellicht is ouderlijke betrokkenheid niet alleen maar een effectieve toevoeging; misschien zijn ouders wel dé sleutel tot een effectieve behandeling van kinderen met overgewicht. In de eerste plaats zijn ouders de belangrijkste rolmodellen voor hun kinderen én zijn ze hoofdverantwoordelijke wat betreft het doen van boodschappen en het verzorgen van maaltijden. Daarnaast kunnen ouders het eetgedrag van hun kind ook beïnvloeden door het gebruik van bepaalde opvoedtechnieken, zoals het uitoefenen van controle. Verondersteld wordt, dat ouders die teveel controle uitoefenen op de voedselinname van hun kinderen wellicht interfereren met de vaardigheid van kinderen om hun inname zelf te reguleren. Dit zou kunnen leiden tot verstoord eetgedrag, zoals eten in de afwezigheid van honger, 'restrained eating' en uiteindelijk tot gewichtstoename (Birch \& Fisher, 2000; Birch, Fisher \& Krahnstoever Davison, 2003; Robinson, Kiernan, Matheson \& Haydel, 2001). Tot nu toe is het bewijs voor potentiële negatieve effecten van restrictie vooral correlationeel van aard. 
Het eerste deel van dit proefschrift richt zich op het verband tussen restrictie en gewicht, voedsel voorkeuren en voedselinname. Het hoofddoel van hoofdstuk 2 was uit te zoeken of er een positieve associatie bestaat tussen de hoeveelheid ouderlijke controle (ervaren door het kind) en de gewichtsstatus van het kind. Eerder onderzoek liet zo een positief verband tussen Child Feeding Questionnaire (CFQ) scores en gewicht van het kind zien; hoe meer ouderlijke controle ouders rapporteerden, des te zwaarder hun kind (Birch, Fisher $\&$ Krahnstoever Davison, 2003). Echter, de resultaten van hoofdstuk 2 duiden erop dat zowel de gewichtsstatus van het kind als de gewichtsstatus van de ouder(s) niet samenhangen met ervaren controle, gemeten met een kinderversie van de CFQ. Daarnaast werd gevonden dat de rapportages van ouders over controle goed overeenkwamen met de percepties van hun kinderen. De studie die is beschreven in hoofdstuk 2 was exploratief, en de resultaten zijn van correlationele aard. Daarom kan er niets geconcludeerd worden over een mogelijk causaal verband tussen ouderlijke controle en gewichtsstatus van het kind; alleen experi-menteel onderzoek waarbij de mate van controle gemanipuleerd wordt in kinderen met een normaal gewicht kan licht op deze kwestie schijnen. Daarom zijn de studies die zijn beschreven in hoofdstukken 3 en 4 experimenteel van aard. Hoofdstuk 3 beschrijft een studie naar de mogelijke ongewenste effecten van het verbieden van snacks in kinderen. Er werd onderzocht of het verbieden van aantrekkelijke snacks zou leiden tot een groter verlangen naar en een grotere inname van het voorheen verboden voedsel. De resultaten van deze studie laten zien dat het verlangen naar het verboden voedsel inderdaad significant toeneemt in de verbodsgroep, terwijl het constant blijft in de controlegroep. Er zijn geen significante verschillen gevonden wat betreft de absolute inname van het verboden voedsel. Echter, de relatieve inname van het voorheen verboden voedsel (inname verboden voedsel / totale inname) was significant groter in de verbodsgroep. Dus, het opleggen van een verbod bij jonge kinderen met een normaal gewicht leidt tot een groter verlangen naar en een relatief grotere inname van voorheen verboden snacks. 
Tot slot vonden we in hoofdstuk 3 dat kinderen van wie de ouders ofwel heel weinig of juist heel veel restrictie in de thuissituatie rapporteerden significant meer kilocalorieën consumeerden tijdens het onderzoek dan kinderen die thuis werden blootgesteld aan een gemiddeld niveau van ouderlijke restrictie. Samengevat laten de resultaten van deze studie zien dat restrictie ongewenste effecten kan hebben op de voedselvoorkeuren van kinderen.

Het doel van de studie in hoofdstuk 4 was om deze resultaten te repliceren en uit te breiden. Daarom werd er een experiment uitgevoerd dat qua opzet vergelijkbaar was. Echter, niet alleen de effecten van het verbieden van aantrekkelijk voedsel werden onderzocht. Daarnaast werd onderzocht of het verbieden van relatief minder aantrekkelijk voedsel (in dit geval fruit) tot dezelfde resultaten zou leiden. In de eerste fase van het onderzoek kregen kinderen in de 2 verbodsgroepen een verbod voor fruit of snoep opgelegd. Kinderen in de controlegroep mochten zowel fruit als snoep eten. Tijdens de tweede fase van het onderzoek mochten kinderen uit alle drie de groepen eten van zowel het fruit als het snoep. Wat betreft het verlangen naar verboden voedsel vonden we dat kinderen die geen snoep mochten eten in fase 1 een onveranderd hoog verlangen rapporteerden voor snoep, terwijl het verlangen naar snoep afnam in de twee andere groepen. Er werden geen verschillen gevonden wat betreft het verlangen naar fruit. Wat betreft inname, vonden we dat kinderen in beide verbodsgroepen meer van het voorheen verboden voedsel consumeerden dan kinderen in de controlegroep. Daarnaast was ook de totale voedselinname hoger in de twee verbodsgroepen dan in de controlegroep. De data van hoofdstuk 4 repliceren de resultaten beschreven in hoofdstuk 3: het verbieden van aantrekkelijke (en ongezonde) voeding leidt tot een groter verlangen naar en een verhoogde inname van dat voedsel. Daarnaast kunnen de effecten van restrictie gegeneraliseerd worden naar relatief minder aantrekkelijk voedsel. Deze twee hoofdstukken wijzen duidelijk op een causaal verband tussen verbieden en voedselvoorkeur en inname. 
In het laatste hoofdstuk van deel 1 van dit proefschrift wordt het concept van restrictie toegepast en onderzocht in een heel andere setting, vergeleken met de eerdere hoofdstukken. In hoofdstukken 3 en 4 worden vooral de negatieve effecten van restrictie benadrukt, terwijl in hoofdstuk 5 wordt onderzocht of restrictie ook kan worden aangewend als strategie om fruitconsumptie te bevorderen. De effecten van het verbieden van fruit werden vergeleken met de mogelijke effecten van visuele aantrekkingskracht op fruitconsumptie in kinderen. Fruit werd op twee manieren aangeboden (normaal en visueel aan-trekkelijk) aan de deelnemende kinderen. In de eerste fase van het onderzoek mochten de kinderen van beide soorten fruit eten (controlegroep) of een van de twee soorten fruit werd verboden (normaal fruit verboden groep / visueel aan-trekkelijk fruit verboden groep). Tijdens de tweede fase van het onderzoek werd het verbod opgeheven en mochten alle kinderen van beide soorten fruit eten. De resultaten lieten zien dat visuele aantrekkingskracht een sterk positief effect had op de inname van fruit. Het verbieden van fruit leek in deze studie geen effecten te hebben op fruitinname.

Het tweede deel van dit proefschrift richt zich op de rol van ouders bij het behandelen van overgewicht. In hoofdstuk 6 wordt de Child Eating Disorder Examination-Questionnaire (ChEDE-Q; Decaluwé, 1999,) als methode om psychopathologisch eetgedrag vast te stellen, geëvalueerd. De ChEDE-Q werd op enkele punten aangepast en vergeleken met de Child Eating Disorder Examination Interview (ChEDE; Bryant-Waugh et al, 1996), welke gezien wordt als de gouden standaard. Eerder onderzoek liet zien dat er een discrepantie bestaat tussen het interview en de vragenlijst: op alle subschalen zijn er significante verschillen tussen de twee meetmethodes. Kinderen rapporteren meer psychopathologie wanneer de vragenlijst wordt gebruikt. Het grootste verschil tussen het interview en de vragenlijst wordt gevonden met betrekking tot het vaststellen van eetbuien: vergeleken met het interview is aangetoond dat met de vragenlijst het aantal eetbuien wordt overschat (Decaluwé \& Braet, 2004). 
In deze studie werd de ChEDE-Q aangepast door gebruikte concepten te definiëren, voorbeelden te geven, en het antwoord format aan te passen. Door deze aanpassingen werd de discrepantie tussen de vragenlijst en het interview verkleind. De resultaten lieten zien dat de gemaakte veranderingen aan de vragenlijst inderdaad verbeteringen waren: de scores van de ChEDE-Q kwamen in grotere mate overeen met de ChEDE scores. Met deze resultaten in het achterhoofd werd besloten om in de behandelstudie (hoofdstuk 7) de ChEDE-Q te gebruiken. Echter, eetbuien zouden apart worden vastgesteld door middel van een kort interview.

In hoofdstuk 7 wordt een interventie, die enkel gericht is op ouders van kinderen met overgewicht, geëvalueerd. De ouders van 98 kinderen met overgewicht of obesitas werden willekeurig toegewezen aan de behandelgroep of de wachtlijst controle groep. De interventie was succesvol wat betreft het reduceren van overgewicht in het kind. Daarnaast was er geen significante terugval bij de vervolgmeting na drie maanden. Zoals verwacht nam het overgewicht niet af in de wachtlijst controle groep. Naast de effecten op gewicht werden er voor beide groepen hoofdeffecten van tijd gevonden: psychopathologisch eetgedrag nam af, de eigenwaarde van kinderen nam toe en de frequentie van negatieve gedachten nam af. Tot slot nam ook het gewicht van ouders in de behandelgroep significant af. Er werd geconcludeerd dat de ouderinterventie significante effecten had op BMI van zowel kind als ouder. In het algemeen zijn de effecten van de ouderinterventie veelbelovend. De relatief korte interventie leidde tot bruikbare resultaten. Daarnaast is een interventie die zich enkel richt op ouders waarschijnlijk kostenreducerend in vergelijking met de gangbare behandeling waarbij zowel ouders als kinderen sessies volgen.

Een tweede doel van hoofdstuk 7 was het identificeren van voorspellers van behandelsucces. Regressie analyses identificeerden vier significante voorspellers van BMI afname in kinderen: Sociaal Economische Status (SES), leeftijd van het kind, aanwezigheid van de ouders en BMI percentiel van het kind vóór de behandeling. Zoals verwacht voorspelden een grotere aanwezigheid van de ouders en een lagere leeftijd van het kind behandelsucces. 
Echter, tegen de verwachting in, voorspelde een lagere SES meer BMI afname tijdens de behandeling. Tot slot bleek BMI percentiel van het kind voor de behandeling de sterkste voorspeller: hoe minder overgewicht voor de behandeling, des te groter de afname in gewicht. Aan de ene kant is dit onverwacht, aangezien kinderen met ernstiger overgewicht meer ruimte hebben om te verbeteren. Aan de andere kant impliceert deze bevinding wellicht dat het type interventie, geëvalueerd in hoofdstuk 7, (relatief kort en niet zeer intensief) het beste werkt voor kinderen die nog niet morbide obees zijn. Wellicht profiteren de ernstigere gevallen meer van een langdurigere en intensievere vorm van behandeling.

Kort samengevat ondersteunen de studies in deel 1 van dit proefschrift de hypothese dat restrictie leidt tot paradoxale effecten zoals een toegenomen verlangen naar en een grotere inname van het verboden voedsel. Het tweede deel van dit proefschrift demonstreert dat een interventie enkel gericht op de ouders effectief is in het reduceren van overgewicht bij kinderen. 
References 
American Psychiatric Association (1994). Diagnostic and Statistical Manual of Mental disorders, $4^{\text {th }}$ edition. Washington, DC: American Psychiatric Association.

Anderson, R. N. (2002). Deaths: leading causes for 2000. National Vital Statistics Report, 50, 1- 85 .

Baecke, J. A., Burema, J., \& Frijters, J. E. (1982). A short questionnaire for the measurement of habitual physical activity in epidemiological studies. American Journal of Clinical Nutrition, 36, 936-942.

Barlow, S. E., \& Dietz, W. H. (1998). Obesity evaluation and treatment: Expert Committee Recommendations. Pediatrics, 102, E29.

Baumrind, D. (1971). Current patterns of parental authority. In H. R. Schaffer (Eds.), Social Development. Oxford: Blackwell Publishing Ltd.

Birch, L.L., \& Fisher, J.A. (1995). Appetite and eating behavior in children. Pediatric clinics of North America, 42, 931-953.

Birch, L.L., \& Fisher, J.O. (2000). Mother's child-feeding practices influence daughters eating and weight. American Journal of clinical Nutrition, 71, 1054-1061.

Birch, L.L., Fisher, J.O., Mackey, C.N., Grimm-Tomas, K., Sawyer, R., \& Johnson, S.L. (2001). Confirmatory factor analysis of The Child Feeding Questionnaire: A Measure of parental attitudes, beliefs and practices about child feeding and obesity proneness. Appetite, 36, 201-210.

Birch, L.L., Fisher, J.O., Krahnstoever Davison, K. (2003). Learning to overeat: maternal use of restrictive feeding practices promotes girls' eating in the absence of hunger. The American Journal of Clinical Nutrition, 78, 215-220.

Black, C. M. D., \& Wilson, G. T. (1996). Assessment of eating disorders: interview versus questionnaire. International Journal of Eating Disorders, 20, 43-50.

Bönnhoff, N., Eissing, G., Baumann, T., \& Kuß, S. (2002). Steigerung des Obst und Gemüseverzehrs bei Grundschulkindern. Ernährungsumschau, 49, 340-343.

Bonomi, A. G., Plasqui, G., Goris, A. H. C., \& Westerterp, K. R. (2009). Improving assessment of daily energy expenditure by identifying types of physical activity with a single accelerometer. Journal of Applied Physiology, 107, 655-661.

Braet, C. (2006). Patient characteristics as predictors of weight loss after an obesity treatment for children. Obesity, 14, 148-155. 
Brown, R., \& Ogden, J. (2004). Children's eating attitudes and behaviour: a study of the modelling and control theories of parental influence. Health Education Research, 19, 261-271.

Bruce, B., \& Wilfley, D. (1996). Binge eating among the overweight population: a serious and prevalent problem. Journal of the American Dietetic Association, 96, 58-61.

Bryant-Waugh, R. J., Cooper, P. J., Taylor, C. L., \& Lask, B. D. (1996). The use of the Eating Disorder Examination with children: a pilot study. International Journal of Eating Disorders, 19, 391-397.

Buddeburg-Fisher, B., Klaghofer, R., \& Reed, V. (1999). Associations between body weight, psychiatric disorders and body image in female adolescents. Psychotherapy and psychosomatics, 68, 325-332.

Carter, J. C., Aimé, A. A., \& Mills, J. S. (2001). Assessment of bulimia nervosa: a comparison of interview and self-report questionnaire methods. International Journal of Eating Disorders, 30, 187-192.

Centraal Bureau voor de Statistiek (2005). Gerapporteerde gezondheid en leefstijl, percentages / aantallen, totaal kenmerk gebruikers. Statline CBS: http://statline.cbs.nl/statweb

Centraal Bureau voor de Statistiek (2006). Gerapporteerde gezondheid en leefstijl. Medische consumptie, gezondheid en aandoeningen, functiebeperkingen en leefstijl naar kenmerken van de gebruikers 2000-2005. Statline CBS: http://statline.cbs.nl/statweb

Clarke, W. R., \& Lauer, R. M. (1993). Does childhood obesity track into adulthood? Critical Reviews in Food Science and Nutrition, 33, 423-430.

Cole, T. J., Bellizzi, M. C., Flegal, K. M., \& Dietz, W. H. (2000). Establishing a standard definition for child overweight and obesity worldwide: international survey British Medical Journal, 320, 1240-1245.

Constanzo, P.R., \& Woody, E.Z. (1984). Parental perspectives on obesity in children: the importance of sex differences. Journal of Social and Clinical Psychology, 2, 305-313.

Constanzo, P.R., \& Woody, E.Z. (1985). Domain-specific parenting styles and their impact on the child's development of particular deviance: the example of obesity proneness. Journal of Social and Clinical Psychology, 3, 425-445.

Cooke, L. J., Wardle, J., Gibson, E.L., Sapochnik, M., Sheiham, A., \& Lawson, M. (2004). Demographic, familial and trait predictors of fruit and vegetable consumption by pre-school children. Public Health Nutrition, 7, 295-302. 
Cooper, Z., \& Fairburn, C. G. (1987). The Eating Disorder Examination: a semi structured interview for the assessment of the specific psychopathology of eating disorders. International Journal of Eating Disorders, 6, 1-8.

Corwin, R.L., Wojnicki, F.H., Fisher, J.O., Dimitriou, S.G., Rice, H.B., \& Young, M.A. (1998). Limited access to a dietary fat option affects ingestive behavior but not body composition in male rats. Physiology and Behavior, 65, 545-553.

Decaluwé, V. (1999). Child Eating Disorder Examination-Questionnaire. Dutch translation and adaptation of the Eating Disorder Examination-Questionnaire, authored by C. G. Fairburn \& S. J. Beglin. Unpublished manuscript.

Decaluwé, V., Braet, C., \& Fairburn, C. G. (2003). Binge eating in obese children and adolescents. International Journal of Eating Disorders, 33, 78-84.

Decaluwé, V., \& Braet, C. (2004). Assessment of eating disorder psychopathology in obese children and adolescents: interview versus self-report questionnaire. Behaviour Research and Therapy, 42, 799-811.

Decaluwé, V., Braet, C., Moens, E., \& van Vlierberghe, R. (2006). The association of parental characteristics and psychological problems in obese youngsters. International Journal of Obesity, 30, 1766-1774.

De Zwaan, M., \& Mitchell, J. E. (1992). Binge eating in the obese. Annals of Medicine, 24, 303-308.

Dietz, W. H., \& Robinson, T. N. (2005). Overweight children and adolescents. New England Journal of Medicine, 352, 2100-2109.

Douketis, J. D., Macie, C., Thabane, L., \& Williamson, D. F. (2005). Systematic review of long-term weight loss studies in obese adults: clinical significance and applicability to clinical practice. International Journal of Obesity, 29, 1153-1167.

Dudeja, V., Misra, A., Pandey, R. M., Devina, G. , Kumar, G., \& Vikram, N. K. (2001). BMI does not accurately predict overweight in Asian Indians in northern India. British Journal of Nutrition, 86, 105- 112

Dutch Food Consumption Survey. (1998). Zo eet Nederland 1998. Resultaten van de Voedsel Consumptie Peiling 1997-1998. The Hague: Voedingscentrum.

Elfhag, K., \& Rossner, S. (2005). Who succeeds in maintaining weight loss? A conceptual review of factors associated with weight loss maintenance and weight regain. Obesity Reviews, 6, 67-85.

Epstein, L. H., \& Wing, R. R. (1987). Behavioural treatment of childhood obesity. Psychological Bulletin, 101, 331-342. 
Epstein, L. H., Valoski, A., Wing, R. R., McCurley, J. (1990). Ten-year follow-up of behavioral, family-based treatment for overweight children. Journal of the American Medical Association, 264, 2519-2523.

Epstein, L. H., Valoski, A., Wing, R. R., \& McCurley, J. (1994). Ten-year outcomes of behavioral family-based treatment for childhood obesity. Health Psychology, $13,373-383$

Epstein, L.H., Gordy, C.C., Raynor, H.A., Beddome, M., Kilanowski, C.K., \& Paluch, R. (2001). Increasing fruit and vegetable intake and decreasing fat and sugar intake in families at risk for childhood obesity. Obesity Research, 9, 171-178.

Fairburn, C. G., \& Cooper, Z. (1993). The Eating Disorder Examination (12 ${ }^{\text {th }}$ edition). In: C. G. Fairburn \& G. T. Wilson (Eds.), Binge eating: nature, assessment and treatment (pp. 317-360). New York: Guilford Press.

Fairburn, C. G., \& Wilson, G. T. (1993). Binge eating: definition and classification. In: C. G. Fairburn \& G. T. Wilson (Eds.), Binge eating: nature, assessment and treatment (pp. 3-15). New York: Guilford Press.

Fairburn, C. G., \& Beglin, S. J. (1994). Assessment of eating disorders: interview or self-report questionnaire? International Journal of Eating Disorders, 16, 363-370.

Faith, M.S., Scanlon, K.S., Birch, L.L., Francis, L.A., \& Sherry, B. (2004). Parent-child feeding strategies and their relationships to child eating and weight status. Obesity Research, 12, 1264-1272.

Fisher, J.O., \& Birch, L.L. (1999). Restricting access to palatable foods affects children's behavioral response, food selection, and intake. American Journal of Clinical Nutrition, 69, 1264-1272.

Foster, G. D., Wadden, T. A., Voght, R. A. \& Brewer, G. (1997). What is a reasonable weight loss?: Patients' expectations and evaluations of obesity treatment outcomes. Journal of Consulting and Clinical Psychology, 65, 79-85.

Galloway, A.T., Fiorito, L.M., Lee, Y., \& Birch, L.L. (2005). Parental pressure, dietary patterns, and weight status in girls who are 'picky eaters'. Journal of the American Dietetic Association, 105, 541-548.

Galloway, A.T., Fiorito, L.M., Francis, L.A., \& Birch, L.L. (2006). 'Finish your soup': counterproductive effects of pressuring children to eat on intake and affect. Appetite, $46,318-323$.

Golan, M., \& Crow, S. (2004a). Parents are key players in the prevention and treatment of weight-related problems. Nutrition Reviews, 62, 39-50. 
Golan, M., \& Crow, S. (2004b). Targeting parents exclusively in the treatment of childhood obesity: long term results. Obesity Research, 12, 357-361.

Golan, M., Kaufman, V., \& Shahar, D. R. (2006). Childhood obesity treatment: targeting parents exclusively vs. Parents and children. British Journal of Nutrition, 95, 1008-1015.

Gonzales, N., Cauce, A.M., \& Mason, C. (1996). Interobserver agreement in the assessment of parental behavior and parent-adolescent conflict; African American mothers, daughters, and independent observers. Child Development, 67, 1483-1498.

Gortmaker, S. I., Must, A., Perrin, J. M., Sobol, A. M., \& Dietz, W. H. (1993). Social and economic consequences of overweight in adolescence and young adulthood. New England Journal of Medicine, 329, 1008-1012.

Guerrieri, R. (2005). Toen de koekjestrommel de fruitschaal verdrong...: De toxische omgeving als oorzaak van obesitas. De psycholoog, 40, 642-646.

Guidetti, M., \& Cavazza, N. (2008). Structure of the relationship between parents' and children's food preferences and avoidances: An explorative study. Appetite, $50,83-90$.

Harter, S. (1985). Manual for the self-perception profile for children. Denver, CO: University of Denver.

Health-Council-of-the-Netherlands. (2002). Voedingsnormen energie, eiwitten, vetten en verteerbare koolhydraten. Den Haag.

Hearn, N., Baranowski, T., Baranowski, J., Doyle, C., Smith, M., Lin, L.S., \& Resnicow, K. (1998). Environmental influences on dietary behavior among children: Availability and accessibility of fruits and vegetables enable consumption. Journal of Health Education, 29, 26-32.

Hedley, A. A., Ogden, C. L., \& Johnson, C. L. (2004). Prevalence of Overweight and Obesity Among US Children, Adolescents, and Adults, 1999-2002. The Journal of the American Medical Association, 291, 2847-2850.

Herman, C. P., \& Mack, D. (1975). Restrained and unrestrained eating. Journal of Personality, 43, 647-660.

Hung, H.C., Joshipura, K.J., Jiang, R., Hu, F.B., Hunter, D., Smith-Warner, S.A., et al. (2004). Fruit and vegetable intake and risk of major chronic disease. Journal of the National Cancer Institute, 96, 1577-1584. 
Hurk, K., van den, Dommelen, P. van, Wilde, J.A., de, Verkerk, P.H., Buuren, S., van \& HiraSing, R.A., (2006). Prevalentie van overgewicht en obesitas bij jeugdigen 4-15 jaar in de periode 2002-2004. TNO-rapport KvL/JPB/2006.010.

James, P. T., Leach, R., Kalamara, E. \& Shayeghi, M. (2001). The worldwide obesity epidemic. Obesity Research, 9, s228-233.

Jansen, A., van den Hout, M., \& Griez, E. (1990). Clinical and non-clinical binges. Behaviour Research and Therapy, 28, 439-444.

Jansen, A., Theunissen, N., Slechten, K., Nederkoorn, C., Mulkens, S., \& Roefs, A. (2003). Overweight children overeat after exposure to food cues. Eating Behaviors, 4, 197-209.

Jansen, A., Havermans, R., Nederkoorn, C., \& Roefs, A. (2008). Jolly fat or sad fat? Subtyping non-eating disordered overweight and obesity along an affect dimension. Appetite, 51, 635-640.

Jansen, E., Mulkens, S, \& Jansen, A (2007). Do not eat the red food! Prohibition of snacks leads to their relatively higher consumption in children. Appetite, 49, 572-577.

Jansen, E., Mulkens, S., Emond, Y., \& Jansen, A. (2008). From the Garden of Eden to the land of plenty: restriction of fruit and sweets intake leads to more fruit and sweets consumption in children. Appetite, 51, 570-575.

Jansen, E., Mulkens, S., Sanders, E., \& Jansen, A. (2011). How do children experience their parents' feeding practices? A study using the Dutch Child Feeding Questionnaire- child version. Netherlands Journal of Psychology, 66, 26-32.

Jelalian, E., \& Saelens, B., E. (1999). Empirically Treatments in Pediatric Psychology: Pediatric Obesity, 24, 223-248.

Johnson, B., Brownell, K.D., St. Jeor, S.T., Brunner, R.L., \& Worby, M. (1997). Adult obesity and functioning in the family of origin. International Journal of Eating Disorders, 22, 213-218

Kaur, H., Li, C., Nazir, N., Choi, W.S., Resnicow, K., Birch, L.L., \& Ahluwalia, J.S. (2006). Confirmatory factor analysis of the child-feeding questionnaire among parents of adolescents. Appetite, 47, 36-45.

Keller. K.L., Pietrobelli, A., Johnson, S.L., \& Faith, M.S. (2006). Maternal restriction of children's eating and encouragements to eat as the 'non-shared environment': a pilot study using the child feeding questionnaire. International Journal of Obesity, 30, 1670-1675. 
Kuczmarski, R. J., Carroll, M. D., Flegal, K. M., \& Troiano, R. P. (1997). Varying body mass index cutoff points to describe overweight prevalence among U.S adults: NHANES III (1988 to 1994). Obesity Research, 5, 542-548.

Kushner, R. F., \& Aronne, L. J. (2004). Obesity and the Primary Care Physician. In G. Bray \& C. Bouchard (red.), Handbook of Obesity (pp. 33-44). New York: Basel.

Landauer, T. K., Carlsmith, J. M., \& Lepper, M. (1970). Experimental analysis of the factors determining obedience of four-year-old children to adult females. Child Development, 41, 601-611.

Langnäse, K., Asbeck, I., Mast, M., Müller, M. J. (2004). Influence of socioeconomic status on long-term effect of family-based obesity treatment intervention in prepubertal overweight children. Health Education, 104, 336-343.

Lamborn, S., Mounts, N., Steinberg, L., Dornbusch, S. (1991). Patterns of competence and adjustment among adolescents from authoritative, authoritarian, indulgent and neglectful families. Child Development, 62, 1049-1065.

Lowe, M. R., Whitlow, J. W., \& Bellwoar, V. (1991). Eating regulation: the role of restraint, dieting and weight. International Journal of Eating Disorders, 10, 461-471.

Luce, K. H., \& Crowther, J. H. (1999). The reliability of the Eating Disorder Examination Self-Report Questionnaire Version (EDE-Q). International Journal of Eating Disorders, 25, 349-351.

Maccoby, E., \& Martin, J. (1983) In Hetheringron, E. (Ed). Handbook of Child Psychology: Socialization, Personality and Social Development. New York: Wiley.

Mann, T., \& Ward, A. (2001), Forbidden Fruit: Does thinking about a prohibited food lead to its consumption? International Journal of Eating Disorders, 29, 319-327.

Matz, P. E., Foster, G. D., Faith, M. S., \& Wadden, T. A. (2002). Correlates of body image dissatisfaction among overweight women seeking weight loss. Journal of Consulting and Clinical Psychology, 70, 1040-1044.

McCrory, M.A., Fuss, P.J., McCallum, J.E., Yao, M., Vinken, A.G., Hays, N.P., et al. (1999). Dietary variety within food groups: Association with energy intake and body fatness in men and women. American Journal of Clinical Nutrition, 69, 440-447.

Moens, E., Braet, C., \& van Winckel, M. (2010). An 8-year follow up of treated obese children: Children's, process and parental predictors of treatment success. Behaviour Research and Therapy, 48, 626-633. 
Mokdad, A. H., Ford, E. S., Browman, B. A., Dietz, W. H., Vinicor, F., Bales, V. S. \& Marks, J. S. (2003). Prevalence of obesity, diabetes, and obesity-related health risk factors, 2001. Journal of the American medical Association, 298, 76-79.

Mulkens, S., Jansen, E., \& Jansen, A. (2004, October). Prevention of obesity in adulthood: short term effects of behavioural versus cognitive behavioural therapy for seriously overweight children. Poster session presented at the annual meeting of the Eating Disorder Research Society, Amsterdam.

Müller, M. J., Danielzik, S., \& Pust, S. (2005). School- and family-based interventions to prevent overweight in children. Proceedings of the Nutrition Society,

$64,249-254$.

Nederkoorn, C., Jansen, E., Mulkens, S., \& Jansen, A. (2007). Impulsivity predicts treatment outcome in obese children. Behaviour Research and Therapy, 45, 1071-1075.

Neovius, M., Linné, Y., \& Rossner, S. (2005). BMI, waist- circumference and waist-hip-ratio as diagnostic tests in adolescents. International Journal of Obesity, 29, 163-169.

Ogden, C. L., Flegal, K. M., Carroll, M. D., \& Johnson, C. L. (2002). Prevalence and trends in overweight among US children and adolescents. 1999-2000. The Journal of the American Medical Association, 288, 1728-1732.

Ogden, C. L., Carroll, M. D., Curtin, L. R., McDowell, M. A., Tabak, C. J., \& Flegal, K. M. (2006). Prevalence of overweight and obesity in the United States, 1999-2004. The Journal of the American Medical Association, 195, 1549-1555.

Oude Luttikhuis, H., Baur, L., Jansen, H., Shrewsbury, V. A., O'Mally, C., Stolk, R. P., et al. (2009). Interventions for treating obesity in children. Cochrane Database of Systematic Reviews. DOI: 10.1002/14651858. 21, CD001872.

Passi, V. A., Bryson, S. W., \& Lock, J. (2003). Assessment of eating disorders in adolescents with anorexia nervosa: self-report questionnaire versus interview. International Journal of Eating Disorders, 33, 45-54.

Paulson, S.E. (1994). Relations of parenting style and parental involvement with Ninthgrade students achievement. The Journal of Early Adolescence, 14, 250-267.

Pelchat, M., \& Pliner, P. (1986). Antecedents and correlates of feeding problems in children. Journal of Nutrition Education, 18, 23-29.

Perri, M. G., Nezu, A. M., \& Vliegener, B. J. (1992). Improving the Long-Term Management of Obesity Theory, Research, and Clinical Guidelines. Obesity: Definition, Prevalence, and Consequences, 3-24. New York: John Wiley \& Sons, Inc. 
Piaget, J. (1965). The moral judgment of the child. New York: Free Press.

Polivy, J., \& Herman, C. P. (1985). Dieting and binge eating: A causal analysis. American Psychologist, 40, 193-204.

Puhl, R. M., \& Brownell, K. D. (2004). Bias, Prejudice, Discrimination and Obesity. In G. Bray \& C. Bouchard (red.), Handbook of Obesity (pp. 69-74). New York: Basel.

Radziszewska, B., Richardson, J., Dent, C., \& Flay, B. (1996). Parenting style and adolescent depressive symptoms, smoking, and academic achievement: ethnic, gender and SES differences. Journal of Behavioral Medicine, 19, 289-305.

Ramirez, E.M. \& Rosen, J.C. (2001). A comparison of weight control and weight control plus body image therapy for obese men and women. Journal of Consulting and Clinical Psychology, 69, 440-446.

Ravussin. E., \& Bogardus, C. (2000). Energy balance and weight regulation: genetics versus environment. British Journal of Nutrition, 83, S17-S20.

Reinehr, T., Brylak, K., Alexy, U., Kersting, M., \& Andler, W. (2003). Predictors to success in outpatient training in obese children and adolescents. International Journal of Obesity, 27, 1087-1092.

Rhee, K. E., Lumeng, J. C., Appugliese, D. P., Kaciroti, N., \& Bradley, R. H. (2006). Parenting styles and overweight status in First grade. Pediatrics, 117, 2047-2054.

Rhodes, S. K., Shimonda, K. C. \& Waid, L.R. (1995). Neurocognitive deficits in morbidly obese children in with obstructive sleep apnea. Journal of Pediatrics, $127,741-744$.

Robinson, T.N., Kiernan, M., Matheson, D.M., \& Haydel, K.F. (2001). Is parental control over children's eating associated with childhood obesity? Results from a populationbased sample of third graders. Obesity Research, 9, 306-312.

Roblin, L. (2007). Childhood obesity: food, Nutrient, and eating-habit trends and influences. Applied Physiology, Nutrition, and Metabolism, 32, 635-645.

Rolls, B.J., Rolls. E.T., Rowe. E.A., \& Sweeney, K. (1981). Sensory-specific satiety in man. Physiology and Behavior, 27, 137-142.

Rolls, E.T., \& Rolls, J.H. (1996). Olfactory Sensory-Specific-Satiety in Humans. Psychology and Behavior, 61, 461-473. 
Schokker, D. F., Visscher, T. L. S., Nooyens, A. C. J., van Baak, M. A., E Seidell, J. C. (2007). Prevalence of overweight and obesity in the Netherlands. Obesity Reviews, 8, 101-108.

Schwartz, M. S., \& Chadha, A. (2008). Type 2 diabetes mellitus in childhood: obesity and insulin resistance. The Journal of the American Osteopathic Association, $108,518-524$

Serdula, M. K., Ivery, D., Coates, R. J., Freedman, D. S., Williamson, D. F., \& Byers, T. (1993). Do obese children become obese adults? A review of the literature. Preventive Medicine, 22, 167-177.

Shroff, H., \& Thompson, J. K. (2006). The tripartite influence model of body image and eating disturbance: a replication with adolescent girls. Body Image, 3, 17-23.

Stalonas, P. M., Perri, M. G.. \& Kerzner, A. B. (1984). Do behavioral treatments of obesity last? A five year follow-up investigation. Addictive Behaviors, 9, 175-184.

Stang, J., Rehorst, J., \& Golicic, M. (2004). Parental feeding practices and risk of childhood overweight in girls: implications for dietetics practice. Journal of the American Dietetic Association, 104, 1076-1079.

Steinberg, L., Lamborn, S., Dornbush, S., \& Darling, N. (1992). Impact of parenting practice on adolescent achievement: authoritative parenting, school involvement and encouragement to succeed. Child Development, 63, 1266-1281.

Stice, E., Presnell, K., Shaw, H. \& Rohde, P. (2005). Psychological and behavioural risk factors for obesity onset in adolescent girls: a prospective study. Journal of Consulting and Clinical Psychology, 73, 195-202.

Stice, E., Martinez, E. E., Presnell, K., \& Groesz, L. M. (2006). Relation of successful dietary restriction to change in bulimic symptoms: a prospective study of adolescent girls. Health Psychology, 25, 274-281.

St-Onge, M., Keller, K.L., \& Heymsfield, S.B. (2003). Changes in childhood food consumption patterns: a cause for concern in light of increasing body weights. The American Journal of Clinical Nutrition, 78, 1068-1073.

Tagney, J.P., Wagner, P.E., Gavlas, J., \& Gramzow, R. (1991). The Test of Self Conscious Affect for Adolescents (TOSCA-A). Fairfax, VA: George Mason University.

Tanofsky-Kraff, M., Yanovski, S.Z., Wilfley, D.E., Marmarosh, C., Morgan, C.M. \& Yanovski, J.A. (2004). Eating-disordered behaviors, body fat, and psychopathology in overweight and normal-weight children. Journal of Consulting and Clinical psychology, 72, 53-61. 
The Netherlands Nutrition Centre, The Hague (n.d.). Keuzetabel producten.

Retrieved February 24, 2008 from

http://www.voedingscentrum.nl/EtenEnGezondheid/Gezond+etenKeuzetabel/

USDA / ARS Children's Nutrition Research Center. (n.d.). Children's BMI-percentile-forage Calculator. Retrieved March 13, 2011, from http://www.kidsnutrition.org/bodycomp/bmiz2.html

Van Dongen-Melman, J. E. W. M., Koot, H. M., \& Verhulst, F. C. (1993). Cross cultural validation of Harter's self-perception profile for children in a Dutch sample. Educational and Psychological Measurement, 53, 739-753.

Van Wieringen. (1985). Bijlage 3: Gewicht-lengtenormen. Tijdschrift voor Sociale Geneeskunde, 63, 99-100.

Van Winckel, M., \& Van Mil, E. (2001). Wanneer is dik té dik? In Braet, C., \& Van Winckel, A. J. M. (red.). Behandelingsstrategieën bij kinderen met overgewicht. Houten Diegem: Bohn Stafleu Van Loghum.

Veerman, J. W. (1989). De competentiebelevingsschaal voor kinderen, CBSK. Een experimentele handleiding. Competence perception scale for children. Manual. Duivendrecht: Paedologisch Instituut.

Visscher, T. L., Kromhout, D., \& Seidell, J. C. (2002). Long term and recent time trends in the prevalence of obesity among Dutch men and women. International Journal of Obesity, 26, 1218-1224.

Wabitsch, M. (2000). Overweight and obesity in European children: definition and diagnostic procedures, risk factors and consequences for later health outcome. European Journal of Pediatrics, 159, 8-13.

Wadden, T. A., Sternberg, J. A., Letizia, K. A., Stunkard, A. J., \& Foster, G. D. (1989). Treatment of obesity by very low calorie diet, behavior therapy, and their combination: a five-year prospective. International Journal of Obesity, 13, 39-46.

Wayner, M.J., Greenberg, I., Tartaglione, R., Nolley, D., Fraley, S., \& Cott, A. (1972). A new factor affecting the consumption of ethyl alcohol and other sapid fluids. Physiology and Behavior, 8, 345-362.

Werrij, M. Q., Mulkens, S., Hospers, H., \& Jansen, A. (2006). Overweight and obesity: the significance of a depressed mood. Patient education and counseling, 62, 126-131. 
West, F., Sanders, M. R., Cleghorn, G. J., \& Davies, P. S. W. (2010). Randomised clinical trial of a family-based lifestyle intervention for childhood obesity involving parents as the exclusive agents of change. Behaviour Research and Therapy, 48, 1170-1179.

Whitaker, R. C., Wright, J. A., Pepe, M. S., Seidel, K. D., \& Dietz, W. H. (1997). Predicting obesity in young adulthood from childhood and parental obesity. The New-England Journal of Medicine, 337, 869-873.

Wilfley, D. E., Tibbs. T. L., Van Buren, D. J., Reach, K. P., Walker, M. S., \& Epstein, L. H. (2007). Lifestyle interventions in the treatment of childhood overweight: A meta-analytic review of randomized controlled trials. Health Psychology, 26, 521-532.

Wing, R. R. (1998). Behavioral approaches to the treatment of obesity. In G. A. Bray, C. Bouchard, \& W. P. T. James, Handbook of obesity (pp. 855 - 873). New York: MarcelDekker.

Wrotniak, B. H., Epstein, L. H., Paluch, R. A., \& Roemmich, J. N. (2004). Parent weight change as a predictor of child weight change in family-based behavioral obesity treatment. Archives of Pediatric and Adolescent Medicine, 158, 342-347.

Zametkin, A. J., Zoon, C. K., Klein, H. W., \& Munson, S. (2004). Psychiatric Aspects of Child and Adolescent Obesity: A Review of the Past 10 Years. Psychiatry, 43, 134-150. 
Childhood overweight: parents in control? 
Dankwoord 
Een bekend Afrikaans gezegde is 'it takes a village to raise a child'. Oftewel; een kind grootbrengen doe je niet alleen, maar met je hele omgeving. En zo voelde het ook een beetje met het schrijven van dit proefschrift: ook al was ik zelf degene die de uiteindelijke woorden op papier zette, een heus 'dorp' aan mensen leverde een directe of indirecte bijdrage aan het eindresultaat. Niet meer dan terecht dus om die personen op deze plek te bedanken voor hun expertise, inspiratie en steun.

)

Anita, promotor, en meer dan dat! Naast de geweldige begeleiding de afgelopen jaren ben je voor mij een bron van inspiratie. Scherpzinnig, recht door zee en ambitieus. Ondanks je belachelijk volle agenda maakte je altijd tijd voor brainstormsessies of antwoorden op mijn vragen. Maar wat ik misschien nog wel het meest aan je waardeer is de roze bril die je altijd op hebt. Je weet altijd het positieve te benadrukken. En als ik soms alleen maar beren op de weg zag, zorgde jouw roze bril gelijk voor een vrolijkere kijk op het geheel. Je enthousiasme voor onderzoek werkt aanstekelijk. Je bent een bijzonder mens, ik heb veel van je geleerd de afgelopen jaren, bedankt daarvoor!

○ Sandra, mijn copromotor en dagelijks begeleider; dank! Dank voor je expertise, je kritische blik, je bereikbaarheid, aandacht, motiverende woorden, persoonlijke betrokkenheid, en alle gezellige etentjes. En met name bedankt voor je engelengeduld de afgelopen twee jaar. Ik kan me zo voorstellen dat je je afvroeg wanneer het allemaal af zou komen, nadat ik de zoveelste deadline niet haalde. Ik weet dat je me ervoor wilde behoeden dat het geen slepende zaak zou worden. Denk dat we allebei opluchting voelen nu het boekje er eindelijk ligt! Ik had me geen fijnere begeleider kunnen wensen, dank! 
Lieve collega's van de eetgroep. Jullie waren geweldig. Ik heb veel geleerd van onze brainstormsessies. Naast leergierige, enthousiaste onderzoekers heb ik jullie leren kennen als een ontzettend gezellige en hechte club collega's.

De gezellige etentjes in Anita's tuin (of woonkamer na wegwaaien van de tent). de congressen (inclusief logeren in het ranzigste hotel ooit) en de gesprekjes in de koffiehoek; het zijn momenten die ik zal koesteren.

Mijn paranimfen, Janneke en Ramona; jullie zijn de besten! Ramona, kort na elkaar werden we Aio's bij de eetgroep, en het klikte gelijk. Je bent een lieve, te bescheiden en zeer talentvolle dame. Onze gesprekken over onderzoek, mannen, kindjes, koetjes en kalfjes zorgden ervoor dat ik me snel op mijn plek voelde. Bedankt voor je vriendschap en steun! Ik hoop dat we nog lang vriendinnen blijven. Janneke, ik heb beloofd dat ik mijn afscheidstekst uit de OnderUns zou rectificeren ;) Natuurlijk praatten we onder werktijd een enkele keer over mooie schoenen, hippe tassen, de fijnste webshops en de leukste gadgets. Maar uiteraard werkten we vooral keihard en was ons onderzoek het voornaamste onderwerp van gesprek. Janneke, het was geweldig om jou als kamergenootje te hebben. Ik heb onwijs met en om je gelachen. Je bent een superslimme vrouw met haast Zuidelijk temperament. Ik hoop dat onze vriendschap nog lang voortduurt.

Collega's van CPS; Bedankt voor alle gezelligheid en steun! Een speciaal woord van dank voor Jessie en Truus. Jullie zijn feitelijk het hart van CPS, bedankt voor het regelen van ontelbaar veel dingen, jullie zijn onmisbaar!

Felisa en Yvonne, mijn student-assistent en onderzoeksassistent. Hartelijk dank voor de vele uren werk die jullie in mijn project hebben gestoken! Vragenlijsten scoren, bergen met data invoeren, niks was teveel. Jullie werkten allebei zeer nauwkeurig en met veel enthousiasme! Zonder jullie had dit boekje er waarschijnlijk nog steeds niet gelegen. Dank! 
Harm, Ellen en Yvette, bedankt voor jullie enorme inzet bij het verzamelen van data voor verschillende studies. Het was erg leuk om met jullie te werken!

$b$ Therapeuten van de 'Vinger in de pap' interventie: Christianne, Heidi, Nadine, Sandy en Willemien, bedankt voor jullie inzet bij het trainen van de ouders. Het waren niet altijd de gemakkelijkste bijeenkomsten, maar de deelnemers hebben veel van jullie geleerd. Zonder jullie was de behandelstudie niet mogelijk geweest.

Alle proefpersonen die hebben meegedaan aan de verschillende studies, bedankt! Zonder proefpersonen geen proefschrift. In het bijzonder een dankjewel voor alle kleutertjes die deelnamen aan het verschillende 'verbods-experimenten'; jullie waren zo enthousiast en werkten geweldig mee, de leukste en spontaanste proefpersoontjes die er zijn!

$b$

Lieve (schoon)familie, vrienden \& vriendinnen, collega's bij CO-EUR. Als ik iedereen die de afgelopen jaren interesse heeft getoond in de voortgang van mijn proefschrift hier met naam en toenaam moet noemen, ben ik wel even bezig. Vandaar één welgemeend 'DANKJULLIEWEL' voor jullie allemaal. Zonder jullie interesse, steun, liefde, gezelligheid, afleiding en motivatie was het schrijven van dit proefschrift een veel grotere opgave geweest.

)

Lieve pap en mam, dankjulliewel voor jullie eeuwige interesse, onvoorwaardelijke vertrouwen en trots. Jullie waren ervan overtuigd dat het me ging lukken. Jullie hebben me altijd gestimuleerd om mijn best te doen, zonder ooit te pushen. Wat is het toch fijn om een warme thuisbasis te hebben! 
Liefste Patriek: jij doet me elke dag weer inzien dat werk uiteindelijk maar werk is, en dat liefde het allerbelangrijkst is. Ze zeggen wel eens dat er achter elke succesvolle man een sterke vrouw staat. Ik zou willen zeggen: achter elke vrouw die naast baan en gezin haar proefschrift afrond, staat een geweldige man! En natuurlijk wil ik je ook bedanken voor de lay out en het ontwerp voor de omslag van dit proefschrift; ook dit is een product van ons samen!

En tot slot, Liv en Feline, liefste meisjes van me. Ook al zijn jullie de voornaamste reden van de vertraging van dit proefschrift, het is heerlijk dat jullie er zijn! Jullie zorgden er ook voor dat ik soms met een andere bril naar zaken kon kijken. Met een 'mama-bril' naar eetgedrag bij kinderen kijken leverde niet zelden verhelderende inzichten op. Liefjes, jullie zijn de kersjes op mijn taart, daar kan geen boekje tegenop! 
Curriculum Vitae 
Esther Jansen was born in Heerlen (the Netherlands) on September 4, 1980. In 1998 she graduated from secondary school (VWO; Sint Michiel in Geleen). She started studying psychology at Maastricht University in September 1998, and graduated in October 2002. From 2002 to 2004 she worked as a research assistent at the Faculty of Psychology and Neuroscience. In April 2004 she started her PhD project at the department of Clinical Psychological Science, Maastricht University. Since October 2008 she is employed by the Centre for Obesity Europe (CO-EUR, Heerlen).

\section{Publications}

Jansen, E., Mulkens, S., \& Jansen, A. (2011). Tackling childhood overweight: treating parents exclusively is effective. International Journal of Obesity, 35, 501-509.

Jansen, E., Mulkens, S., Sanders, E., \& Jansen, A. (2011). How do children experience their parents' feeding practices? A study using the Dutch Child Feeding Questionnaire-child version. Netherlands Journal of Psychology, 66, 26-32.

Jansen, E., Mulkens, S., \& Jansen, A. (2010). An Apple a day keeps the doctor away. How to promote fruit consumption in children: visual appeal versus restriction. Appetite, 54, 599-602.

Jansen, E., Mulkens, S., Emond, Y., \& Jansen, A. (2008). From the Garden of Eden to the land of plenty. Restriction of fruit and sweets intake leads to more fruit and sweets consumption in children. Appetite, 51, 570-575.

Jansen, E., Mulkens, S., Hamers, H., \& Jansen, A. (2007). Assessing eating disordered behaviour in overweight children and adolescents: bridging the gap between a self-report questionnaire and a gold standard interview. Netherlands Journal of Psychology, 63, 102-106.

Jansen, E., Mulkens, S., \& Jansen, A. (2007). Do not eat the red food! Prohibition of snacks leads to their relatively higher consumption in children. Appetite, 49, 572-577.

Havermans, R., Jansen, E., Guerrieri, R., \& Jansen, A. (2007). Dikke kijkbuiskinderen. Of waarom kinderen dik worden van televisie kijken. De Psycholoog, 42, 582-588.

Nederkoorn, C., Jansen, E., Mulkens, S., \& Jansen, A. (2007). Impulsivity predicts overweight and treatment outcome in obese children. Behaviour Research and Therapy, 45, 1071-1075. 